\title{
Usuarios de la Información y Web 2.0
}

JUAN JOSÉ CALVA GONZÁLEZ

Coordinador

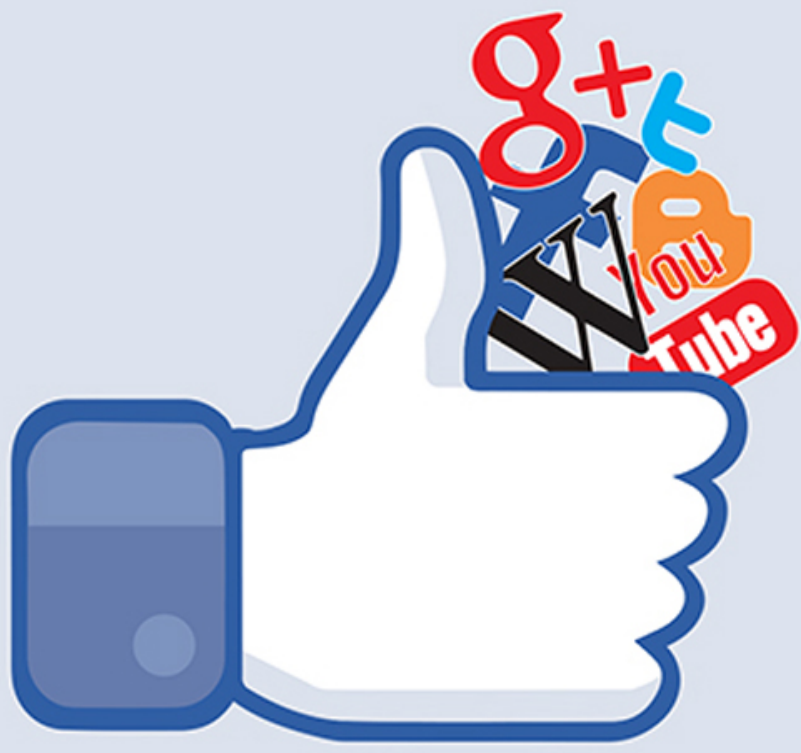

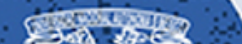




\section{La presente obra está bajo una licencia de:}

\section{http://creativecommons.org/licenses/by-nc-sa/3.0/deed.es MX}

\section{Atribución-No Comercial-Licenciamiento Reciproco 3.0 Unported}

Eres libre de:

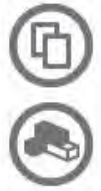

copiar, distribuir y comunicar públicamente la obra

hacer obras derivadas

Bajo las condiciones siguientes:

Atribución - Debes reconocer la autoría de la obra en los términos

especificados por el propio autor o licenciante.

No comercial - No puedes utilizar esta obra para fines comerciales.

Licenciamiento Recíproco - Si alteras, transformas o creas una obra a

partir de esta obra, solo podrás distribuir la obra resultante bajo una licencia

igual a ésta.

\section{Esto es un resumen fácilmente legible del: texto legal (de la licencia completa)}

En los casos que sea usada la presente obra, deben respetarse los términos especificados en esta licencia.
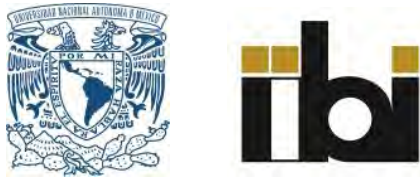


\section{Usuarios de la Información y Web 2.0}


Instituto de Investigaciones Bibliotecológicas y de la Información 


\title{
Usuarios de la Información y Web 2.0
}

\author{
Coordinador \\ Juan José Calva González
}

Universidad Nacional Autónoma de México

2017 

Z678.88 Usuarios de la Información y Web 2.0 / coordinador U78 Juan José Calva González. -- México : UNAM, Instituto de Investigaciones Bibliotecológicas y de la Información, 2017.
viii, 180 p. -- (Usuarios de la información) ISBN: 978-607-02-9298-9
Usuarios -- Necesidades de Información -- Comunida- des -- Estudios de Casos 2. Usuarios -- Web 2.0 -- Servi- cios de Información - Comunidades -- Estudios de ca- sos I. Calva González, Juan José, coordinador II. ser.

Diseño de portada: Mario Ocampo Chávez

Primera edición, 2017

D.R. (C) Universidad NaCional Autónoma de México

Ciudad Universitaria, 04510, Ciudad de México

Impreso y hecho en México

ISBN: 978-607-02-9298-9 


\section{Contenido}

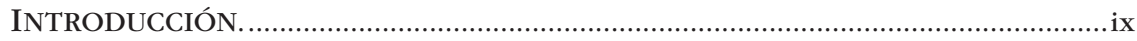

Juan José Calva González

INICIÁNDONOS EN EL CONOCIMIENTO DEL USUARIO 2.0

1

Isabel Villaseñor Rodríguez

LOS USUARIOS Y EL USO DE INTERNET

Y LAS HERRAMIENTAS DEL WEB 2.0.

Edgar Guzmán Prieto

ANÁLISIS DE LA BÚSQUEDA DE INFORMACIÓN ACADÉMICA

UTILIZANDO LA WEB 2.0, POR LOS ALUMNOS DE MATEMÁTICAS

DE LA FACULTAD DE CIENCIAS DE LA UNAM.

Luis Alberto Fuentes Gatica

LOS AGRICULTORES DE AGAVE AZUL DEL MUNICIPIO DE TEQUILA, JALISCO: PANORAMA HISTÓRICO DE LOS ACONTECIMIENTOS POLÍTICOS, SOCIALES Y ECONÓMICOS QUE HAN INFLUIDO

EN EL SURGIMIENTO DE SUS NECESIDADES DE INFORMACIÓN

Armando Sánchez Soto

LAS MUJERES AGRICULTORAS DE AGAVE AZUL DE TEQUILA, JALISCO: UN ACERCAMIENTO A LOS FACTORES SOCIALES, ECONÓMICOS Y FAMILIARES QUE INFLUYEN EN EL SURGIMIENTO

DE SUS NECESIDADES DE INFORMACIÓN.

Armando Sánchez Soto

EL EMPLEO DE LA TECNOLOGÍA POR LOS DOCENTES

DE ESCUELAS SECUNDARIAS: UNA APROXIMACIÓN. 89

Angélica Guevara Villanueva

LA COMUNIDAD DE DOCENTES DE EDUCACIÓN

BÁSICA Y SU INVESTIGACIÓN DENTRO DE LOS ESTUDIOS

DE USUARIOS DE LA INFORMACIÓN.. 117

Angélica Guevara Villanueva 
ESTUDIOS DE USUARIOS EN DIVERSAS COMUNIDADES

PRODUCTORAS PRINCIPALMENTE DE VÍTIS VINÍFERA.

Juan José Calva González

NECESIDADES DE INFORMACIÓN DEL PERSONAL

ACADÉMICO DEL INSTITUTO DE GEOGRAFÍA

PARA PUBLICAR EN REVISTAS INDEXADAS.

159

Antonia Santos Rosas

NIVELES DE USUARIOS DE LOS SISTEMAS

DE INFORMACIÓN GEOGRÁFICA.

Antonia Santos Rosas 


\section{Introducción}

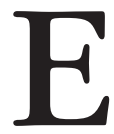

usuario de la información para el cual existen esas instituciones llamadas bibliotecas pertenece a comunidades muy variadas dentro de diversos sectores sociales que pueden ir desde los agroindustriales, hasta los alumnos de secundaria, licenciatura, o bien los propios docentes, en fin, la variedad de las comunidades de usuarios es muy amplia y extensa.

La investigación sobre las diferentes comunidades de usuarios lleva a encarar la planeación de dichas investigaciones porque si cada comunidad es diferente, entonces el método para abordarlas como objeto de investigación también debe serlo, por mencionar un ejemplo, no se puede utilizar el cuestionario como instrumento en todas las comunidades, sino que debe ajustarse tanto el método, como la técnica y el instrumento según las características propias de cada una de ellas, así como la parte del fenómeno de las necesidades de información (surgimiento, comportamiento o satisfacción) que se vaya a estudiar. Lo anterior hace que los estudios de usuarios se puedan volver más complejos; por ejemplo, a los vitivinicultores o a los agaveros no es posible abordarlos con la aplicación de un cuestionario; es decir, un método totalmente cuantitativo, más bien habría que inclinarse por una metodología cualitativa. Este tipo de com- 
plejidades llevaría a que los estudios de las diferentes comunidades de usuarios de la información fueran no solo interesantes, sino que pudieran llegar a aportar un conocimiento que desarrollara la teoría existente sobre los usuarios de la información.

La tecnología actual de la Web 2.0 viene a sumarse a la investigación sobre las diferentes comunidades de usuarios de la información, teniendo que ligar al usuario, la tecnología y los servicios bibliotecarios así como a las bibliotecas o cualquier otra unidad de información (como centros de documentación, archivos, hemerotecas, etc.), para tomar todo eso en cuenta a la hora de llevar a cabo una investigación sobre los usuarios.

Este libro se propone no solo mostrar los aspectos sobre las diferentes comunidades de usuarios de la información y su investigación, sino también cómo la tecnología de la Web 2.0 afecta de manera importante y de forma exponencial, el acceso que se tiene a la información, sobre todo a la información electrónica, añadiendo la parte substancial de la Web 2.0 ya que al compartir la información, la pone en común; es decir la solidariza, a la vez que participa en su propia formación, ya que en algún momento los usuarios no son solo consumidores de información, sino que pasan a ser creadores de la misma; véase por ejemplo el caso de las wikis. Así, los diferentes capítulos que se muestran en esta obra son solo una pequeña parte de todo el potencial de investigación que se puede llevar a cabo en los ámbitos de usuarios y tecnología, en este caso en la Web 2.0.

La relación usuario y Web 2.0 es nada más una parte del problema de investigación ya que también está lo correspondiente a las bibliotecas y sus servicios bibliotecarios y de información que utilizan esta tecnología. Temática que será abordada por sí misma en otra obra posterior, que logrará completar los tres elementos: el usuario, como eje central, el uso de la tecnología para acceder a la información y ésta para ser utilizada por las bibliotecas.

Juan José Calva González 


\title{
Iniciándonos en el conocimiento del Usuario 2.0
}

\author{
ISABEL VILLASEÑOR RODRÍGUEZ
}

Universidad Complutense de Madrid

\section{INTRODUCCIÓN}

$\mathrm{E}$

1 presente trabajo se ha desarrollado a partir de distintos elementos que pueden considerarse como puntos de partida. Por una parte, constituye la presentación de un avance de las investigaciones llevadas a cabo por la autora en el marco del proyecto colectivo de investigación "Usuarios 2.0 de la información audiovisual y textual" del Centro Universitario de Investigaciones Bibliotecológicas (Universidad Nacional Autónoma de México), que, integrado por profesores mexicanos y españoles de distintas universidades (UNAM, Universidad Complutense de Madrid, Universidad de Zaragoza y Universidad de Extremadura), pretende, en el periodo que abarca los años de 2011 a 2014, conocer al que hemos llamado "Usuario 2.0" con la intención de determinar su perfil. En la primera etapa de dicha investigación se ha abordado el estado del arte en el ámbito de nuestras disciplinas, pudiendo comprobar que, aunque existe abundante bibliografía sobre las herramientas que utiliza este usuario, apenas existen publicaciones que se centren en el mismo y en su caracterización. Por esa razón, hemos querido acercarnos a nuestro asunto desde disciplinas que ha- 
bitualmente se han encontrado alejadas de la Bibliotecología y la Documentación, como son la sociología y la antropología, ya que nuestro objeto de estudio es el ser humano en relación con la sociedad de la que forma parte. Al mismo tiempo, otro punto del que hemos partido ha sido el de considerar a este usuario desde su pertenencia a una o varias redes sociales, así como a un individuo que forma parte de una nueva cultura y que maneja una serie de herramientas creadas para su desarrollo. De ahí que nuestra intención sea, también, la de conocer el contexto en el que se mueve.

\section{EL CONTEXTO DEL USUARIO 2.0 Y SU DETERMINACIÓN}

El modelo sobre las necesidades de información (Modelo NEIN), desarrollado por Calva González ${ }^{1}$ con la finalidad de poder explicar el fenómeno de las necesidades de información en su aplicación teórica y práctica, considera, además de las tres fases que conforman el fenómeno (surgimiento de las necesidades de información, manifestación de estas a través de un comportamiento informativo y satisfacción de dichas necesidades) la existencia de distintos factores que influyen de manera determinante en todo el proceso y que constituyen el contexto en el que se desenvuelve el individuo. Este contexto es el rol que desempeña una persona en su vida cotidiana, laboral o social. Está formado por situaciones pasadas, presentes o futuras y se refiere tanto a factores internos como externos que, combinados, determinan tanto el surgimiento de la necesidad de información como el comportamiento informativo desarrollado para la búsqueda de esta misma, así como la satisfacción o insatisfacción al respecto. Los factores internos tienen que ver con las características particulares de cada persona (conocimientos, experiencia, habilidades, hábitos, intereses personales, personalidad, motivaciones, ambiciones, etc.) mientras que los factores externos (el ambiente) lo constituyen elementos que se encuentran fuera del

1 Las necesidades de información. Fundamentos teóricos y métodos, México. 
sujeto (actividad laboral, lugar donde vive, ambientes que lo rodean, tales como el social, económico, político, educativo, cultural, geográfico o físico, etc.). A este respecto, Aurora González Teruel ${ }^{2}$ afirma que la consideración de este asunto significa un cambio de paradigma en los estudios de necesidades y usos de información que se dio en los años 80 . De la perspectiva del sistema a la perspectiva del usuario, según esta autora, empieza a tenerse más en cuenta el hecho de que toda conducta informativa está regida por una gama de variables únicas para cada individuo y para cada problema. Importa el usuario, sus aspectos cognitivos, afectivos, sus características individuales junto a su ambiente externo. Pero este hecho no solo afecta a la conducta informativa del usuario, sino también al surgimiento de la necesidad de información y a su satisfacción o insatisfacción.

En el presente trabajo hemos afrontado el estudio de algunos elementos que consideramos implícitos en el contexto externo del Usuario 2.0 para poder llegar a un conocimiento de este en relación con el fenómeno de las necesidades de información. Calva dice que los factores externos son las presiones "[...] que el medio ambiente externo ejerce sobre el sujeto tales como los aspectos sociales, políticos, económicos, educativos, etcétera". ${ }^{3}$ Esta presión o influencia provoca en el individuo una respuesta (surgimiento de la necesidad, comportamiento informativo, satisfacción o insatisfacción) y es variable de comunidad a comunidad, lo que puede dificultar que se pueda tener un conocimiento completo. De cualquier forma, a pesar de la dificultad, "[...] es posible indagar sobre el ambiente en el cual se ubica una comunidad de usuarios" 4 para poder predecir necesidades y comportamientos informativos.

2 Los estudios de necesidades y usos de la información: fundamentos y perspectivas actuales.

3 Op. cit., 157-158.

$4 \quad$ Ibid., 158. 
Por todo lo dicho anteriormente, en el presente trabajo analizaremos brevemente aquellos elementos que consideramos de interés al acercarnos al contexto o ambiente donde se ubica el Usuario 2.0 con el fin de poder conocer sus necesidades y comportamiento informativos. Estos elementos o factores externos que aceptamos como determinantes vienen marcados por la pertenencia de ese usuario a la "Cultura 2.0" y a las redes sociales, y por el uso que hace de ciertas herramientas concretas. Por otra parte, consideramos que la metodología a emplear en el estudio de este nuevo usuario de información caracteriza de alguna manera su contexto en tanto que requiere de técnicas adaptadas al ambiente en el que se desenvuelve. Por último, la tendencia cada vez más generalizada de establecer tipologías de usuarios 2.0 o de usuarios de Internet, constituye un elemento a tener en cuenta a la hora de hacer este acercamiento al conocimiento del usuario que es objeto de nuestro estudio. A continuación desarrollamos brevemente algunas ideas relacionadas con cada uno de estos elementos.

\section{LA CULTURA 2.0 Y LAS REDES SOCIALES}

Existe abundante bibliografía que aborda el concepto de cultura o civilización. Aunque no es este el principal interés de nuestro estudio, necesitamos una conceptualización de la cual partir para afrontar el concepto de "Cultura 2.0". Por eso, de entre todas las posibles, nos basaremos en la definición que de "cultura" o "civilización" ofrece Tylor cuando dice que: "[...] en sentido etnográfico amplio, es aquel todo completo que incluye el conocimiento, las creencias, el arte, la moral, el derecho, las costumbres y cualquier hábito y capacidades adquiridas por el hombre en cuanto miembro de la sociedad" 5 . Ateniéndonos a lo que nos ocupa, Domingo Barbosa et. al., ${ }^{6}$ distinguen entre "Cultura 0.0" y "Cultura 0.2", afirmando que la

5 Primitive Culture: Researches into The Development of Mythology, Philosophy, Religion, Art and Custom.

6 CULTURA 2.0. Técnicas de investigación en entornos digitales. 
primera parte de la cultura general como contraposición a la ideada desde el espectro de la Red, del ciberespacio, titulada Cultura 2.0. Ambas distintas y distantes pugnando por la hegemonía de lo real. La primera, supone lo consciente y lo vivido; la segunda, lo virtual, imaginación de la primera. Los autores señalan la igualdad de ambas, considerando la 2.0 como una prolongación necesaria para comprendernos y seguir existiendo en la realidad. Es mucho más que lo entendido como "realidad virtual": empaqueta actos, creencias, valores que abarcan a toda la experiencia social y organizan la sociedad desde esa posibilidad de intercambio y comunicación.

Por otra parte, podríamos afirmar, de entrada, que la característica esencial del Usuario 2.0 la constituye el pertenecer o formar parte de una red social. En la actualidad, resulta ya cuantiosa la bibliografía existente sobre el concepto, la tipología y el funcionamiento de las redes sociales. En este sentido, vamos a incidir en algunas nociones destacadas en obras de reciente publicación que resultan de verdadero interés. Una ${ }^{7}$ de estas obras es la de Nicholas A. Christakis ${ }^{8}$ y James H. Fowler, ${ }^{9}$ dos de los teóricos de redes sociales más reconocidos en el mundo, que presentan en ella una novedosa concepción de tales redes basada en descubrimientos recientes en campos tan dispares como la genética, las matemáticas, la psicología o la sociología.

7 Conectados: El sorprendente poder de las redes sociales y cómo nos afectan.

8 Profesor de Sociología Médica en el Departamento de Política Sanitaria de la Facultad de Medicina de Harvard, de Sociología en el Departamento de Sociología de la Facultad de Artes y Ciencias de Harvard y de Medicina en la Facultad de Medicina de la misma universidad. Desde 1999, investiga la forma en que los factores y las interacciones sociales afectan a la salud y a la esperanza de vida de los individuos.

9 Doctor en Ciencias Políticas, encarna una nueva concepción de esta disciplina al quererla conectar con las ciencias de la naturaleza para identificar las fuerzas sociales y biológicas que subyacen en la naturaleza humana. Es profesor en la Universidad de California en San Diego, en el Departamento de Ciencias Políticas y en el Center for Wireless and Population Health Systems. 
Los autores hablan del origen y funcionamiento de las redes y revelan sus efectos en nuestra vida cotidiana a partir de lo que llaman la Regla de los Tres Grados de Influencia. Con frecuencia, dan cuenta de distintas investigaciones de campo propias y ajenas para ejemplificar lo que dicen. Se trata de un estudio general sobre las redes sociales reales que en algunas referencias se ejemplifica con redes virtuales. Para estos autores, una red social no es solo un grupo (colección de personas), sino que se requiere de algo más: "[...] un conjunto específico de conexiones entre las personas que la componen". ${ }^{10}$ Distinguen entre redes sociales reales, naturales (del mundo real) y redes sociales virtuales, que definen como "[...] servicios que permiten a los usuarios construir un perfil público o semipúblico en un entorno de acceso limitado, mostrar una lista de otros usuarios con quienes comparten una conexión y ver y navegar por las conexiones de otras personas del mismo sistema". ${ }^{11}$ Para ellos, una de las propiedades básicas de una red social es la de su forma (estructura o tipología) y destacan 6 reglas de la vida en la red en relación con su estructura (conexión) y función (forma en que se contagian) que debemos tener en cuenta al trabajar con una red social, sea del tipo que sea. Estas reglas son:

- Primera regla: "[...] somos nosotros quienes damos forma a nuestra red". ${ }^{12}$ Se refiere a la diversidad que existe de elecciones (muchas posibilidades) y está relacionada con lo que los autores llaman la propiedad transitiva (3 personas forman un triángulo en un solo grupo), que emplean para medir hasta qué punto está bien entrelazada una red.

- Segunda regla: "[...] nuestra red nos da forma a nosotros", ${ }^{13}$ esto es, nuestro lugar nos afecta.

- Tercera regla: "[...] nuestros amigos nos influyen". ${ }^{14}$

10 Conectados..., 23.

11 Ibid., 278.

12 Ibid., 30.

13 Ibid., 33.

14 Ibid., 34. 
- Cuarta regla: "[...] los amigos de los amigos de nuestros amigos también nos influyen". ${ }^{15}$ Se trata de lo que los autores denominan difusión hiperdiádica o contagio emocional, relacionado con el importante papel que juegan las redes en la propagación de las emociones. En este sentido cabe saber que la imitación de conductas puede darse consciente o inconscientemente y que todo depende de la posición en la red. Hay personas influyentes e influenciables porque, "[...] al estar integrados en redes sociales y sometidos a la influencia de otros a quienes estamos vinculados, necesariamente perdemos parte de nuestra individualidad [...] Sin embargo, el sorprendente poder de las redes sociales no reside sólo en el efecto que los demás tienen sobre nosotros, sino también el que nosotros tenemos sobre los demás". ${ }^{16}$

- Quinta regla: "[...] la red tiene vida propia”, ${ }^{17}$ es una suerte de superorganismo humano, con una anatomía y una fisiología (estructura y función) propias que los miembros ni controlan ni perciben. Se trata de la propiedad grupal, esto es, debemos estudiar al grupo entero y no sólo a individuos porque en las redes existen propiedades emergentes: atributos del todo que surgen de la interacción y conexión de los pares.

Y en relación con las reglas expuestas, los autores hablan de la Teoría de los 6 grados de separación y 3 grados de influencia en los demás, que acaban por agotarse porque los vínculos de las redes acaban por agotarse también.

En cuanto a las redes sociales en Internet, aunque los autores reconozcan las ventajas destacadas por sus defensores (la no limitación geográfica, la no limitación por timidez o discriminación, el inmenso poder para multiplicar los efectos de cualquier iniciativa, etc.) y que la tecnología puede estar cambiando la forma en que

15 Ibid., 35.

16 Ibid., 36.

17 Ibid., 38. 
nos "conectamos", hacen hincapié en el hecho de que no suponen algo nuevo: "[...] las nuevas tecnologías... se limitan a hacer posible nuestra ancestral tendencia a conectar con otros humanos [...] Por muy abstractas, grandes, complejas y supermodernas que sean las redes sociales formadas en el ciberespacio, siguen reflejando tendencias humanas universales y fundamentales que aparecieron en nuestra prehistoria, cuando nos contábamos historias alrededor de una hoguera en la sabana africana", ${ }^{18}$ porque "[...] los seres humanos somos animales sociales que vivimos en grupos y próximos unos de otros... Nuestras relaciones con otros seres humanos son cruciales," [...] "la sociabilidad humana y las redes sociales tienen antiguas raíces genéticas"19 (las redes están en nuestros genes). De cualquier forma, los autores reconocen que Internet ha facilitado nuevas formas sociales que introducen cuatro modificaciones radicales en los tipos de redes de interacción social existentes hasta ahora:

- Enormidad: la vasta magnitud de nuestras redes y del número de personas a las que se puede llegar.

- Comunalidad: una ampliación de la escala en la que podemos compartir información y contribuir a esfuerzos colectivos.

- Especifidad: un impresionante incremento en la particularidad de los vínculos que podemos formar.

- Virtualidad: la capacidad de asumir identidades virtuales.

Por su parte, David de Ugarte, economista y tecnólogo, "nativo digital" y figura pionera del análisis de redes sociales y de Internet en lengua española, en su libro El poder de las redes. Manual ilustrado para personas, colectivos y empresas abocadas al ciberactivismo, quiere definir lo que está cambiando y de qué forma las personas normales podemos ganar con ello independencia y poder de comunicación. Por eso habla de movimientos que represen-

18 Ibid., 266-267.

19 Ibid., 224 
tan indicios de una nueva forma de organización y comunicación social que poco a poco va adquiriendo fuerza (tanto dentro como fuera de Internet), como, por ejemplo, las "ciberturbas" y las redes distribuidas.

Ugarte distingue entre red centralizada (sólo hay una manera de unir dos nodos cualesquiera), red descentralizada (jerarquizada) y red distribuida. Esta última ofrece muchas formas alternativas de relacionarse, de forma que nadie depende de nadie para poder llevar su mensaje a cualquier persona; esto es, no tiene que pasar necesariamente y siempre por los mismos nodos para poder llegar a otros. Se trata de una red de iguales, aunque haya nodos más conectados que otros. La dinámica se basa en que alguien propone y se suma quien quiere, de forma que la dimensión de la acción dependerá de las simpatías y del grado de afinidad que suscite la propuesta. Este sistema se llama pluriarquía y ofrece mayor capacidad de movilización y rapidez de reflejos que la red descentralizada. Se basa en una multiplicidad de agentes que actúan autónomamente, coordinándose espontáneamente en la red, al margen de las clásicas formas y jerarquías. Un "orden espontáneo" (swarming). Algunos ejemplos de este tipo de red son:

- Blogsfera o red de bitácoras: gran red global de blogs, autora y origen de las movilizaciones de los últimos años. Uno de los pilares de la Web 2.0.

- Ciberactivismo: "[...] toda estrategia que persigue el cambio de la agenda pública, la inclusión de un nuevo tema en el orden del día de la gran discusión social, mediante la difusión de un determinado mensaje y su propagación a través del 'boca a boca' multiplicado por los medios de comunicación y publicación electrónica personal". ${ }^{20}$ Es la red social en su conjunto la que practica y hace crecer el ciberactivismo, desde la periferia hacia el centro.

20 David Ugarte, El poder de las redes..., 85. 
- Ciberturba: "La culminación en la movilización en la calle de un proceso de discusión social llevado a cabo por medios electrónicos de comunicación y publicación personales en el que se rompe la división entre ciberactivistas y movilizados". ${ }^{21}$ En ellas no hay organizador, sino "propositores" que se diluyen en el movimiento. Se sustenta en una primera fase de debate y otra de convocatoria y movilización en la calle.

- Contextopedia: diccionarios enciclopédicos ligados a los blogs o a una empresa; "[...] espacio personal o corporativo dedicado a definir términos habituales en el blog, conclusiones que se consideran y alcanzadas y debates cerrados". ${ }^{2}$ Un ejemplo es Wikipedia.

- Web 2.1: "[...] red de usuarios que crean y publican reciclando una y otra vez los materiales de su red". ${ }^{23}$ La ubica desde mediados de 2006. Algunas son: YouTube, Jumpcut, Flickr, Picasa Web Albums y Picnic. La web 2.1 no solo se limita a la creación audiovisual; también aparecen nuevos servicios para federar contenidos en los blogs.

En este contexto se ha desarrollado la Cultura 2.0. El profesor Figueroa Alcántara sintetiza perfectamente el sentido de esta cultura con la siguiente frase: "[...] la cultura de obsequiar, compartir, colaborar, reconocerse y solidarizarse en la sociedad red". ${ }^{24}$ Es una cultura símbolo de un nuevo movimiento social que, según este autor, tiene sus raíces en los sistemas de generación del saber o intercambio abierto de conocimientos de las universidades e instituciones de investigación científica a finales de los años cincuenta. Son atributos de esta cultura: la libre circulación de información, la colaboración, el intercambio de conocimientos, la generosidad pa-

21 Ibid., 73.

22 Ibid., 106.

23 Ibid., 117.

24 "La importancia de los bienes comunes de información para una sociedad y cultura libres", 598. 
ra ayudar a otros, la reciprocidad, la solidaridad, la crítica abierta y el reconocimiento social de los mejores dentro de la comunidad.

Los principios fundamentales de esta ética son, según este autor, los siguientes:

- Toda la información debe ser de libre acceso. Es indispensable que la información se mueva de forma abierta para que sea de valor social y para que toda persona que la necesite pueda utilizarla y contribuya, eventualmente, al desarrollo del conocimiento y la sociedad. Esto se aplica a todo tipo de información, sin importar medios o tecnologías de almacenamiento, difusión, etc.

- Para todo miembro de esta cultura debe ser prioritario colaborar, transmitir y compartir. Estas premisas y condiciones de la acción individual y colectiva 2.0 garantizan el progreso tecnológico y social, así como la solución de todo tipo de retos intelectuales y científicos.

- El acceso a todo tipo de dispositivos y redes que permitan acceder a datos, información y conocimientos debe ser ilimitado y total. Esto tiene que ver no tan solo con el acceso físico, sino también con la idea de acceso libre y sin restricciones para realizar modificaciones de diseño, programación, códigos, etc., lo cual permitirá su perfeccionamiento progresivo y su uso social.

- Hay que desconfiar de la autoridad y promover la descentralización y la conformación de redes independientes. Ésta es la mejor alternativa para favorecer la libre circulación de la información, con sistemas abiertos que no dependan de una autoridad central, gubernamental o privada.

- Los miembros de la Cultura 2.0 deben ser valorados por sus contribuciones, no por su identidad étnica, edad, títulos académicos o estatus laboral. Es decir, su reconocimiento se basa en sus logros concretos, examinados críticamente dentro de la comunidad, y no en criterios subjetivos y relativos. 
- A través de las tecnologías de la comunicación y la información se puede crear belleza y arte de múltiples formas y características. Un buen aporte 2.0, además de solucionar un problema o un reto intelectual, debe ser bello, elegante, atender criterios estéticos y cumplir con criterios esenciales de usabilidad.

- Los medios tecnológicos pueden mejorar la vida social si se usan solidariamente, si se colabora y comparte y si se privilegia ante todo la democratización de la información. Los miembros de la Cultura 2.0 valoran su entorno cultural y sus principios éticos dentro de sus comunidades en tanto elementos indispensables que definen a sus actividades como un nuevo movimiento social que busca la construcción de un mejor mundo y quiere mejorar nuestras vidas.

Se trata de compartir en red, y esto abarca movimientos sociales y culturales que tienen como finalidad el libre flujo de información y de datos de manera distribuida y cooperativa. Algunas de las tendencias más significativas son: el intercambio de archivos, el intercambio de información de manera anónima, la conversación mediante correo electrónico, chat, blogs, entornos wiki, mensajería instantánea, redes sociales, etc.

\section{METODOLOGÍA PARA ESTUdiAR AL USUARIO 2.0}

Han sido muchos y variados los acercamientos que se han hecho al tema que nos ocupa. Aquí queremos presentar uno que nos ha resultado de gran interés por su carácter bipolar al combinar lo clásico y lo novedoso. Los profesores Barbosa, Vázquez, Seco y Jiménez, proponen la aplicación de la metodología (técnicas) "clásica" de las ciencias sociales (antropología, etnografía y sociología) al ciberespacio, presentando casos prácticos de investigaciones llevadas a cabo en entornos digitales o mediados por ordenador. Intentan justificar por qué la antropología ha de ocuparse del estudio del ciberespacio y cuestionar si las técnicas tradicionales de la etnografía 
son aplicables a este nuevo entorno inmaterial. Para ello hablan de la ciberantropología, subdisciplina de la antropología que se ocupa del estudio etnográfico de las relaciones entre los hombres y las máquinas a finales del siglo XX, en el que las nuevas tecnologías sirven como agentes de producción social y cultural. Estos estudios crecen y se reorientan a investigar las comunidades electrónicas tanto desde la perspectiva de los contextos, donde las tecnologías del ordenador se desarrollan, como la interacción entre los diseñadores, los usuarios y las comunidades que resultan de esa interacción, a veces imaginadas e inventadas, pero capaces de crear nuevas identidades, los ciborgs o vecinos electrónicos, así como vivir en regiones y comunidades que resultan de esa interacción. Esto crece y abarca cada vez más facetas y dimensiones de los entornos digitales y cubre los diversos grupos de población implicados y las innovaciones, tanto tecnológicas como sociales, que surgen a una velocidad vertiginosa.

La consideración de que la Cultura 2.0 (la ideada desde el "espectro" de la Red) es una prolongación necesaria de la Cultura 0.0 para comprendernos y seguir existiendo en la realidad, resulta de gran novedad ya que se asegura la igualdad de ambas. Por otra parte, los autores defienden la etnografía como "viejo" método de trabajo e investigación antropológico perfectamente válido para aproximarnos a las nuevas tecnologías, una vez que se adapte a las peculiaridades concretas con las que "lo ciborg" nos desafía. La antropología nos permite descubrir el ordenamiento intrínseco de la sociedad, ese descubrimiento nos permite comprender y esa comprensión nos llevará a mejorar la calidad de vida de los miembros de este nuevo sistema. Entre las técnicas a utilizar están:

- Entrevistas a profundidad: la clásica es un cara a cara entre informante e investigador; el éxito está en la capacidad del investigador de extraer la información pertinente; la respuesta es abierta y hay que motivar al informante para que se sienta a gusto y colabore. No se trata de usar una lista de preguntas limitada, ya que se pueden incluir nuevas o suprimir las que no procedan o hayan sido respondidas de manera espontánea más que un repertorio de preguntas, se trata de disponer de 
una serie de temas —una guía-; es el complemento ideal de la observación participante; la cual debe ser informal, abierta y flexible. Pueden usarse como instrumentos la grabación de audio y video y un cuaderno de campo; conviene anotar los matices observados, las evasivas y las incongruencias entre el lenguaje gestual y el verbal. Una adaptación a la investigación en línea es el blog, que permite disponer de todas las transcripciones rápidamente y no necesita el cara a cara permanente.

- Grupos de discusión: también llamada focus group o focus group discussion, debate en grupos de interés, entrevista en grupos de debate; entrevista realizada simultáneamente a un grupo de $6 / 8$ personas seleccionadas por sus intereses similares para constituir un grupo homogéneo entre media hora y dos horas, con un moderador formado tanto en la dinámica de grupos como en la técnica de la entrevista. Se hacen varias sesiones (grabadas), algunos temas en los que puede centrarse el debate son: la colección del centro, los servicios, la conducta del usuario cuando busca información, las necesidades de los usuarios respecto al centro etc. Se trata de una técnica eficiente para obtener información cualitativa de los usuarios, ya que se optimizan el tiempo y los recursos (información de un grupo y no de una sola persona) y resulta más agradable para los usuarios; debe hacerse un número de preguntas limitado para que las respondan todos en poco tiempo, se requieren habilidades del moderador para controlar la sesión. Los usuarios pueden sentirse condicionados si es que se conocen; los resultados no son generalizables y puede surgir un líder de opinión que tome el control del debate.

- Encuestas: en la red se puede llegar a un número muy amplio de informantes y esto supone un costo insignificante; la muestra no representa un universo conocido. Los cuestionarios pueden ser alojados en servidores específicos que muestran en línea nuestras preguntas para que el informante responda y a tiempo real podremos ir comprobando los resultados y exportarlos al software de tratamiento adecua- 
do obteniendo un ahorro en tiempo y esfuerzo. Automatizando y mecanizando la recolección de datos podremos centrarnos desde el principio en la interpretación de los resultados, la encuesta puede ser incrustada en la web del proyecto o enviar el enlace por mensajería o correo electrónico; se requiere un lenguaje claro y conciso. Al inicio, debe aparecer la identificación de quiénes somos y qué buscamos, después los campos de clasificación sociológica de edad, estudios, localidad, etc.; las preguntas agrupadas por proximidad y afinidad temática, primero van las cerradas y luego las abiertas; conviene evitar las preguntas directas y agradecer la colaboración y es conveniente una prueba piloto.

- Análisis de contenido: método, procedimiento o conjunto de técnicas aplicables a mensajes escritos u orales. Su finalidad es la de conocer las entrelíneas de cada mensaje, o determinar la manera en la que son llevados estos mensajes a los diferentes públicos.

- Historias de vida: constituyen una metodología que nos permite reunir los acontecimientos más significativos de nuestras vidas, desde que nacemos hasta el momento en que nos enfrentamos a ordenar los pasos andados. Para hacer una historia de vida utilizamos como principal herramienta la memoria, pues nos permite reconstruir de dónde venimos, la formación paulatina de nuestra familia, el contexto social, cultural, político y económico que nos ha tocado vivir y todos aquellos hechos que nos han marcado.

- Observación participante: poco utilizada y valorada por las ciencias sociales clásicas; distingue y le da valor añadido a la antropología. Se requiere formación específica y una serie de características personales que le permitan al investigador conectar e interactuar con el informante como la empatía, ya que el mejor observador no es el que habla mucho sino el que hace hablar a los demás, esta es la primera técnica a utilizar, pues permite hacernos una composición de lugar previa y localizar y contactar con los informantes a los que entrevistaremos en profundidad, posteriormente, tendremos 
que registrarnos como usuarios registrados y participar en los eventos de la comunidad a estudiar. Debe buscarse la estructura interna e intentar dar una explicación completa, debe ser concienzuda y metódica, hay que ser lo más objetivos posible y hay que interpretar, no integrarse tanto en la comunidad que se pierda la globalidad del proceso y se acabe siendo un informante más. Existen dos corrientes: periférica, donde el observador se mantiene al margen, hay una observación sin interferencias, pero la impresión recibida es demasiado lejana de la realidad por la escasa implicación; y la activa, donde el observador adquiere un rol dentro de la comunidad estudiada; la examinación es muy profunda porque el observador llega a ser informante por sí mismo, aunque se corre el peligro de contaminar la inspección con sensaciones y vivencias personales. Hay que buscar el equilibrio entre ambas, no hay que descubrir con demasiada premura el rol de investigador porque se pueden provocar ciertas reacciones en la comunidad. Observar, escuchar, preguntar, tomar registro de lo que se ve y se interpreta, fecha y lugar. Se usan cámaras fotográficas, de video y grabadoras.

- Técnicas audiovisuales.

- Programas para investigación cualitativa (los primeros se dieron en los 80 con Fielding y Lee, los más populares son: The Ethnographer, Nud.ist, Atlas.ti, Nvivo, MAXqda, QUALRUS. Hoy, existe una oferta amplia: se llaman genéricamente CAQDAS (Computer Assisted Qualitative Data Análisis Software).

- Foro: foro de mensajes, de opinión o de discusión, se trata de una aplicación web que le da soporte a discusiones $\mathrm{u}$ opiniones en línea; muchos foros tienden a crear comunidades con reglas propias y hasta con un lenguaje propio.

- Avatares: representación gráfica mediante un dibujo o una fotografía de una persona para su identificación.

- Chat: anglicismo que se refiere a una comunicación escrita a través de Internet entre dos o más personas que se realiza instantáneamente con una acepción amplia. 
- Correo electrónico: servicio de red que permite a los usuarios enviar y recibir mensajes y archivos rápidamente (también denominados mensajes electrónicos o cartas electrónicas) mediante sistemas de comunicación electrónicos. Principalmente se usa este nombre para denominar al sistema que provee este servicio en Internet, mediante el protocolo SMTP, aunque por extensión también puede verse aplicado a sistemas análogos que usen otras tecnologías. Por medio de mensajes de correo electrónico se puede enviar no solamente texto, sino todo tipo de documentos digitales. Su eficiencia, conveniencia y bajo costo están logrando que el correo electrónico desplace al correo ordinario para muchos usos habituales.

- Quedada, kedada, kdd: reunión en el mundo real de un grupo mayoritario de personas pertenecientes a una comunidad virtual, que tiene como propósito confraternizar y terminar de conocer a las personas con las que se tiene contacto solamente telemático. Suelen tener carácter periódico y rotativo; pueden ser espontáneas y los foreros anuncian el encuentro y se reúnen, o planificadas, se ponen de acuerdo e incluso quedan de acuerdo para planificar.

\section{TiPOLOGÍA DE USUARIOS 2.0}

Hasta el momento, son escasos los trabajos de carácter teórico que afronten una tipología de Usuarios 2.0. En las lecturas hechas hasta ahora, hemos podido ver algunas "clasificaciones" y caracterizaciones de usuarios en la red fundadas esencialmente en resultados obtenidos a través de trabajos de campo. Así, el antropólogo Alfonso Vázquez Achero ${ }^{25}$ nos dice que existen diferentes tipos de comunidades virtuales (con características particulares), que se basan en los resultados obtenidos de una investigación llevada a cabo

25 Ciberantropología. Cultura 2.0. 
por observación participante en red mediante visitas a múltiples comunidades y su registro. Se observaron las pautas de comportamiento de los componentes, las posibilidades de cada comunidad y la manera en que los nuevos miembros se posicionaban en la red. ${ }^{26}$ Algunas de estas comunidades son:

- BBS (Bulletin Borrad System): sistema de tablero de anuncios anterior a Internet.

- Foros de discusión, de mensajes o de opinión: sus usuarios reciben el nombre de foreros o foristas. Contamos con foros generales y temáticos, abiertos o restringidos y usuarios registrados o invitados, activos o latentes; entre ellos están los lurkers (que leen pero no escriben), spamers (introducen publicidad en los foros), troles (insultan o molestan a otros usuarios), leechers (sólo obtienen beneficios, sin aportar nada a cambio), fakes (se hacen pasar por otros miembros), títeres (inscritos en el foro dos o más veces haciéndose pasar por diferentes miembros), chaters (utilizan un lenguaje casi jeroglífico, herencia de los mensajes sms), arqueólogos (se afanan en tener en primera página temas antiguos), novatos (participan sin tener en cuenta las normas de la comunidad), el administrador (normalmente creador del foro, puede eliminar o corregir a los usuarios y cuenta con un status especial) y los usuarios moderadores (tienen la potestad para controlar cierto tipo de intervenciones e incluso eliminar mensajes que se consideran no adecuados).

- La blogosfera: conjunto de webblogs repartidos por el ciberespacio.

- Portales web.

- Correo electrónico y grupos de correo electrónico (e-mail y e-mail groups): las listas de correo o listas de distribución, en las que los usuarios interesados se inscriben y reciben periódicamente información en su buzón; pueden responder y

26 Los tipos son prácticamente los mismos que aparecen en Wikipedia. 
enviar lo que ellos consideren importante al resto de la lista.

- Grupos de noticias (news groups): parecidas al e-mail de grupo. Al darse de alta, el usuario irá recibiendo información periódica de este grupo.

- Chat/IRC: herramientas similares que nos permiten comunicarnos en tiempo real con otras personas.

- Dimensión de Usuario Múltiple (Multi-user dimension, MUD): es un sistema que permite a sus usuarios convertirse en el personaje que deseen y visitar mundos imaginarios en los que participar junto a otros individuos en juegos $\mathrm{u}$ otro tipo de actividad.

- $\quad$ Sistemas Peer to Peer (P2P): programas que permiten intercambiar ficheros electrónicos.

- Bienes comunes: "[...] un bien común de información es un sistema de información donde se considera primordial el uso común y colectivo, así como la producción, difusión y preservación comunal para las generaciones actuales y futuras". ${ }^{27}$

- Wikis: una wiki puede entenderse como un espacio web colaborativo para la creación libre y solidarizada de contenidos. Permiten que cualquier usuario, de manera colaborativa, pueda crear, editar, borrar o modificar contenidos, en forma interactiva, sencilla, rápida, eficiente y fácil de aprender.

- Redes sociales, de las que hablamos a continuación.

Se trata de una tipología que refleja todas aquellas herramientas que existen (y se usan) en el ambiente del usuario $2.0 \mathrm{y}$ que se han desarrollado con la enorme expansión de las nuevas tecnologías.

La propia Wikipedia, al hablar de los foros de discusión, determina una clasificación que se recoge en los propios foros, explicando cada uno de los términos que en ellos se emplean. De esta manera, podemos saber que sus usuarios reciben el nombre de foreros o foristas; que existen usuarios de foros generales y/o temáticos y de

27 H. A. Figueroa Alcántara, op. cit., 599. 
foros abiertos y/o restringidos así como usuarios registrados o invitados, activos o latentes. Entre los usuarios de los foros están los lurkers (que leen pero no escriben), spamers (introducen publicidad en los foros), troles (insultan o molestan a otros usuarios), leechers (sólo obtienen beneficios, sin aportar nada a cambio), fakes (se hacen pasar por otros miembros), títeres (inscritos en el foro dos o más veces haciéndose pasar por diferentes miembros), chaters (utilizan un lenguaje casi jeroglífico, herencia de los mensajes sms), arqueólogos (se afanan en tener en primera página temas antiguos), novatos (participan sin tener en cuenta las normas de la comunidad), el administrador (normalmente creador del foro, puede eliminar o corregir a los usuarios y cuenta con un status especial) y los usuarios moderadores (tienen la potestad para controlar cierto tipo de intervenciones e incluso eliminar mensajes que se consideran no adecuados).

Dolors Reig ${ }^{28}$ da a conocer otra tipología basada en aspectos relacionados con las actitudes y conductas de los usuarios de redes sociales que, en su día, estableció OFCOM. ${ }^{29}$ Podemos encontrar:

- Alpha socializers: personas que usan los sitios sociales en intensos y cortos periodos de tiempo para coquetear, conocer gente nueva o entretenerse.

- Buscadores de atención: personas que buscan la atención y los comentarios de los demás, "posteando" fotos y personalizando sus perfiles.

- Seguidores: personas que se unen a sitios sociales para estar al día de las actividades de sus contactos en la vida real.

- Fieles: personas que usan las redes sociales para recuperar amistades del pasado.

- Funcionales: personas que tienden a usar los sitios de redes sociales con un único objetivo y puntual.

- No usuarios: pueden clasificarse en distintos grupos, basa-

28 Actitudes, comportamiento, usos, clasificación de los usuarios de las redes sociales.

29 Organización reguladora independiente para las industrias de la comunicación en Reino Unido. 
dos en las razones que se aducen para no utilizar redes sociales tales como la preocupación por la seguridad, la poca experiencia técnica, motivos intelectuales al considerar las redes sociales como una pérdida de tiempo.

Domingo Barbosa et. al., ${ }^{30}$ al considerar la red como nuestro territorio, nuestra aldea global, afirman que los usuarios son la tribu, y una tribu con unas características irrepetibles, ya que un mismo usuario suele tener una identidad en cada escenario: en su vida física y en su vida virtual. Cada usuario tiene su rol, su función en este espacio virtual. Para poder comprender de forma amplia y globalizada esta tribu, se tendrán en cuenta no solo a quienes están integrados en las nuevas tecnologías, sino también a aquellos que por una u otra razón se han ido quedando al margen. Todos estamos dentro (aborigen digital), la diferencia es que unos controlan este medio y otros no. Entre los excluidos y los integrados, se abre la brecha digital (desigualdades económicas, sociales y personales). Para estos autores existe, pues, una gran diversidad de pobladores en esta aldea, entre los que destacan:

- Nativos digitales: han nacido en un entorno ya tecnificado.

- Inmigrantes digitales: han conocido la época previa y se han ido introduciendo en la sociedad red a medida que las TIC iban llegando a sus vidas.

- Fóbicos sociales: encerrados en sus cuatro paredes tienen como única ventana al mundo la red de redes. Tienen timidez o introversión que se mueve dentro de parámetros normales; con la red tienen la posibilidad de explorar, construir, reconstruir y jugar con distintas identidades, de crear identidad, de esconderse detrás de un rol. Sufren grandes cambios de todo tipo como trastorno psicológico que podría definirse como una timidez exagerada que se convierte en patología; se huye de las relaciones sociales o no hay un

CULTURA 2.0 ... 
perfil. Cualquier persona, independientemente de su edad, sexo, nivel económico o sociocultural puede padecer este trastorno.

Como complemento, existen distintas variables a tener en cuenta: sexo (el acceso a la red presenta una oportunidad de expansión sin discriminación. En la sociedad 2.0 el porcentaje de mujeres es más elevado que el de hombres, al menos en el mundo occidental); clase social (el acceso a Internet está condicionado por infraestructuras marcadas por factores económicos; Internet no es una necesidad vital y a veces es un lujo, la idea de "Internet para todos" es una utopía y es evidente la existencia de la brecha digital); edad (la red está tomada mayoritariamente por jóvenes y adolescentes con un interés lúdico y comunicativo, principalmente); ubicación espacial (el acceso a la red es más sencillo en el mundo occidental y en las zonas urbanas, donde más población se condense y más ingresos se puedan generar, allí habrá mayor conexión. En países con economías menos favorecidas, el acceso es de peor calidad y menos extendido); profesión (si el trabajo es un componente básico del sistema social, ineludiblemente no podrá escapar a los cambios que afectan a esta; hay quien necesita la red para su trabajo - medio- y quien tiene la red en sí como trabajo - fin-).

Otro ejemplo es el que nos proporciona Rautenstrauch, ${ }^{31}$ quien asegura que en las redes sociales podemos clasificar los usuarios en los siguientes perfiles, según su participación en los medios sociales:

- Creador (creator): Publica una web, mantiene un blog, publica videos y música que ha creado y escribe historias o artículos que hace públicos.

- Conversador (conversationalists): Actualiza sus estados en redes sociales y publica en Twitter.

- Crítico (critics): Comenta en otros blogs/foros, publica análisis de productos/servicios y contribuye a escribir/editar artículos en Wikis.

31 "Tipos de usuarios en Redes Sociales". 
- Coleccionista (collectors): Usa fuentes RSS, vota por páginas web y etiqueta páginas/fotos.

- $\quad$ Participativo (joiners): Tiene perfiles en redes sociales y los mantiene.

- Espectador (spectators): Lee blogs, escucha podcasts, ve vídeos de otros, lee foros, análisis de productos/servicios y tweets.

- Inactivo (inactives): No hace nada de todo esto.

Por último, en cuanto al Usuario 2.0 en concreto, Sergio Ortega Santamaría ${ }^{32}$ nos ofrece una serie de características que lo hacen realmente particular:

- Es consumidor y creador de contenidos (aporta, difunde, comparte y colabora).

- Cuenta con una cultura tecnológica avanzada.

- Apoya, informa, discute y opina.

- Busca una aprobación social continua para alimentar cierta tentación egocéntrica.

- Utiliza estrategias que le permiten superar las limitaciones de los procesos de acceso y gestión de la información.

- Se trata de un usuario al que no es difícil seguir la pista y mucho menos contactar con él por cualquiera de los canales multimedia que gestiona y comparte.

- Ha sido y es pionero en la utilización de herramientas y aplicaciones en línea y lo seguirá siendo mientras estas le ayuden a gestionar su trabajo, mantener su red de contactos y establecer una actitud y disposición colaboradora.

- Consume una gran variedad de información y se convierte a su vez en productor y trabajador de la misma, beneficiándose de las ventajas significativas del conocimiento que se construye.

32 "Evolución del perfil del usuario: Usuario 2.0". 
- Cuenta con conocimientos de inglés y de ciertos tecnicismos.

- Dispone de capacidad para comunicarse con cierta coherencia.

- Es respetuoso con los demás, o conocedor de las normas y convenciones establecidas en cada caso.

- Su rasgo más distintivo no es tanto lo que sabe o deja de saber sino el modo en que comunican esto.

- Sabe lo que busca antes de encontrarlo.

\section{BIBLIOGRAFÍA}

Calva González J. J. (2004), Las necesidades de información. Fundamentos teóricos y métodos. México: UNAM.

Christakis, N. A. y J. H. Fowler. (2010). Conectados: El sorprendente poder de las redes sociales y cómo nos afectan. Barcelona: Taurus.

CULTURA 2.0. Técnicas de investigación en entornos digitales (2010),. D. Barbosa, A. Vázquez, J. Seco y J. M. Jiménez. Barcelona: UOC.

Figueroa Alcántara, H. A. (2010). "La importancia de los bienes comunes de información para una sociedad y cultura libres" Memoria del $7^{\circ}$ Seminario HispanoMexicano de Investigación en Bibliotecología y Documentación: 7, 8 y 9 de abril de 2010. Coordinador, J. R. Ortega, compilador, C. Augusto Ramírez Velásquez. México: UNAM, Centro Universitario de Investigaciones Bibliotecológicas, 597-629.

(2011), "Sistemas wiki y peer to peer: dos paradigmas emergentes de producción colaborativa e intercambio de información en la sociedad en red". Actas del VIII Seminario hispano mexicano de investigación en Bibliotecología y Documentación. Madrid: Facultad de Ciencias de la Documentación, Universidad Complutense de Madrid, 223-238. 
González Teruel, A. (2005), Los estudios de necesidades $y$ usos de la información: fundamentos y perspectivas actuales. Gijón: TREA.

Ortega Santamaría, S. (2007), "Evolución del perfil del usuario: Usuario 2.0". No solo Usabilidad, núm. 6. Disponible en: <www.nosolousabilidad.com/articulos/usuario20. htm>. [Fecha de consulta: 11 de noviembre 2011].

Rautenstrauch, R. (2011). "Tipos de usuarios en Redes Sociales". Disponible en: $<$ http://www.netconsultingmarke ting.es/tipos-de-usuarios-en-redes-sociales/>. [Fecha de consulta: 2 de febrero 2012].

Reig, D. Actitudes, comportamiento, usos, clasificación de los usuarios de las redes sociales. Disponible en: $<$ http://www.dreig.eu/caparazon/2009/02/09/actitudescomportamiento-usos-clasificacion-de-los-usuarios-delas-redes-sociales/>. [Fecha de consulta: 11 de noviembre 2011].

Tylor, E. Burnett (1873). Primitive Culture: Researches into The Development of Mythology, Philosophy, Religion, Art and Custome, London: John Murray.

Ugarte, D. de (2007). El poder de las redes. Manual ilustrado para personas, colectivos y empresas abocadas al ciberactivismo. Barcelona: El Cobre Ediciones.

Vázquez Achero, A. (2008). Ciberantropología. Cultura 2.0. Barcelona: UOC. 


\title{
Los usuarios y el uso de Internet y las herramientas del Web 2.0
}

\author{
Edgar GuzMán Prieto \\ Universidad Nacional Autónoma de México
}

$\mathrm{E}$

n primer lugar están los alumnos de educación básica secundaria, dos de estas escuelas están ubicados en la Ciudad de México en la delegación Xochimilco y las otras en el Estado de México en el municipio de Chalco, comunidad de Santa Catarina Ayotzingo. De las secundarias de la ciudad, una es la General "Dr. Alfonso Pruneda" y la otra es la Técnica Núm. 79. La del Estado de México es la "Juan Aldama" Núm. 325, una secundaria oficial.

Otros usuarios que también incluimos son los alumnos universitarios, usuarios de la Biblioteca Central de la UNAM y los alumnos de la Facultad de Física, también de la UNAM.

La muestra de la población de los alumnos de secundaria es la siguiente:

Tabla 1

\begin{tabular}{|l|c|c|c|c|}
\hline \multicolumn{1}{|c|}{ Escuela } & Primer grado & Segundo grado & Tercer grado & Total \\
\hline General & 86 & 92 & 88 & 266 \\
\hline Técnica & 95 & 91 & 76 & 262 \\
\hline Oficial & 78 & 78 & 73 & 229 \\
\hline
\end{tabular}

Fuente: elaboración propia 
La mayor concentración de población se presenta en las escuelas de la Ciudad de México, esto debido quizá a que la escuela del Estado de México está en un municipio apartado de la cabecera municipal, que es Chalco.

Lo rescatable de estas indagaciones es que todos los alumnos, en estos tiempos de innovaciones tecnológicas, ya hacen uso de las computadoras con acceso a Internet para muy diversos asuntos que a continuación abordaremos, sobre todo en relación al uso que le dan a Internet (Tabla 2), independientemente de que tengan, o no, computadora en casa. Pues pueden acceder a ella en un café Internet, o en la casa del amigo, del primo etc.

Tabla 2. El uso de internet

\begin{tabular}{|l|c|c|c|}
\hline \multicolumn{1}{|c|}{ Uso de internet } & Oficial \% & General \% & Técnica \% \\
\hline Jugar en línea & 5.1 & 6.98 & 7.23 \\
\hline Ver o escuchar programas o música & 7.3 & 33.68 & 33.8 \\
\hline Buscar información escolar & 45 & 19.20 & 20.09 \\
\hline $\begin{array}{l}\text { Descarga de diversos formatos (videos, } \\
\text { música, etc.) }\end{array}$ & 5.2 & 11.78 & 12.77 \\
\hline $\begin{array}{l}\text { Buscar información temas de interés } \\
\text { (noticias y videojuegos) }\end{array}$ & 14.4 & 8.12 & 7.61 \\
\hline Relacionarse (chatear) & 21 & 19.20 & 18.03 \\
\hline Otro (publicar en redes sociales) & 2 & 1.05 & .47 \\
\hline
\end{tabular}

Fuente: elaboración propia

En la Tabla 2 podemos observar que los alumnos usan Internet para escuchar música y ver videos de diversa índole, pero la mayoría de ellos buscan en la Red información escolar, ojo, hablamos de Internet, no de la Web 2.0 pese al título de esta ponencia. Esto nos muestra que Internet es de gran utilidad para estos jóvenes estudiantes.

La Tabla 3 en la siguiente página nos muestra los sitios de la Web a los que recurren estos alumnos para buscar la información que los ayuda a cumplir con sus tareas escolares. Si hay diferencias entre las escuelas, por ejemplo si se trata de una escuela ge- 
neral, la primera opción para buscar información serán las redes sociales, la cual pueden obtener de algún compañero, o directamente de los profesores, o simplemente colocando la pregunta en su muro; y si se trata de una secundaria técnica van directamente al buscador Google para resolver sus dudas o hacer las investigaciones que tengan que realizar. En la escuela del Estado de México, al igual que en la general, lo que prefieren hacer primero es preguntar en las redes sociales y en segundo lugar, recurren al buscador de Google.

Tabla 3

\begin{tabular}{|l|c|c|c|}
\hline \multicolumn{1}{|c|}{ Sitios Web } & Oficial & General & Técnica \\
\hline Wikipedia & 47 & 185 & 197 \\
\hline YouTube & 66 & 160 & 148 \\
\hline Google & 102 & 244 & 241 \\
\hline Yahoo respuestas & 50 & 74 & 59 \\
\hline Redes sociales & 157 & 249 & 204 \\
\hline Otros & 10 & 11 & 6 \\
\hline
\end{tabular}

Fuente: elaboración propia

La Tabla 4 nos muestra el uso que hacen de las redes sociales los alumnos de secundaria, en comparación con la anterior (Tabla 3) en la que la mayoría mencionó que utilizan las redes para buscar información. Esta Tabla 4 refleja que la gran mayoría de los alumnos usan las redes para chatear, para estar en constante comunicación, lo cual es seguido por el intercambio de videos y/o, fotos; esto en las dos secundarias de la Ciudad de México, pero en la del Edo. de México usan las redes sociales mayormente para buscar o solicitar información.

Tabla 4

\begin{tabular}{|l|c|c|c|}
\hline \multicolumn{1}{|c|}{ Uso de las redes sociales } & Oficial & General & Técnica \\
\hline Chatear & 112 & 236 & 194 \\
\hline Jugar & 32 & 64 & 65 \\
\hline
\end{tabular}


Usuarios de la Información...

\begin{tabular}{|l|c|c|c|}
\hline Entretenimiento & 43 & 96 & 89 \\
\hline Buscar o solicitar información & 113 & 98 & 79 \\
\hline $\begin{array}{l}\text { Enviar o intercambiar videos, } \\
\text { fotos, etc. }\end{array}$ & 40 & 138 & 104 \\
\hline Otro & 5 & 6 & 4 \\
\hline
\end{tabular}

Fuente: elaboración propia

Tabla 5

\begin{tabular}{|c|c|c|c|}
\hline $\begin{array}{c}\text { Redes sociales me ayudan } \\
\text { en trabajos escolares }\end{array}$ & Oficial & General & Técnica \\
\hline Sí & 125 & 172 & 142 \\
\hline No & 104 & 77 & 63 \\
\hline
\end{tabular}

Fuente: elaboración propia

Para estos alumnos las redes sociales son de gran importancia porque los ayudan con sus trabajos escolares, lo que mencionan es que pueden intercambiar información y las tareas, por lo que ya no es necesario salir de casa para hacer trabajos en equipo; y si, por ejemplo, no van a clases, pueden pedirles a sus compañeros la tarea y otras cosas.

Aquellos que mencionaron que no les ayudan las redes sociales sostienen que estas no cuentan con las suficientes normas de autenticidad y por lo tanto no encuentran información de interés, "solo es para el chisme", dicen, y prefieren ir a la biblioteca.

Como se puede ver, estos alumnos de secundaria ya usan las herramientas de la Web 2.0 pero todavía falta mucho para terminar de enseñarles la gran utilidad que pueden tener estas en la vida académica y así poder sacarles mayor provecho.

Una comunidad académica en pleno uso de estas herramientas de la Web 2.0 son los universitarios de la UNAM, como lo indica en el trabajo que nos presenta Torres Piñon sobre el "Uso de herramientas Web 2.0 por los usuarios de la biblioteca central de la UNAM" (Torres Piñón, 2014).

Su muestra fue de 366 usuarios y empleó un cuestionario como instrumento para recabar la información. 
Este trabajo identifica qué tipo de herramientas son las empleadas y para qué las utilizan estos alumnos.

Gráfica 1. Datos demográficos: nivel de estudios

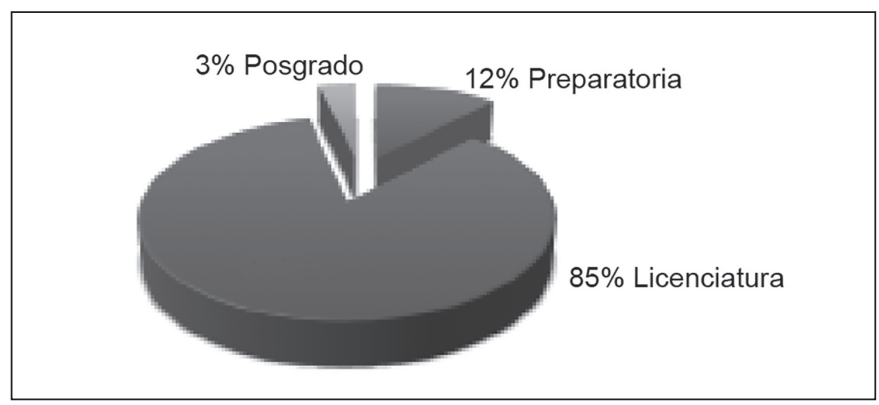

Fuente: Torres Piñón, 2014.

En la Gráfica 1 la mayor muestra de alumnos asistentes está cursando la licenciatura, lo cual puede deberse a que la Biblioteca Central tiene alrededor 4 facultades (Arquitectura, Filosofía y Letras, Psicología y Derecho)

Gráfica 2. Lugares desde donde los usuarios acceden a Internet

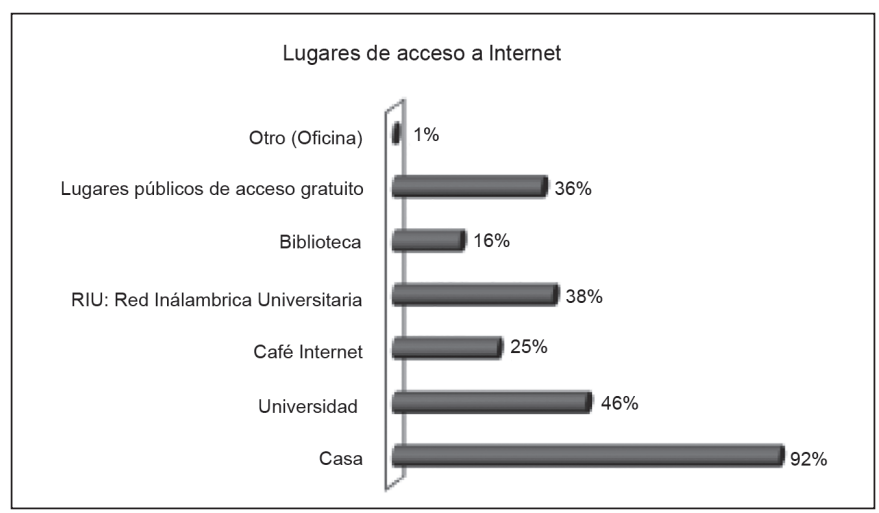

Fuente: Torres Piñon, 2014. 
La Gráfica 2 nos indica dónde acceden estos alumnos a Internet, y así averiguamos que más del $90 \%$ de los encuestados lo hace desde su casa; $46 \%$ desde la universidad, y otros desde lugares públicos con acceso gratuito y dentro de la Red Inalámbrica Universitaria, esta gráfica nos hace suponer que los alumnos no tienen problema para poder acceder a Internet, y lo hacen casi desde cualquier lugar.

La siguiente gráfica nos revela que el empleo de Internet que hacen los usuarios de la Biblioteca Central es principalmente para buscar información, y luego para estar comunicados entre amigos, colegas, etc. Y después, con un poco menos de uso, viene Internet para el intercambio de archivos, ya sean documentos de Word, pdfs, o archivos en audio, videos o simplemente los links.

\section{Gráfica 3. Actividades que los usuarios realizan en Internet}

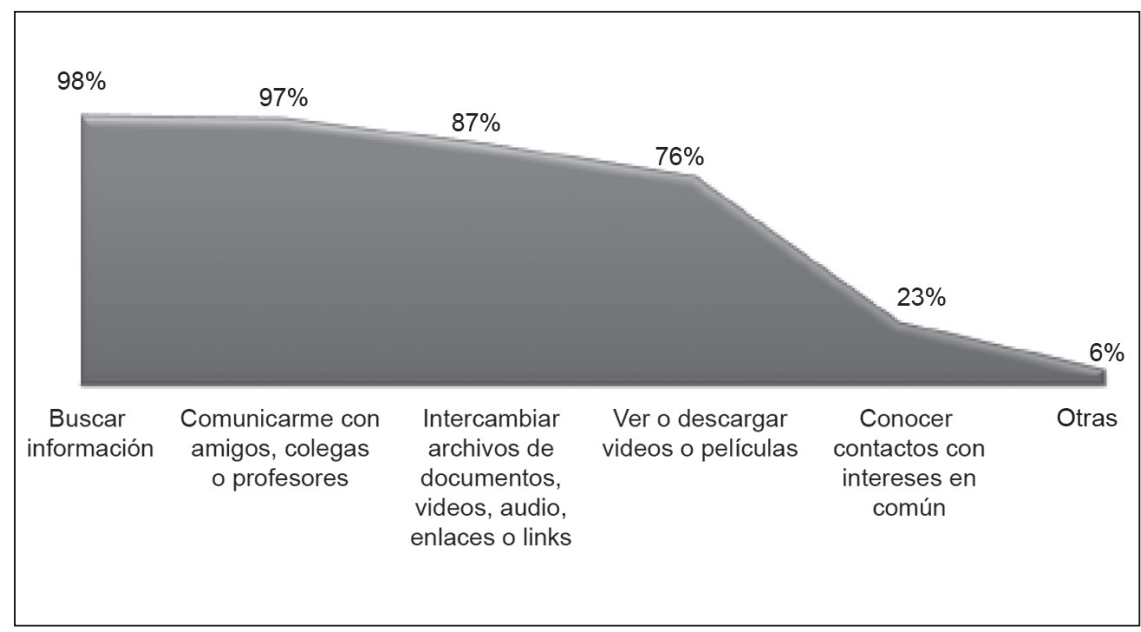

Fuente: Torres Piñón, 2014. 
Los usuarios y el uso de Internet...

Gráfica 4. Herramientas de la Web 2.0 que los usuarios utilizan

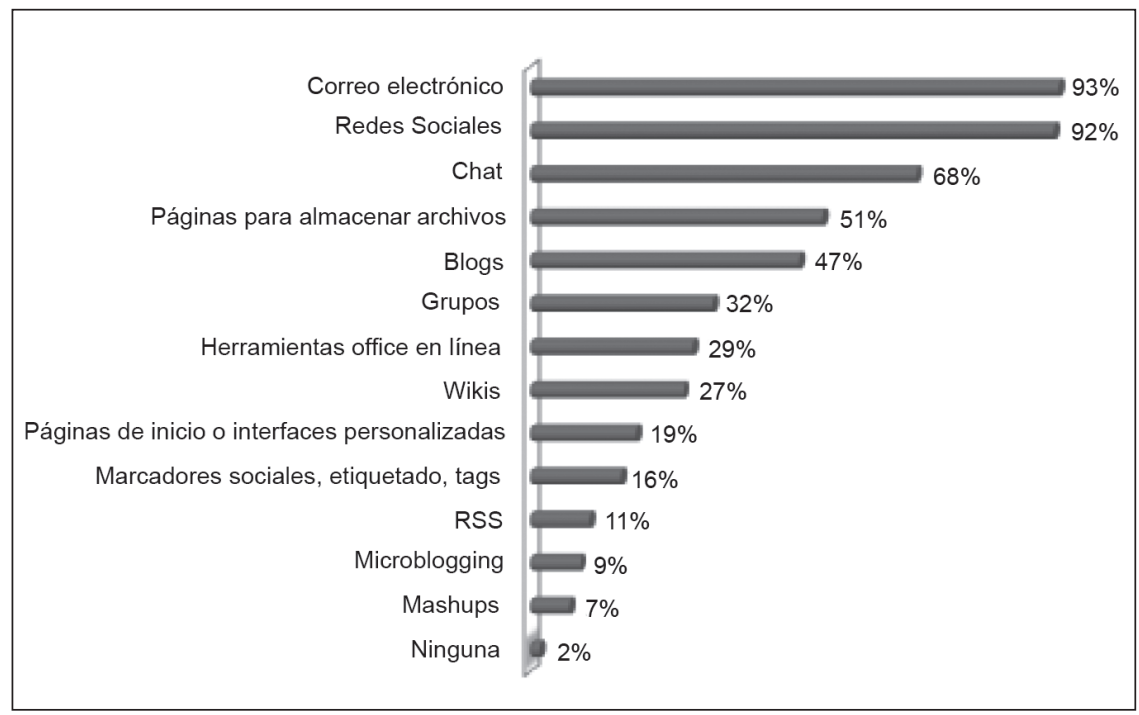

Fuente Torres Piñón, 2014.

Dentro del uso de las herramientas Web 2.0 (Gráfica 4), estos usuarios emplean principalmente el correo electrónico, seguido de las redes sociales y del chat, aunque este está también dentro de las redes sociales. De acuerdo a la Gráfica 3, en tercer lugar está subir, intercambiar y almacenar archivos en la nube.

Asimismo se les preguntó a estos usuarios qué sitios de la Web 2.0 acostumbran usar, y la gran mayoría respondió que: YouTube, seguido de Facebook, Google+ y la Wikipedia, principalmente.

La frecuencia de uso de estas herramientas para la gran mayoría de los jóvenes es diaria; siempre están ahí.

Ya específicamente El uso de Wikipedia por alumnos de la licenciatura de física en la UNAM (2014), explora el uso de herramientas de la Web 2.0, que son las wikis.

Para realizar esta indagación empleó una muestra de 105 alumnos. La información que obtuvo se muestra en la siguiente página. 
Usuarios de la Información...

Tabla 6

\begin{tabular}{|c|c|}
\hline Usan Wikipedia & Alumnos \\
\hline Sí & 76 \\
\hline No & 29 \\
\hline
\end{tabular}

Fuente: elaboración propia

De esos 105 alumnos sólo 76 hacen uso de la Wikipedia, pero ¿por qué usan Wikipedia?

- Es rápida y fácil de usar.

- Sirve para encontrar definiciones.

- Y para entender conceptos y ecuaciones.

- Se conocen más autores y se hacen más experimentos.

- Se obtienen fuentes bibliográficas.

Gráfica 5. Frecuencia de uso de Wikipedia

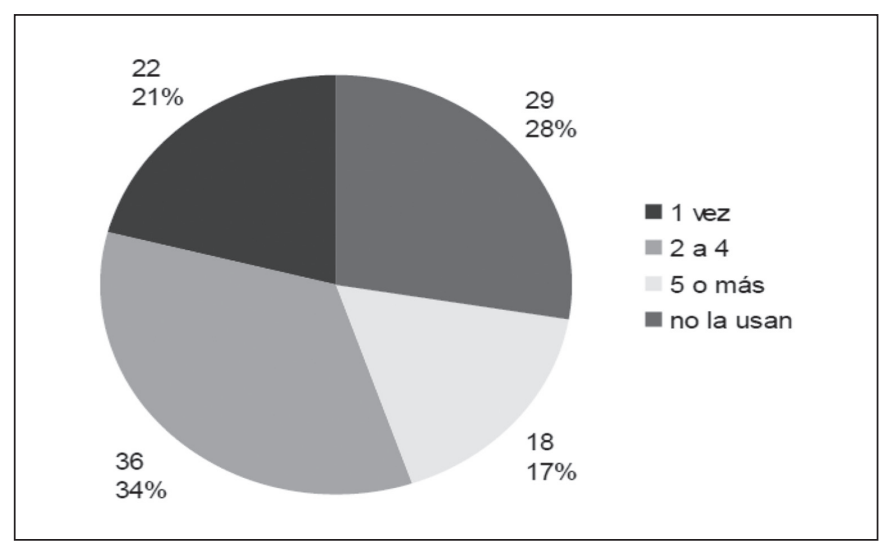

Fuente: Sales Ortega, 2014.

La Gráfica 5 nos informa qué tan frecuentemente usan Wikipedia los alumnos de toda la muestra. La Tabla 6 nos indica que, la mayoría la usa entre 2 y 4 veces por semana. Esto nos informa que quienes sí usan Wikipedia lo hacen con gran frecuencia. 
Tabla 7

\begin{tabular}{|c|c|}
\hline Recomiendan usar Wikipedia & Alumnos \\
\hline Sí & 60 \\
\hline No & 16 \\
\hline
\end{tabular}

Fuente: elaboración propia

La Tabla 7 expresa si los alumnos recomiendan el uso de la Wikipedia; 60 de ellos comentaron que sí porque encuentran fácil y rápidamente la información; caso contrario, quienes mencionaron que no la recomiendan, mencionaron que es demasiado conocida y también porque se puede dar el caso de que la información que ofrece puede ser errónea y poco fiable.

La Tabla 8 nos refiere si los alumnos que emplearon la Wikipedia la citan en sus trabajos y sólo 32 de ellos dijeron que sí, mientras que el resto respondió que no, ya sea porque les da vergüenza o porque muchos profesores les prohíben usar la Wikipedia en sus trabajos.

Tabla 8

\begin{tabular}{|c|c|}
\hline Citan Wikipedia & Alumnos \\
\hline Sí & 32 \\
\hline No & 44 \\
\hline
\end{tabular}

Fuente: elaboración propia

Por lo cual, con este trabajo de Sales Ortega surge una incógnita ¿por qué prohíben los profesores el uso de la Wikipedia?, si actualmente esta herramienta es ampliamente usada como fuente de consulta. 


\section{CONCLUSIONES}

En los trabajos aquí presentados se aprecia que el acceso a Internet ya no es tan limitado como antes, y que con los grandes avances tecnológicos, ya no solo de los dispositivos periféricos - llámense iPhone o Tablet, etc. - sino también el de las herramientas que podemos encontrar en la Web 2.0, tenemos una gran diversidad de usuarios, como los niños y niñas de primaria, a quienes la SEP ya hizo entrega de tablets mediante su programa "Inclusión y Alfabetización Digital Dotación de Tabletas Ciclo Escolar 20142015", con la esperanza de que les den un buen uso y de que los ayude en su formación académica, y no solamente que las usen como medio de entretenimiento o diversión.

También nosotros, especialistas de la información, debemos incursionar en el ambiente web, y ofrecerles a nuestros alumnos herramientas con las que puedan localizar información para su formación académica. Al msmo tiempo, podemos trabajar para que seamos nosotros mismos quienes creemos esas herramientas y estas puedan ser usadas igualmente en las bibliotecas; como ejemplo tenemos las ya famosas aplicaciones para tablets o smartphones, que actualmente son muy utilizadas por los usuarios de estos dispositivos.

Tenemos aún mucho por hacer y los tipos de usuarios siguen incrementándose, así que nosotros debemos estar a la vanguardia en el uso y en el aprendizaje de estas herramientas y dispositivos.

\section{BiBLIOGRAFÍA}

Anaya Rivas, J. M. (2013). Análisis del uso de Internet y redes sociales de los alumnos de educación media básica en Santa Catarina Ayotzingo. México.

Guzmán Prieto, E. (2012). El uso de las redes sociales para la búsqueda de información escolar de los alumnos de educación básica en el pueblo de San Gregorio Atlapulco y San Luis Tlaxialtemalco en Xochimilco. México. 


\section{Los usuarios y el uso de Internet...}

Sales Ortega, I. S. (2014). El uso de Wikipedia por alumnos de la licenciatura de física en la UNAM. México.

Torres Piñón, O. N. (2014). Uso de herramientas web 2.0 por los usuarios de la Biblioteca Central de la UNAM. México. 


\section{Análisis de la búsqueda de información académica utilizando la Web 2.0, por los alumnos de matemáticas de la Facultad de Ciencias de la UNAM}

Luis Alberto Fuentes Gatica

Universidad Nacional Autónoma de México

\section{INTRODUCCIÓN}

onociendo que los estudios de comportamiento informati-
vo se han realizado con mayor frecuencia en comunidades
científicas que están muy vinculadas con Internet, y debido a las investigaciones y campos en los que se desarrollan, se pretende realizar un estudio en el que se incluya a la matemática, para conocer el uso que han hecho los alumnos de dicha disciplina en todo lo relacionado con la llamada Web 2.0.

Con base en esto, se llevará a cabo un proyecto que estudie el análisis de la búsqueda de información de los estudiantes de matemáticas y la forma en que utilizan las herramientas de la Web 2.0 (blogs, wikis, Facebook, Twitter, etc.) con el fin de saber si les son útiles, y si están de verdad inmersos en las redes sociales; y también, conocer la manera en que se desenvuelven dentro de ellas y si son utilizadas para fines académicos o como medio para recuperar información producida por la docencia e investigación.

Para conocer las herramientas de la Web 2.0 que utiliza la comunidad científica, esta investigación analizará la relación que tienen los alumnos de matemáticas de la Facultad de Ciencias de la 
UNAM con Internet (y sus herramientas), con la idea de obtener información académica sobre las nuevas tecnologías que hoy son accesibles para la mayoría de las personas. También se buscará saber cómo contribuyen las redes sociales a la formación académica y la investigación.

Esto ha generado cuestionamientos generales entre los cuales tenemos los siguientes:

¿Cuáles son las redes sociales que usan los alumnos de matemáticas de la Facultad de Ciencias, para obtener información académica?

¿La Web 2.0 contribuye efectivamente a que los alumnos tengan más acceso a la información académica que requieren?, ¿existen relaciones entre la Web 2.0, la información que buscan y el nivel de formación que poseen los estudiantes?, ¿los estudiantes conocen todos aquellos medios en los que se puede encontrar la información académica requerida para sus carreras, en Internet y con el uso de las herramientas de la Web 2.0?

Los objetivos de este estudio son los siguientes:

- Determinar las fuentes a las que más acceden los estudiantes y dónde acuden a consultarlas.

- Identificar los impedimentos u obstáculos que enfrentan para conseguir la información o acceder a ella.

- Determinar si las fuentes y los recursos de información a los que acuden en Internet son suficientes para realizar sus tareas, trabajos e investigaciones durante el semestre.

A partir de las interrogantes que surjan de esta investigación se buscará comprobar las siguientes hipótesis:

1. ¿Estos estudiantes consultan efectivamente las bases de datos de Internet para obtener información?

2. ¿Recurren a los artículos publicados en revistas electrónicas para recabar información acerca de las materias que cursan? 
3. ¿Las redes sociales de la Facultad de Ciencias tienen una participación importante respecto a compartir información que contribuya al desarrollo académico?

Para realizar este trabajo se utilizó la técnica de la encuesta y como instrumento se empleó el cuestionario. El estudio se dividió en 3 partes:

- La primera menciona lo que es la Web 2.0, la Facultad de Ciencias de la UNAM y su comunidad.

- La segunda describe la metodología utilizada para realizar dicho estudio.

- La tercera parte es el análisis de los resultados, y también incluye las conclusiones.

\section{LA WEB 2.0}

La Web 1.0 se considera enmarcada desde sus inicios hasta el 2001, seguida de un periodo post burbuja.com que llegó hasta el 2004, cuando se empieza a cuestionar esa denominación, y de allí surgió la Web 2.0, la cual se define a continuación.

Podemos definir a la Web 2.0 como un conjunto de aplicaciones que sacan partido de las ventajas intrínsecas de la Web y desarrollan un servicio que mejora en la medida en que más personas lo utilicen; remezclando los datos de múltiples recursos, incluyendo cada vez más a los usuarios individuales y ofreciendo sus datos y servicios de tal forma que puedan ser reutilizados por otros, con lo cual fue creando una arquitectura de participación en red, que terminó desbancando a la Web 1.0 para ofrecer experiencias de usuario cada vez más ricas. ${ }^{1}$

El término Web 2.0 nació a mediados de 2004 y creció hasta ser portada de los principales semanarios mundiales durante la navi-

1 T. O’Reilly “¿Qué es Web 2.0?”, (2005) (citado por Dídac Margaix, Arnal. 
dades de 2006. Este fenómeno tecno-social se fue popularizando a partir de sus aplicaciones más representativas, la Wikipedia, YouTube, Flickr, Blogger, Slideshare, MySpace, Facebook y pronto captaron una gran cantidad de usuarios que se convirtieron en generadores de contenidos. Mencionamos algunas diferencias con respecto a la Web 1.0 para aportar claridad.

Con la Web 1.0, solo podía leerse la información que se nos aportaba, sin poder hacerle ninguna modificación a esas páginas.

En la Web 2.0, en cambio, podemos escribir, modificar el texto, crear perfiles, etc., y hacer más factible la comunicación e indización para el usuario de la información dándole herramientas con las cuales la pueda compartir, ya sea de carácter informativo, científico o de divulgación, dependiendo esto más bien de la comunidad en la que se encuentre inmerso cada usuario de la Web.

Otra gran diferencia era que la Web 1.0 empleaba megas (Mb) de textos y fotos, en tanto que la Web 2.0 utilizaba ya gigabytes (Gb) en sus audios y videos.

En la Web 1.0, el usuario solo consumía la información pasivamente, mientras que con la Web 2.0, todo el que quiera colaborar, participa y expresa sus ideas, las cuales pueden ser productivas para otro tipo de usuarios interesados en algún otro campo específico. Es decir, que la Web 2.0 permite compartir y ya no ser controlado por el sistema, sino interactuar con él.

Podemos decir, en breve, que la Web 2.0 hace referencia a un grupo de tecnologías que tienden a estar profundamente asociadas con blogs, wikis, podcasts, RSs feeds, etc., los cuales les facilitan más las cosas a los socialmente conectados por la Web, donde lo antes mencionado está disponible para agregar y editar en el nuevo espacio de información.

La respuesta larga es más complicada e involucra a la economía, basada ahora más en la tecnología y en las nuevas ideas acerca de la sociedad conectada. Para algunos; sin embargo, se trata sólo de investigar la tecnología de nuevo, un tiempo de exuberancia renovada después del punto com. 
En una entrevista para IBM, el inventor de la Web Sir Tim Berners-Lee, dijo que la Web 2.0 era un tremendo déjà vu (ya visto), y cuando le preguntaron si ésta era diferente a lo asombroso que había sido la llamada Web 1.0, contestó lo siguiente:

Totalmente no, la Web 1.0 buscaba conectar a las personas, se trataba de un espacio interactivo y creo que la Web 2.0 es sólo como un pedazo de jerga, nadie sabe ni siquiera lo que significa. Si para ti la Web 2.0 es blogs y wikis, entonces esto varía de persona a persona. Y de hecho sí sabias, esta 'Web 2.0' lo que significa es que puedes utilizar los estándares que han sido producidos por todas esas personas que han trabajado con la Web 1.0. ${ }^{2}$

La distinción es la clave para entender dónde están los límites entre la Web, como un conjunto de tecnologías, y la Web 2.0. Se trata de intentar conceptualizar el significado de un conjunto de resultados que están permitidos para estas tecnologías de la Web. Entendiendo esta distinción podemos pensar más claramente los problemas que nos presentan ambas tecnologías y los resultados de estas, lo que podría ayudar aún más a entender por qué algunas podrían ser clasificadas como Web 2.0, o quizá no.

Existe un cierto número de servicios y aplicaciones que demuestran las bases del concepto de la Web 2.0, que ya se están usando en cierta medida en la educación. Estos servicios y aplicaciones no son realmente tecnologías como tales, sino servicios (o los procesos del usuario) construidos usando partes de otras tecnologías y los estándares abiertos en los que ya se basaba Internet.

Lo anterior incluye blogs, wikis, servicios compartidos de multimedia, sindicación de contenidos, podcastings y servicios de contenido etiquetado. Mostramos algunos ejemplos a continuación: ${ }^{3}$

- Blogs: el término web-log, o blog fue acuñado por John Barger en 1997 y se refiere a una simple página Web que consiste

$2 \quad$ Ibid., 5.

3 Ibid., 7. 
en breves párrafos de opinión, entradas de diarios personales o links (vínculos) llamados posts, arreglados cronológicamente anteponiendo primero el más reciente, con el estilo de un periódico en línea. Algunos blogs les permiten a los visitantes dejar comentarios a las entradas que se han escrito.

- Wikis: una wiki es una página o conjunto de páginas Web, las cuales pueden ser editadas fácilmente por cualquiera que tenga acceso a ellas. A diferencia de los blogs, las wikis generalmente tienen una función histórica, que permite que las versiones anteriores puedan ser examinadas y se revise su función, restaurando versiones previas.

Los defensores del poder, incluso lúdico, que tienen las wikis, citan la facilidad del uso de estas herramientas, su extrema flexibilidad y el acceso abierto, como algunos de las muchas razones por las que resultan útiles para el trabajo en grupo.

- Servicios compartidos de multimedia: una de las áreas de mayor crecimiento está en aquellos servicios que facilitan el almacenamiento y la distribución de contenidos multimedia. Ejemplos bien conocidos incluyen a YouTube (video), Flickr (fotografías) y Odeo (podcast). Estos populares servicios se basan en la idea de la "escritura" Web (donde los usuarios no son solo consumidores, sino que contribuyen activamente a la producción de los contenidos de la Web) lo que incluso permiten hacer en una escala masiva.

- La Fácil Sindicación de Contenidos (RSS): es una familia de formatos que les permite a los usuarios obtener información sobre las actualizaciones del contenido de RSS habilitado en sitios web, blogs o podcasts, sin tener que visitar el sitio. En cambio, la información de la página Web (por lo general el título de una nueva historia y resumen, junto con el nombre del sitio Web de origen) es recolectada dentro de una fuente (que utiliza el formato RSs) y pone al corriente al usuario en un proceso conocido como sindicación. 
Todo esto conforma la llamada Web 2.0, en la cual se parte de ideas particulares a ideas generales, esto mediante contenidos que permiten la interacción con el usuario, como los blogs, wikis, etc., los cuales se estructuran de una manera adecuada para poder ser mejor consultados y recuperados.

En esto, la Facultad de Ciencias juega un papel importante en la investigación de la UNAM y del país, ya que forma científicos en las áreas de las ciencias duras como la física, las matemáticas y la Biología, las cuales son de gran importancia para el desarrollo y los avances de México. A continuación se hace una breve reseña de la carrera de matemáticas.

\section{LA CARRERA DE MATEMÁTICAS}

\section{EN LA FACULTAD DE CIENCIAS DE LA UNAM}

Los antecedentes de la carrera de matemáticas en la Facultad de Ciencias se encuentran en la Escuela Nacional de altos Estudios que se inauguró en 1910. En 1922, cuando la universidad Nacional consigue su autonomía, el director de la Facultad de Filosofía y Letras, Antonio Caso, llamó a un prestigiado maestro, Sotero Prieto, para que reorganizara la parte de matemáticas y a Isaac Ochoterena para el área de biología.

En 1934 se construye la Facultad de Ciencias Fisicomatemáticas que integraba a la Escuela Nacional de Ingenieros, la Escuela Nacional de Ciencias Químicas y el Departamento de Ciencias Fisicomatemáticas.

Después, el 2 de enero de 1939 se crea la Facultad de Ciencias, que se dividió en siete departamentos: matemáticas, física, química, biología, geología, geografía y astronomía. Después solo quedarían 3 departamentos: biología, matemáticas y física.

En 1947, respondiendo a las necesidades crecientes en el área de los seguros, las pensiones y las finanzas se creó, dentro del departamento de matemáticas, la carrera de actuaría. 
Tiempo después, en 1977, esta facultad se trasladó a las instalaciones que ocupa actualmente, y en los años 90, se integró la carrera de Ciencias de la Computación al departamento de matemáticas. Actualmente esta carrera cuenta con 1338 alumnos.

\section{Metodología}

La Facultad de Ciencias de la UNAM, cuenta con 7 carreras que son:.

- Biología

- Física

- Matemáticas

- Actuaria

- Ciencias ambientales

- Ciencias de la computación

- Ciencias de la tierra

En este estudio se tomó solamente la carrera de matemáticas, para lo cual se aplicó la técnica de encuesta utilizando como instrumento un cuestionario para recopilar la información necesaria del total de la población, la cual fue de 30 alumnos inscritos en la carrera de Matemáticas.

\section{Resultados}

Se encuestaron a 59 alumnos inscritos en la materia de investigación de operaciones de la carrera de matemáticas y sólo se obtuvieron resultados sobre 53, por motivos de ausencia el día que se aplicó el cuestionario, lo que representa el 90\% del total de la muestra, un porcentaje adecuado para el estudio y que le da confiabilidad.

Como solo se obtuvieron 53 cuestionarios esto significa que este número se toma como el $100 \%$ de la muestra, lo que se verá reflejado en las tablas 3, 6, 8, 10 y 11.

Para llevar a cabo la revisión de las respuestas, se analizó una por una, y las que eran abiertas se cerraron de acuerdo con lo que contestaron los alumnos. 
Después, se tabularon para ver los resultados que arrojaron cada una y estos se muestran a continuación.

Tabla 1. Género de los alumnos inscritos en la carrera de matemáticas

\begin{tabular}{|l|c|c|}
\hline \multicolumn{1}{|c|}{ Género } & Núm. de alumnos & Porcentaje \\
\hline Masculino & 32 & $60 \%$ \\
\hline Femenino & 21 & $40 \%$ \\
\hline Total & 53 & $100 \%$ \\
\hline
\end{tabular}

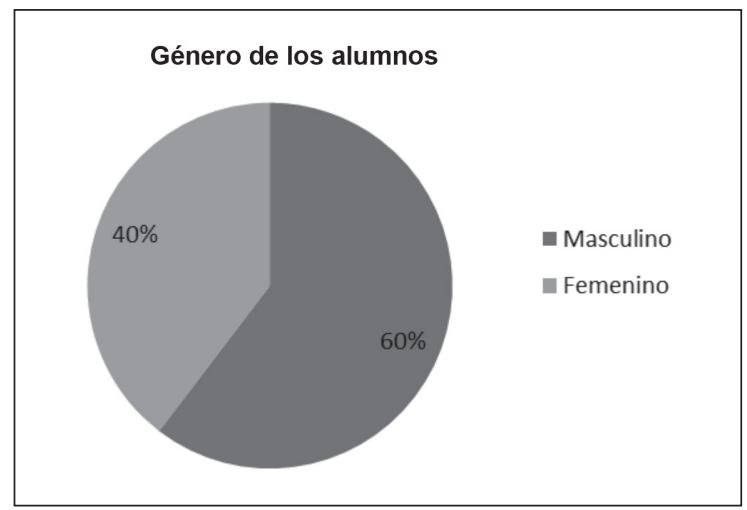

El $60 \%$ del total de la muestra pertenece al género masculino y el $40 \%$ al género femenino.

Tabla 2. Semestre que cursan los alumnos

\begin{tabular}{|c|c|c|}
\hline Semestre & Núm. de alumnos & Porcentaje \\
\hline $4^{\circ}$ & 16 & $30 \%$ \\
\hline $5^{\circ}$ & 17 & $32 \%$ \\
\hline $6^{\circ}$ & 13 & $24 \%$ \\
\hline $7^{\circ}$ & 3 & $6 \%$ \\
\hline $8^{\circ}$ & 1 & $2 \%$ \\
\hline $9^{\circ}$ & 3 & $6 \%$ \\
\hline Total & 53 & $100 \%$ \\
\hline
\end{tabular}




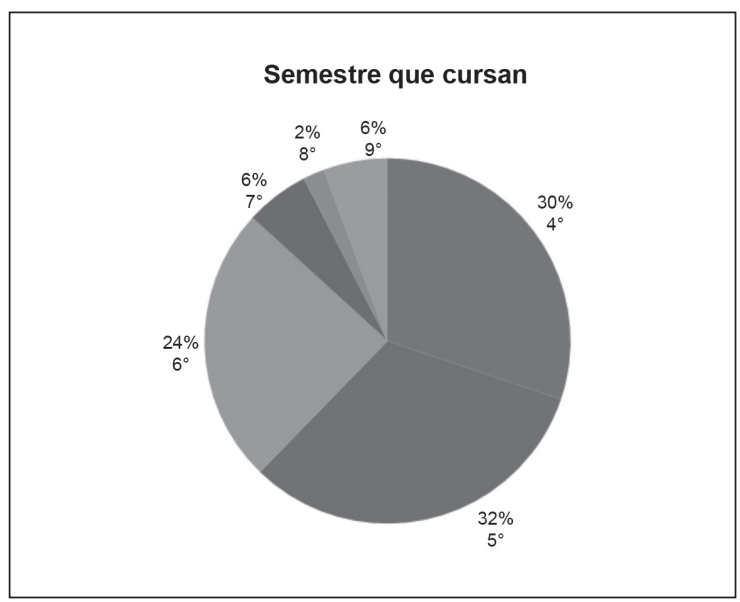

El 32\% de los alumnos inscritos en esta materia cursa el $5^{\circ}$ semestre de la carrera, mientras que el $30 \%$ está en $4^{\circ}$; el $24 \%$ ya está en $6^{\circ}$, a punto de terminar la carrera, y los otros dos $6 \%$, y $2 \%$, están en $7^{\circ}, 8^{\circ}$ y $9^{\circ}$ semestre.

Tabla 3. Recursos de información de Internet que más utilizan

\begin{tabular}{|l|c|c|}
\hline \multicolumn{1}{|c|}{ Recursos } & Total & Porcentaje \\
\hline Bibliotecas digitales & 34 & $35 \%$ \\
\hline Base de datos de E-books & 31 & $31 \%$ \\
\hline Bases de datos & 19 & $19 \%$ \\
\hline Base de datos de Revistas electrónicas & 10 & $10 \%$ \\
\hline Otros & 5 & $5 \%$ \\
\hline
\end{tabular}




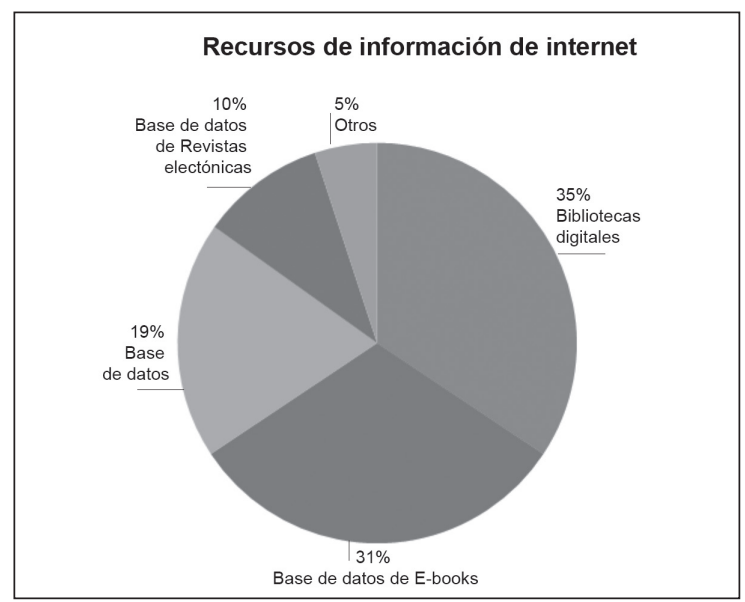

El 35\% de los encuestados señala que el recurso que más utilizan son las bibliotecas digitales, seguidas de las bases de datos de Ebooks, con 31\%; el siguiente recurso más utilizado son las bases de datos con 19\%, estos son los 3 más importantes recursos; en cuarto lugar tenemos las bases de datos de revistas electrónicas, con 10\%, aquí podemos ver que sí tienen conocimiento de que los recursos de información obtenidos en Internet son los más usados, además de que saben utilizarlos para hacer sus tareas; por último, se tiene el rubro de Otros, en el cual solo el 5\% especificó que no son los antes mencionados.

Tablas 4 y 5 . Impedimento para poder consultar los recursos de Internet

\begin{tabular}{|l|c|c|}
\hline \multicolumn{1}{|c|}{ Impedimentos } & Total & Porcentaje \\
\hline No & 23 & $43 \%$ \\
\hline Sí & 21 & $40 \%$ \\
\hline No contestó & 9 & $17 \%$ \\
\hline Total & 53 & $100 \%$ \\
\hline
\end{tabular}




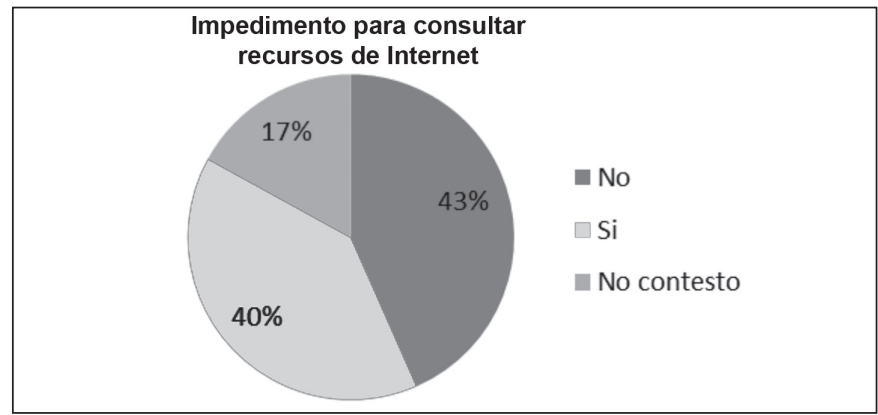

Aquí podemos ver que el $17 \%$ de los encuestados no respondió a la pregunta, de los demás, el $40 \%$ contestó que Sí, y el $43 \%$ que No. Se puede ver que entre el Sí y el No dista sólo el 3\%. Entre tanto, los que Sí han tenido problemas, ha sido prácticamente porque algunos recursos que necesitan para su materia son de paga o no están en un idioma "útil" según los encuestados, y no se podía acceder a ellos si no se pertenecía a la institución que presta esos servicios, debido a que son especializados y por tanto no es fácil obtenerlos.

Tabla 6. Utilización de bases de datos especializadas y cuáles han sido éstas. (Se elaboraron 2 Tablas)

\begin{tabular}{|l|c|c|}
\hline \multicolumn{1}{|c|}{ Respuestas } & Total & Porcentaje \\
\hline No & 43 & $81 \%$ \\
\hline Sí & 10 & $19 \%$ \\
\hline Total & 53 & $100 \%$ \\
\hline
\end{tabular}

Utilización de base de datos especializadas

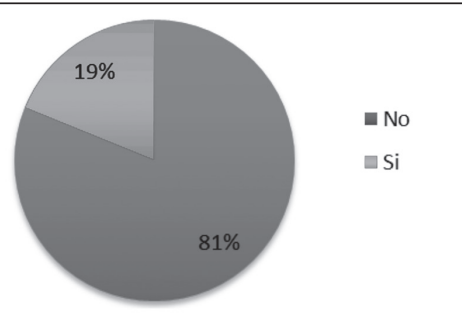


En la Tabla 6, se muestra que el 19\% de los alumnos sí han utilizado bases de datos, contra el $81 \%$ que no las ha consultado. Del $23 \%$ que contestaron que sí, explicaron cuáles son las bases de datos que más han utilizado y esto se muestra en la segunda tabla que está a continuación.

\begin{tabular}{|l|c|c|}
\hline \multicolumn{1}{|c|}{ Bases de datos } & Total & Porcentaje \\
\hline Yahoo Finanzas & 3 & $50 \%$ \\
\hline Jstor, Seeking Alpha, DGB (UNAM) & 2 & $33 \%$ \\
\hline Demográficos, INEGI & 1 & $17 \%$ \\
\hline
\end{tabular}

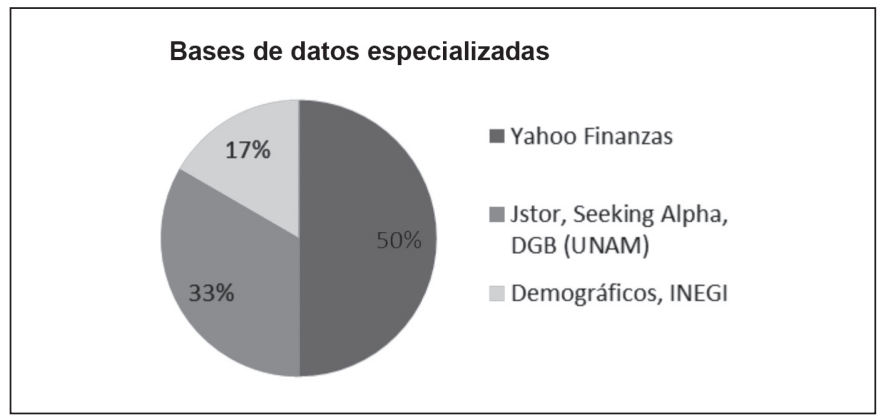

En la segunda tabla se puede observar que los alumnos tienen pocos conocimientos de bases de datos especializadas; el 50\% recurrió a Yahoo Finanzas como la base de datos más utilizada, seguida de la de la DGB (UNAM), Jstor y Seeking Alpha con 33\% y en último lugar recurrieron a Demográficos e INEGI con $17 \%$ respectivamente.

Tabla 7. Se quiso saber por qué obtienen información de páginas Web, blogs y wikis

\begin{tabular}{|l|c|c|}
\hline \multicolumn{1}{|c|}{ Rubros } & Total & Porcentaje \\
\hline Fácil acceso, confiable y sencillo & 35 & $66 \%$ \\
\hline Comodidad & 10 & $19 \%$ \\
\hline Falta de Tiempo & 8 & $15 \%$ \\
\hline Total & 53 & $100 \%$ \\
\hline
\end{tabular}


Usuarios de la Información...

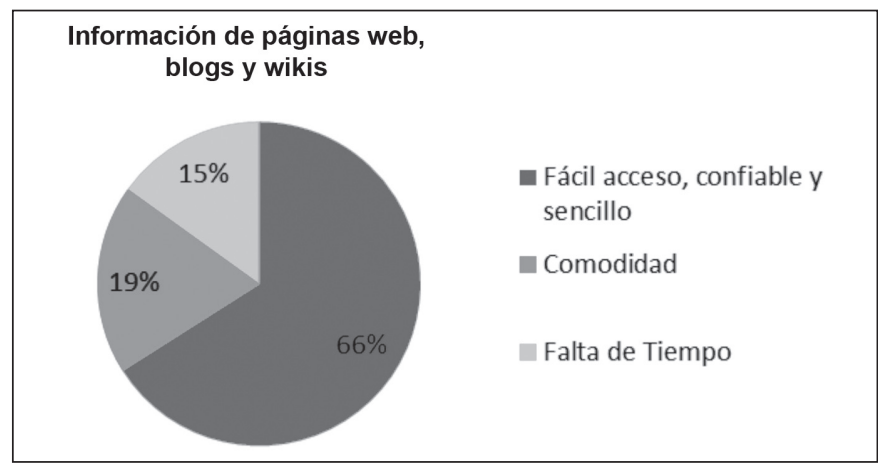

Esta tabla despliega las opiniones de los alumnos con respecto a las páginas Web, wikis y blogs, donde el 66\% dijo que obtiene la información de estos lugares debido a que son de fácil acceso, confiables y su consulta es sencilla; después el 15\% los consulta por falta de tiempo para poder entregar las tareas, y a que deben atender otras materias también, y el 19\% explicó que utiliza estos recursos por comodidad para obtener la información.

Tabla 8. Redes sociales que más utilizan como fuente de información

\begin{tabular}{|l|c|c|}
\hline \multicolumn{1}{|c|}{ Fuentes } & Total & Porcentaje \\
\hline Wikipedia & 36 & $24 \%$ \\
\hline YouTube & 34 & $23 \%$ \\
\hline Slideshare & 23 & $15 \%$ \\
\hline Facebook & 19 & $13 \%$ \\
\hline Blogs & 19 & $13 \%$ \\
\hline Twitter & 10 & $7 \%$ \\
\hline Podcast & 5 & $3 \%$ \\
\hline RSS feeds & 2 & $1 \%$ \\
\hline Flick & 1 & $1 \%$ \\
\hline MySpace & 0 & 0 \\
\hline
\end{tabular}




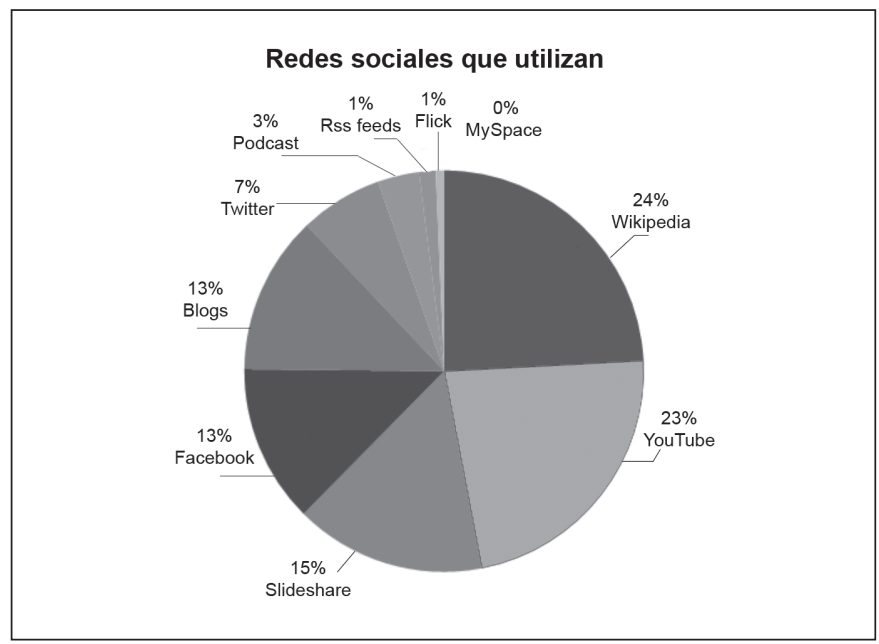

El 24\% de los encuestados dice que la Wikipedia es su principal fuente de información, seguida de YouTube, que obtiene 23\%; en tercer lugar está la red social Slideshare con 15\%, seguido de Facebook y los blogs con un 13\%. Las otras redes restantes tienen porcentajes bajos de uso, estos son MySpace con $0 \%$, Podcast con $3 \%$, Flickr con $1 \%$ y RSS feeds con $1 \%$. Esto puede deberse a falta de conocimiento sobre estas últimas fuentes, o a que las primeras son más populares y más consultadas por la comunidad en la que están inmersos.

Tabla 9. ¿Qué buscadores utilizas?

\begin{tabular}{|l|c|c|}
\hline \multicolumn{1}{|c|}{ Buscadores } & Total & Porcentaje \\
\hline Google & 53 & $80 \%$ \\
\hline Yahoo & 8 & $12 \%$ \\
\hline Bing & 3 & $5 \%$ \\
\hline Ask & 2 & $3 \%$ \\
\hline AltaVista & 0 & 0 \\
\hline
\end{tabular}




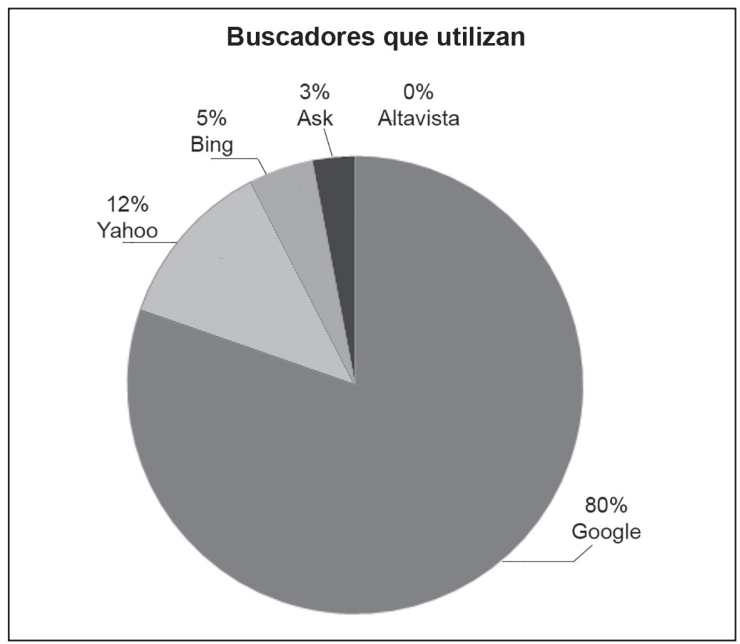

Este resultado era esperable desde que se formuló la pregunta, pues sabemos que Google es uno de los mayores buscadores utilizados a nivel mundial y los encuestados de esta materia no se quedan atrás; el buscador más utilizado es precisamente Google, con $80 \%$, dejando en un segundo lugar a Yahoo con $12 \%$; en un tercero está Bing de Microsoft con 5\%, en cuarto lugar al buscador Ask con 3\%. Desconcierta el hecho de que el buscador AltaVista haya obtenido $0 \%$, quizá los encuestados no quisieron responder la pregunta o quizá nadie lo utilizó, cosa que parece ilógica porque muchas veces este buscador es utilizado para localizar información, sea académica o no.

Tabla 10. Lugar al que acuden para consultar las fuentes de información de Internet.

\begin{tabular}{|l|c|c|}
\hline \multicolumn{1}{|c|}{ Lugares } & Total & Porcentaje \\
\hline Desde su casa & 52 & $54 \%$ \\
\hline Biblioteca de la facultad & 21 & $22 \%$ \\
\hline Centro de computo & 15 & $16 \%$ \\
\hline Biblioteca Central & 4 & $4 \%$ \\
\hline Otras & 3 & $3 \%$ \\
\hline Instituto de matemáticas & 1 & $1 \%$ \\
\hline
\end{tabular}




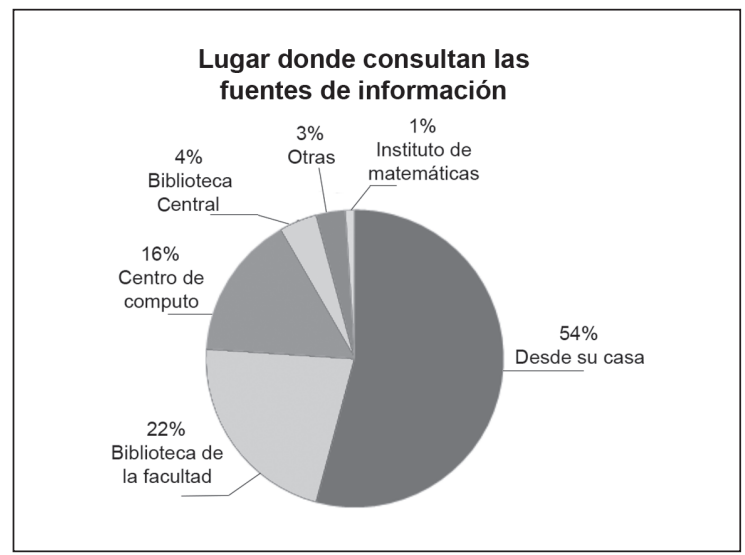

Los encuestados comentaron que la mayoría de las veces consultan las fuentes de Internet en su casa, lo que nos dio un resultado de 54\%; la biblioteca de la facultad es el segundo lugar y obtuvo el $22 \%$; el centro de cómputo quedó en tercer lugar con 16\%; la Biblioteca Central obtuvo $4 \%$ de asistencia al consultar fuentes de información en Internet. Algo inesperado fue el porcentaje obtenido por el Instituto de matemáticas con $1 \%$ de asistencia, y el rubro "otras", sólo alcanzó 3\% y mencionaron que hacen consultas a través de dispositivos móviles desde cualquier parte en la que se encuentren.

Tabla 11. Fuentes de información de Internet especializadas en matemáticas

\begin{tabular}{|l|c|c|}
\hline \multicolumn{1}{|c|}{ Fuentes } & Total & Porcentaje \\
\hline Graficadoras Wolfram Alpha & 16 & $33 \%$ \\
\hline No contestó & 14 & $29 \%$ \\
\hline E-books & 9 & $18 \%$ \\
\hline Blogs de matemáticas & 7 & $14 \%$ \\
\hline Lindo Systems, Inc., Wikiproof & 2 & $4 \%$ \\
\hline Wikimath, Geomath, Eclipse (ecuaciones) & 1 & $2 \%$ \\
\hline
\end{tabular}




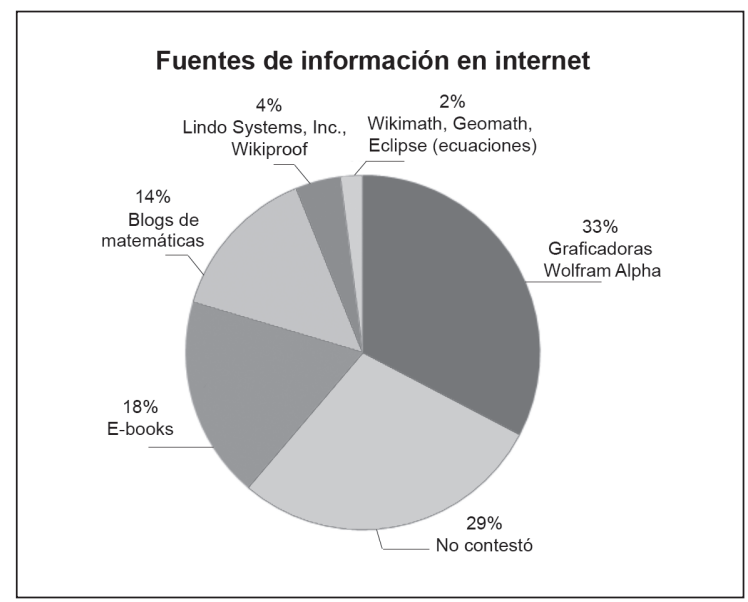

En esta última pregunta las Graficadoras Wolfram Alpha resultaron las más consultadas con 33\%, seguidas del punto No contestó, en el entendido de que no las utilizan o realmente no saben cómo diferenciar entre fuente, recurso y bases de datos; en tercer lugar quedaron los Ebooks, con 18\%, seguidos por los blogs de matemáticas, que pueden ser de profesores o de expertos en la materia, con 14\%, y después están las páginas o alguna wiki que les sirve de apoyo, con $4 \%$ y $2 \%$ respectivamente como se muestra en la gráfica.

\section{DisCUSIÓN}

La mayoría de los encuestados fueron hombres y el semestre que cursan varía desde el $4^{\circ}$ hasta el $9^{\circ}$, esto revela qué tan ágiles o conocedores son de los recursos, y si saben manejar bien las fuentes que les ofrece la Web 2.0.

De acuerdo con los datos obtenidos en esta investigación, se puede decir que para obtener información para sus trabajos y tareas, los alumnos de matemáticas sí recurren a Internet para hacer uso de las fuentes y recursos disponibles, tanto en páginas Web, blogs, redes sociales, como en los otros recursos que se mencionaron arriba. 
Las hipótesis planteadas resultaron válidas para este estudio, y fueron significativos los resultados obtenidos, en tanto que los estudiantes sí hacen uso de las bases de datos en Internet, los artículos de revistas electrónicas, los E-books, etc. Las redes sociales sí influyen para obtener la información que necesitan los encuestados para sus trabajos y tareas en el semestre. Por lo anterior, se puede afirmar que los recursos más consultados son las bases de datos de revistas y bibliotecas digitales, debido a que esa información está actualizada y es de gran importancia.

Otra de las cosas que se pueden observar también es que ellos no conocen muy bien y no saben manejar los recursos y fuentes con las que cuenta la Web 2.0, porque los resultados que despliega la encuesta revelan que el buscador que más utilizan es Google, con un $80 \%$, debido a que es el más rápido y sencillo de utilizar según las respuestas que ellos dieron.

Con respecto a las redes sociales también es interesante saber que Wikipedia es la red que más utilizan para obtener información, con $24 \%$, a la par casi de YouTube que ocupa 23\%. después vienen las otras redes sociales como Facebook, Twitter y las demás mencionadas en el estudio.

También cabe destacar que los alumnos deciden muchas veces buscar información en páginas Web, blogs y wikis, debido a que son fáciles de acceder, gratuitas y fáciles de encontrar, pero esto indica que los alumnos no tienen el conocimiento necesario para encontrar otros recursos y fuentes que sean confiables para los estudios que realizan.

\section{CONCLUSIONES}

Los estudios de usuarios son de gran importancia para identificar las necesidades de los usuarios a los que se les proporcionan servicios, y también para conocer cuáles fuentes y recursos de información en la Web 2.0 consultan y si les son o no de utilidad, para con esto tener mejores servicios que puedan satisfacer plenamente sus necesidades de una manera eficaz. 
Por lo pronto, este estudio ha servido para identificar el comportamiento de los alumnos de matemáticas en cuanto a la Web 2.0, conocer qué recursos de información utilizan más y qué redes sociales tienen más importancia en lo que se refiere a la búsqueda de información académica.

Uno de los recursos que más utilizan estos estudiantes son las bases de datos de revistas electrónicas, ya que contienen información actual y que resulta de gran importancia para sus investigaciones. Otro recurso que más ocupan son las bases de datos en general.

Con esto podemos decir que necesitan tener más bases de datos de revistas electrónicas y también más bases de datos generales que puedan apoyar aún más las investigaciones y trabajos que realizan en el semestre.

Uno de los aspectos más importantes que se pueden mencionar sobre este estudio es que tanto la Facultad de Ciencias como el resto de la propia UNAM cuentan con diferentes accesos a bases de datos que pueden proporcionarles información a los alumnos, que se encuentran disponibles mediante la Web 2.0.

Es importante tener en la facultad un curso que instruya a los estudiantes (desde que inician su carrera), a buscar, manejar y recuperar las herramientas disponibles en la Web 2.0 y de este modo saber con qué recursos pueden contar y que estos son de libre acceso para todos los temas de su interés. Cabe mencionar, que también les será muy útil saber diferenciar qué información y qué fuentes son confiables, para que se sientan seguros al utilizarlas.

\section{BIBLIOGRAFÍA}

Anderson, P. (2007) What is Web 2.0? Ideas, Technologies and Implications for Education. EUA: JISC.

Calva González, J.J. (2010). Necesidades de información y comportamiento en la búsqueda de información de los adolescentes, México: Centro universitario de investigaciones bibliotecológicas. 
Jiménez Dávila, R. G. (2003). "Comportamiento informativo de los docentes de licenciatura de la universidad pedagógica nacional". HEMERA: Revista de Ciencia Bibliotecológica y de la Información, vol. 1, núm. 2, 12-25.

Leonel Alba, J. C.(2012), El comportamiento informativo de los usuarios basado en las TIC de las bibliotecas del Tecnológico de Monterrey, UNAM: Posgrado en Bibliotecología. Disponible en: <http://cuib.unam.mx/publicaciones /12/necesidades información comunidades JUAN ALBA LEONEL.html>. [Fecha de consulta: 28 de octubre 2012].

Lozano, J. M. (s.a.), Génesis de la Facultad de Ciencias. UNAM. Disponible en: <http://www.fciencias.unam.mx/ nosotros/historia/Index Facultad de Ciencias $>$. [Fecha de consulta: 3 de septiembre 2012].

Margaix Arnal, D. (2007). "Conceptos de Web 2.0 y Biblioteca 2.0: origen, def". El profesional de la información, Social Science Citation Index, vol. 16, núm. 2, 95-106.

O'Reilly, T. (2005), ¿Qué es Web 2.0?. O'Reilly Media Inc., El profesional de la información, Social Science Citation Index, vol. 16, núm. 2, 95-96.

Pacheco, L. E. (2003). "Necesidades y comportamiento informativo en usuarios externos de una biblioteca universitaria”. HEMERA: Revista de Ciencia Bibliotecológica y de la Información, vol. 1, núm. 1, 11-36.

Núñez, P. (2004). Las necesidades de información y formación: el enfoque de T. Wilson, sobre el comportamiento informativo, Wikileaming. Disponible en: <http://www. wikilearning.com/monografia/lasnecesidades de inorma ción y formación-El enfoquedetdwilson sobre el compor tamiento informativo/8131-9>. [Fecha de consulta: 23 de noviembre].

Peralta y Fabi, R. (2009). La Facultad de Ciencias y tú: guía del estudiante de la Facultad de Ciencias de la UNAM. México: Secretaria de Comunicación y Divulgación de la Ciencia. 
Usuarios de la Información...

Soriano Rojas, R. (2007). Guía para realizar investigaciones sociales, México: Plaza y Valdez.

Villanueva, A. (2004). "El comportamiento informativo de los investigadores en el área de las matemáticas: un estudio de caso". LIBER: Revista de Bibliotecología, AMBAC, vol. 6, núm. 1, 1-31. 


\section{Anexo}

\section{Universidad Nacional Autónoma de México Instituto de Investigaciones Bibliotecológicas y de la Información Maestría en Bibliotecología y Estudios de la Información}

\section{Cuestionario}

Objetivo: Conocer las fuentes y recursos de información en Internet que utilizan los alumnos de matemáticas, para sus trabajos e investigaciones que realizan en el semestre.

Género:

a) Femenino b) Masculino

Semestre:

1. ¿Cuáles son los recursos de información de Internet que más utilizas? (puedes marcar más de una)

( ) Bases de datos

( ) E-books

( ) Revistas electrónicas

( ) Bibliotecas digitales

( ) Otros, especifique

2. ¿Has tenido algún impedimento para poder consultar recursos de información en Internet? (si tu respuesta es sí pasa a la pregunta 3, si es NO pasa a la 4)

3. Si los haz tenido, ¿cuáles han sido?

4. Haz utilizado bases de datos especializadas, ¿cuáles?

5. Explica por qué usas información obtenida en: páginas web, blogs y wikis.

6. De las siguientes redes sociales, marca con una X las que más utilices como una fuente de información:

( ) Facebook

( ) Twitter

( ) Blogs

( ) Wikipedia

( ) MySpace

( ) YouTube

( ) Podcast

( ) Flickr

( ) Slideshare

( ) RSS feeds 
Usuarios de la Información...

7. ¿Qué buscadores utilizas?
( ) Yahoo
( ) AltaVista
( ) Google
( ) Bing
( ) Ask

8. ¿A qué lugar acude para consultar las fuentes de información de Internet?
( ) Biblioteca de la Facultad
( ) Biblioteca Central
( ) Centro de computo
( ) Instituto de matemáticas
( ) Desde su casa
( ) Otras, especifique

9. ¿Cuáles son las fuentes de información de internet especializadas en matemáticas que utilizas? 


\title{
Los agricultores de agave azul del Municipio de Tequila, Jalisco: panorama histórico de los acontecimientos políticos, sociales y económicos que han influido en el surgimiento de sus necesidades de información
}

\author{
ARMANDo SÁNCHEz Soto \\ Universidad Nacional Autónma de México
}

\begin{abstract}
ctualmente los agricultores de agave azul de Tequila, Jalis$\Delta$ co, como cualquier otra comunidad agrícola y/o rural, ma-nifiestan tener determinadas necesidades de información y un comportamiento informativo derivado de las mismas; esto como consecuencia del desempeño de su trabajo así como de la interacción con su entorno; la mayoría de estas necesidades informativas tienen su antecedente en una serie de fenómenos políticos, sociales y económicos suscitados a lo largo de la historia de dicho lugar, mismos que hasta la fecha siguen influyendo en la definición del perfil informativo de estos agricultores. A continuación se presenta un panorama histórico de estos acontecimientos, ubicados de acuerdo con el orden cronológico en el que se fueron presentando.
\end{abstract}




\section{LOS PRIMEROS AGRICULTORES DE TEQUILA, JALISCO}

Los Caxcanes fueron un pueblo guerrero de origen Chichimeca, quienes conquistaron a la tribu de los tequilas; ${ }^{1}$ fueron los primeros habitantes del actual municipio de Tequila, Jalisco en cultivar el agave azul, esto con el fin de extraer del mismo, los azúcares del corazón del agave cocido, para utilizarlo como edulcorante y en la fabricación de sogas, calzado, telas, prendas de vestir, manufactura de códices: como carburante, como bálsamo medicinal y por supuesto, para la elaboración de bebidas alcohólicas.

Lo anterior nos indica que los Caxcanes eran un pueblo con cierto avance cultural, reflejado en la creación de ciertos instrumentos y productos derivados del maguey que les eran útiles para el desarrollo de su vida cotidiana; situación que nos hace pensar, que cada uno de estos usos correspondió también con las primeras necesidades de información derivadas de su entorno.

De acuerdo con lo anterior y los actuales agricultores de agave azul de dicho lugar, al igual que sus predecesores los Caxcanes, le han encontrado otros usos a la planta además del de producir mezcal; situación que nos indica que, como en aquellos tiempos y éstos también corresponden con el surgimiento de determinadas necesidades de información, un ejemplo de lo anterior es lo siguiente:

Científicos mexicanos descubrieron que los fructanos del agave, carbohidratos que se utilizan para hacer el tequila; actúan en ratas contra varias enfermedades como la diabetes, el cáncer de colon, la osteoporosis y la obesidad; informó el Centro de Investigación y de Estudios Avanzados del Instituto Politécnico Nacional. ${ }^{2}$

1 Grupo sedentario originario de las faldas del cerro de Teochinchán, hoy volcán de Tequila; de quienes se desprende precisamente el nombre actual del municipio, así como de la bebida derivada del agave azul.

2 M. López Pérez, "Agave combate cáncer de colon y diabetes". 


\section{LA INFLUENCIA ESPAÑOLA Y LA INDUSTRIALIZACIÓN DE LA PRODUCCIÓN DEL "VINO-MEZCAL"}

Mediante un proceso de producción que dejó de ser exclusivo de las comunidades indígenas de la región después de la llegada de los españoles al entonces municipio de Tequila, la destilación del "vino mezcal", pasó a manos de estos últimos y dejó de producirse de forma artesanal para tomar un carácter industrial, situación que también provocó el desarrollo masivo de plantaciones agaveras en todo el territorio.

Esta transformación generó que los entonces agricultores de agave azul de Tequila perdieran el control de su producción, el cual pasó a manos de los grandes hacendados. Este acontecimiento marcaría propiamente el inició de una serie de disputas territoriales y productivas entre agricultores y hacendados; las cuales se repetirían de manera constante a través de los siguientes años. Este fenómeno social marcaría el rumbo de las cosas durante décadas - y aun hasta nuestros días-, de lo que también sería el surgimiento de determinadas necesidades de información que se derivaban de la relación entre los agricultores de agave azul y las principales casas productoras de tequila y, en algunos casos, la relación con las propias autoridades gubernamentales.

Un ejemplo de lo anterior es el siguiente: en el video-entrevista realizado a Don Eusebio Quintero Pérez, agricultor de agave azul de Tequila hace más de cincuenta años; este narra la forma en que en la década de los años sesenta, el gobierno en turno, junto con algunas casas tequileras, se apropió de muchas hectáreas de cultivo que no eran de su propiedad y que estaban ubicadas dentro de la ranchería denominada "El Potrero de la Loma" (lugar en donde nació el propio don Eusebio) en los sesenta, situación que se repetiría nuevamente cuarenta años después.

Este es un fragmento de la entrevista:

[...] al no contar yo con recursos económicos, ni tener ningún conocimiento legal para defenderme ante esta injusticia; tuve que buscar yo mismo por mi cuenta, datos, informes, decretos, reglamen- 
tos, leyes, entre muchas otras cosas (necesidades de información); para tratar de entender mi situación y poder resolverla [...]

[...] También tuve que consultar a abogados (de paso), directivos de organizaciones de agaveros, dirigentes de ejidos y familiares que cuentan con alguna profesión (comportamiento informativo) $[. . .]^{3}$

Hasta el momento, la situación de Don Eusebio no ha sido resuelta, pero en palabras de él mismo, dice que por lo menos ese atropello le ha servido para adquirir un tipo de conocimiento en cuanto al derecho agrario y la legislación agrícola, que antes le eran completamente desconocidos (satisfacción de la necesidad de información).

\section{EL SIGLO XIX Y LA PRODUCCIÓN MASIVA DE AGAVE AZUL}

Para 1835, catorce años después de la proclamación de la Independencia de México, la producción de tequila y agave azul dentro del municipio de Tequila alcanzaron cifras muy altas en comparación con las décadas anteriores. Este fenómeno provocó que a partir de entonces, las labores de cultivo tradicionales realizadas de forma individual por los agricultores de dicho lugar comenzaran a dividirse (especializarse), debido a que la demanda del producto era tan grande que ya no era posible que las labores de producción fueran desarrolladas por una sola persona o familia.

Lo anterior provocó que muchos de estos agricultores se encontraran ante el problema de desconocer algunos fenómenos derivados de tan alta exigencia, tales como: enfermedades del agave, ataques de plagas y la aplicación de los primeros agroquímicos, entre otras cosas más.

De lo último se desprende que estas exigencias bien pudieron haber generado las primeras necesidades de información de los agricultores de agave azul, en relación con la transformación de los procesos de su producción artesanal por otros de carácter

3 A. Sánchez Soto "Don Eusebio: un rostro enrojecido". 
industrial, derivados de la aplicación de técnicas de cultivo modernas, necesidad que probablemente y en muchos casos, fue cubierta de manera empírica por el conocimiento ancestral que sus antepasados le heredaron a los agaveros.

La última suposición se fundamenta en la mayoría de las investigaciones realizadas hasta el momento con el cultivo del agave azul, una de las cuales es la que personalmente he realizado para los estudios de Doctorado en Bibliotecología, a través de la tesis titulada: El perfil informativo de los agricultores de agave azul de Tequila Jalisco.

En el desarrollo de esta investigación, hasta el momento, la mayoría de los agricultores entrevistados ha manifestado que a pesar de la existencia de las nuevas y modernas técnicas sugeridas para la producción masiva de agave azul, ellos continúan aplicando con éxito aquellas que son consideradas como tradicionales y que en su mayoría les fueron enseñadas por sus padres o abuelos por transmisión oral.

\section{EL INICIO DEL SIGLO XX Y LA VIDA COTIDIANA DE LOS AGRICULTORES DE AGAVE AZUL DE TEQUILA}

Durante los primeros años del siglo XX las instalaciones industriales productoras de tequila se fueron concentrando y consolidando aún más adentro del municipio, así como en el resto del valle.

Las tabernas alojadas en las haciendas y rancherías productoras de agave azul, afectadas severamente por el conflicto agrario que siguió a los inicios del movimiento revolucionario, fueron perdiendo poco a poco competitividad frente a las grandes casas tequileras, que ya para entonces habían alcanzado un desarrollo prominente, lo que provocó que estas fueran cerrando gradualmente debido a la falta de capital y de recursos humanos, que por lo regular eran acaparados por las grandes destiladoras.

Estas grandes destiladoras, en su interés por mantener el control económico y laboral de los habitantes del municipio, particularmente de los que trabajaban para ellos, comenzaron a dotar de 
servicios urbanos al pueblo con la intención evidente de demostrar que ellos, a pesar de la hegemonía que ejercían dentro de la población, también le aportaban múltiples beneficios.

En concordancia con lo anterior, una aproximación al estilo de vida que mantenían los agricultores de agave azul de aquel lugar, es el que describe Juan Domingo Beckmann Legorreta, actual dueño de la fábrica de tequila "Casa Cuervo" ${ }^{4}$, en una crónica sobre la historia de la fábrica de tequila "José Cuervo":

Rumbo a Tequila los ingenieros agrónomos nos iban contando sobre su relación con los campesinos, mientras afuera podía observarse el horizonte a lo largo y ancho, bañado con un cielo intensamente luminoso que resaltaba el azul de los cerros repletos de tanto agave. La fábrica se encuentra muy cerca del Zócalo del pueblo, en la casa que habitara la familia Cuervo; una vez allí todo se organiza rápidamente; nos entregan el casco protector que llevan todos los trabajadores de la fábrica; pero, lo primero que presenciamos es una especie de danza que ejecutan diariamente los cargadores de los hornos de la fábrica; cuatro esbeltos tipos de rostros morenos y bigotes oscuros que se protegen la cabeza con un sombrero plano de vaqueta, relleno de borra, adornados con un cinturón ancho que estiliza aún más sus cuerpos flexibles y anchos, mismo que protege sus espaldas ante tanto esfuerzo. Estos personajes llaman tequio a cualquier tarea por realizar, así sea la de comerse los 18 tacos de carne colorada que preparan las mujeres en casa, o los trabajos de plantación y limpia de agave que realizan en el campo. ${ }^{5}$

De acuerdo con las entrevistas mencionadas anteriormente, hoy en día algunas de las necesidades de información de los agricultores de agave azul giran en torno a la compra de vestimenta típica relacionada con su trabajo, por ejemplo, los precios de sombreros, de fajas, de calzado industrial, de guantes de carnaza, de camisas de algodón de manga larga (por ser frescas) e incluso de lentes oscuros

4 Hijo del segundo dueño de "Casa Cuervo" de nombre Juan Beckmann Vidal.

5 M. Tercero, "A caballo entre dos tiempos", 34. 
(para evitar el daño de los rayos del sol que se reflejan en el azul de la planta).

\section{EL REPARTO AGRARIO Y LA MODERNIZACIÓN DE LA CADENA PRODUCTIVA DEL AGAVE AZUL}

Para la segunda y tercera década del siglo XX, las noticias relacionadas con la forma de vida de los agricultores de agave azul de Tequila no es bien conocida, de hecho existe confusión en cuanto a cómo se desarrolló respecto a las décadas anteriores; lo cual se debe a que con los reacomodos políticos, sociales y económicos provocados por el movimiento revolucionario de 1910, el estilo de vida de estos agricultores se vio afectado radicalmente y dejó de ser un ámbito meramente rural para convertirse en otro de carácter más industrial.

Lo anterior tendría su auge justamente a partir del reparto agrario promovido por el General Lázaro Cárdenas del Río, ya que con él se rompería el proceso regional que centralizaba la actividad productiva en un solo grupo o dueño, en este caso el de los hacendados-industriales-tequileros, dueños de las grandes fábricas.

Esta transformación económico-social comprendió, además de la organización de ejidatarios y agricultores, la rotación, diversificación e introducción de nuevos cultivos, la selección de semillas, el empleo de maquinaria, el uso de fertilizantes modernos y la creación de institutos, laboratorios y granjas experimentales.

Estos fenómenos, al igual que los mencionados anteriormente, también ocasionaron el surgimiento de determinadas necesidades de información de los entonces agricultores de agave azul de Tequila, pues la ya mencionada transformación industrial trajo consigo nuevas y variadas exigencias en el desarrollo de su trabajo, las cuales, en muchos casos se mantienen. Tomando en cuenta estos hechos, se puede decir que a partir de ese periodo comienza a darse de manera más formal y precisa el surgimiento de determinadas necesidades de información, así como de un mejor comportamiento informativo relacionado con estas. 
Un ejemplo de lo anterior es lo que sucede hoy en día con algunos de los agaveros más acaudalados de Tequila, quienes al ser entrevistados manifiestan lo siguiente:

[...] cuando tenemos una duda con respecto al desarrollo de nuestro trabajo, acudimos a los cursos y talleres que imparten las grandes empresas vendedoras de maquinaría y productos químicos, o bien a los foros, congresos y asambleas de asociaciones, institutos, secretarías de Gobierno, organizaciones de agaveros entre muchas otras cosas.

\section{EL SURGIMIENTO DE LAS PRIMERAS ORGANIZACIONES DE AGAVEROS}

Sería en los años setenta cuando se presentaría en la región tequilera, particularmente en el Municipio de Tequila, Jalisco, la primera crisis de sobrexplotación del agave azul, y tres serían los factores que se conjugaron en el surgimiento de esto: la disminución en la cantidad de agave permitido por la norma oficial del tequila, los créditos que otorgó el gobierno para la habilitación de nuevos cultivos y el intermediarismo que controlaba el acceso de agave a las fábricas.

En este contexto, los productores de agave del municipio de Amatitán, junto con algunos de los de Tequila crearon, en 1976, la Unión de Productores e Introductores de agave azul con la intención de controlar la nueva forma de monopolio de los grandes industriales.

Como en los casos anteriores, estos acontecimientos desencadenaron el surgimiento de nuevas necesidades de información en los agricultores de agave azul, derivadas estas de la lucha política, social y jurídica que los agaveros emprendieron para consolidar sus organizaciones.

Ambas situaciones marcaron el rumbo de lo que hasta hoy representan las diferentes organizaciones de agaveros de Tequila, Jalisco, así como las de sus necesidades de información. Algunas de estas necesidades manifestadas por los entrevistados fueron las siguientes: derecho agrario, leyes agrarias, derecho mercantil, importacio- 
nes, exportaciones, aranceles, créditos bancarios, financiamientos, movimientos sociales, derechos de los trabajadores y la Ley Federal del Trabajo, entre otros.

\section{EL "BOOM TEQUILERO” Y LA JERARQUIZACIÓN DE LOS AGAVEROS}

En 1996, con el surgimiento del llamado "boom tequilero", la producción de tequila y por ende de la materia prima para su elaboración, el agave azul, alcanzaron cifras exorbitantes nunca antes vistas en ninguna otra época.

Debido a esto, la mayor parte de los productores de agave azul alcanzarían una época de gran bonanza que provocaría una jerarquización de ellos mismos, lo cual se reflejaba en el número de hectáreas de cultivo que para entonces poseían, o bien, en el capital con el que contaban para adquirir la maquinaria que acelerara los procesos productivos.

La jerarquía no oficial establecida a partir de estos hechos es la siguiente: ${ }^{6}$

- Agricultores empresarios

- Agricultores independientes

- Agricultores que alquilan sus parcelas

- Agricultores que trabajan para casas tequileras

- Agricultores jornaleros

- Mujeres agricultoras de agave azul

De lo anterior se desprendió una marcada diferencia social, económica, cultural y laboral entre los diferentes tipos de agaveros. Di

6 Se dice que es una jerarquía no oficial porque hasta ahora ningún nivel de gobierno, ya sea local o federal, así como ninguna organización o institución educativa la ha reconocido como tal, simplemente se trata de una estratificación, producto de la cultura popular de los habitantes del municipio. 
cha situación al mismo tiempo se derivó en una serie de necesidades de información particulares de acuerdo con dicha jerarquía.

Como en los casos anteriores, algunas de estas necesidades son las siguientes, tomando en cuenta dos tipos de agaveros:

- Necesidades de información de los agricultores empresarios sobre ofertas de trabajo, noticias, precios del agave, ubicación de polleros y precios de boletos de camión a Guadalajara, entre otras cosas.

- Necesidades de información de los agricultores empresarios sobre exportación, boletos de avión al extranjero, costos de hospedaje en hoteles de lujo, precios de autos de lujo y eventos internacionales, entre otros.

\section{LA DECLARATORIA DE LA UNESCO AL PAISAJE AGAVERO COMO PATRIMONIO DE LA HUMANIDAD Y EL DESPEGUE TURÍSTICO DEL MUNICIPIO DE TEQUILA}

En 2006, a raíz de la Declaratoria de la Unesco sobre el Paisaje Agavero, los ojos del mundo volcaron su atención hacia el Municipio de Tequila dada su riqueza histórica, artística, cultural, económica e industrial.

Debido a lo anterior muchos de los agaveros del lugar — principalmente los que ocupaban los últimos lugares de la jerarquía mencionada anteriormente-, se valieron de eso para obtener ingresos económicos alternos, además de los relacionados con el cultivo del agave azul —en algunos casos ingresos totales- a través de la práctica de oficios alternos como: artesanos, guías de turistas, taxistas, comerciantes informales, afanadores de hoteles, boleros, vendedores de aguas frescas, etc.

Por estas razones, al igual que en las épocas anteriores, estos agricultores mostraron el surgimiento de determinadas necesidades de información, la mayoría de ellas relacionadas con sus nuevos empleos. 
Algunas de estas necesidades de información son: los precios del agave, los precios de autos, los eventos de la región, el turismo, la historia del tequila, la historia de las casas tequileras, la historia del municipio, las leyendas y las fechas importantes del lugar y la región.

\section{BIBLIOGRAFÍA}

Álvarez, J. R. (1964). Jalisco: nueve ensayos. México: Editorial Tlacuilo.

Gómez Arriola, I. (2010). " El plan de manejo para el paisaje agavero y las antiguas instalaciones industriales de Tequila: el patrimonio cultural como detonador del desarrollo regional, antecedentes, compromisos, retos". Apuntes. vol. 22, núm 2, 124 -141.

Hernández, J. de J. (2009). “Tequila: centro mágico, pueblo tradicional. ¿patrimonialización o privatización?”. Andamios, vol. 6, núm. 12 (dic): 41-67.

INEGI (2007). El cultivo del agave tequilero en Jalisco: censo agropecuario. México: INEGI.

López Pérez, M. (2010). "Agave combate cáncer de colon $y$ diabetes". El Universal, Sección Suplementos, 20 de Julio, 2010.

Regalado, J. (1988). "Los agraristas" Jalisco desde la Revolución, movimientos sociales 1929-1940, vol. 5. Gobierno del Estado de Jalisco.

Revista Artes de México (1994). "El tequila: arte tradicional de México". Revista Artes de México, núm. 27.

Sánchez Soto, A. (2013). Don Eusebio: un rostro enrojecido. Entrevista realizada a Eusebio Quintero Pérez, agricultor de agave azul de Tequila Jalisco, Video casero en formato digital (DVD), duración $140 \mathrm{~min}$. México: Tequila, Jalisco. 
Usuarios de la Información...

Tercero M. (2006). "A caballo entre dos tiempos". Cien freeways: D.Fy alrededores. México: UACM.

Torres Rodríguez, A. (2009). "Caxcanes". Centzuntli: pueblos y pobladores indígenas de Centroamérica, México y el Caribe. Disponible en: <http://centzuntli.blogspot. $\mathrm{mx} / 2009 / 10 /$ caxcanes.htm $>$. 


\title{
Las mujeres agricultoras de agave azul de Tequila, Jalisco: un acercamiento a los factores sociales, económicos y familiares que influyen en el surgimiento de sus necesidades de información
}

\author{
Armando SÁnChez Soto \\ Universidad Nacional Autónoma de México
}

\section{INTRODUCCIÓN}

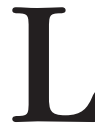

a presente es una investigación derivada de otra, cuya intención era conocer el perfil informativo de los agricultores de lagave azul de Tequila, Jalisco. En un principio se creía que eran únicamente los varones de esta población quienes llevaban a cabo la práctica ancestral de cultivar esta planta; sin embargo, durante el proceso de investigación documental y de campo nos dimos cuenta de que a lo largo de la historia y aun en la actualidad, las mujeres de este lugar han estado siempre involucradas en esta producción.

Se pensaba en un principio que la función de la mujer dentro de la cadena productiva agave-tequila se limitaba únicamente a llevar el producto (la piña del agave) para ofrecérselo a las grandes fábricas tequileras para su venta; pero esta situación ha cambiado radicalmente hoy en día, pues son muchas las mujeres de esta población que dados sus conocimientos tanto empíricos - transmitidos por sus padres o abuelos-, como profesionales - en el caso de aquellas que han cursado alguna carrera relacionada con la agricultura-, se han integrado de forma directa no solo en el cultivo de la planta, sino incluso en actividades empresariales, directivas o de producción, dentro de las mismas casas tequileras. 
Pese a lo anterior, como es de imaginarse, la mayoría de ellas no se ha desprendido de su tradicional función dentro del seno familiar, pues aquellas que ya han formado una familia alternan su trabajo con el cuidado de sus hijos y de su hogar, mientras que para las más jóvenes y aún solteras, a diferencia de sus madres y abuelas, las perspectivas de crecimiento personal, profesional y económico son mucho más amplias que las de sus predecesoras, pero aun así ayudan a estas con el cuidado y la educación de los hermanos menores, o bien con los gastos del hogar.

Al mismo tiempo, estas mujeres conservan su esencia como tales, pues la mayoría de ellas gusta del buen vestir y del uso de maquillajes y accesorios que resalten su feminidad. Las más jóvenes y solteras acuden constantemente a fiestas y a lugares de esparcimiento y diversión, y se mantienen en constante comunicación con el exterior a través de la telefonía móvil y las redes sociales.

Estas actividades laborales, familiares y/o sociales, dada su importancia para el desarrollo de su vida personal y familiar, les generan constantemente determinadas necesidades de información, como conocer las formas de controlar plagas y enfermedades del agave, a la vez que ayudar en las tareas escolares de los hijos o hermanos (as) menores, y también a participar en el costo de los alimentos y aparatos electrodomésticos, así como asistir a los diversos eventos de esparcimiento (conciertos, ferias, eventos deportivos), entre muchas otras cosas más. A continuación se presenta un análisis más detallado de todo lo anterior.

\section{LOS AGRICULTORES DE AGAVE AZUL: IMAGEN Y PRESENCIA}

Histórica y culturalmente el cultivo del agave azul, ha estado asociado con el género masculino, una breve y personal descripción de podría ser la siguiente: "hombres rudos de carácter recio, de rostro enrojecido y piel curtida; ataviados siempre de un sombrero ancho de palma, una camisa blanca o a cuadros de manga larga, su machete colgando de la cintura y su coa en la mano". 
Esta imagen se ha mantenido a lo largo de los años, el reflejo de los rayos del sol que rebotan en el azul de las pencas agaveras es lo que ha provocado, con el tiempo, el enrojecimiento y grosor de la piel de estos hombres, sobre todo en aquellos que ya tienen más de veinte años dedicados a esta actividad. De ahí el hecho de usar el sombrero ancho y las camisas de manga larga. Se dice que se trata de hombres rudos, dado que a través de los años y sobre todo en las épocas de abundancia, han pasado largas horas de pesada faena en los campos agaveros, llevando a cabo todas las prácticas propias del cultivo de esta planta, desde la siembra o el barbecho hasta la jima y transportación de la piña para su venta a las fábricas. Al final de su jornada, ya llegando muy tarde a su hogar, lejos de interactuar con su esposa y sus hijos, su mayor distracción es la de escuchar música mientras se consume el tequila que se extrae del mismo agave, que quizá alguna vez cultivaron y posteriormente les vendieron a las grandes empresas tequileras.

Las mujeres agricultoras de agave azul: una visión histórica

Más allá de lo anterior, y contrariamente a lo que se piensa, documentos históricos y evidencia empírica actual demuestran que además de la fuerza de trabajo masculina, otros personajes, por supuesto, las mujeres y los niños, también han trabajado en los campos agaveros.

Algunos documentos del archivo histórico del municipio de Tequila, Jalisco, redactados durante los primeros años del siglo XIX, sugieren que las mujeres conocían el incipiente mercado del vinomezcal que por entonces se estaba desarrollando en este lugar; pero además de eso también tenían amplios conocimientos con respecto a la forma de cómo cultivar dicha planta. ${ }^{1}$

De acuerdo con lo anterior, se dice que más allá de ayudar en algunas de las labores más sencillas en el cultivo del agave azul,

1 J. Hernández, "Presencia de mujeres en los campos agaveros", 18. 
como el deshierbe, ${ }^{2}$ o el arranque de la planta, ${ }^{3}$ su principal función era la de llevar la piña del agave -y en algunos casos ya el destilado mismo- a las fábricas tequileras para ofrecer el producto; dicho de otra forma, eran quienes se encargaban de la parte comercial de la entonces cadena productiva agave-tequila.

Por lo tanto, en aquel entonces como ahora, en las épocas de mayor abundancia, tanto las mujeres como sus hijos tenían que integrarse en las labores propias del cultivo, más allá de que además de esto, algunas también tuvieran que salir a comercializar el producto.

\section{La visión tradicional}

Tradicionalmente "las mujeres agaveras" de Tequila (como también se les conoce), como en cualquier otra comunidad agrícola y/o rural, cumplían la función casi exclusiva de ser amas de casa dedicadas al cuidado de los hijos, la preparación de los alimentos y la atención del hogar; esto mientras el esposo y los hijos mayores salían al campo a trabajar en busca del sustento.

La mayoría de esas mujeres fueron hijas, esposas o hermanas de agricultores de agave azul tradicionales, a quienes la tradición familiar obligó a cumplir estas funciones, más allá de que también pudieran haber tenido la oportunidad de incorporarse laboral y económicamente en la producción del agave azul, o bien en alguna otra actividad remunerada más allá del seno familiar y del cultivo de esta planta.

En ese sentido, al igual que sus predecesoras su función se limitaba a ser únicamente las encargadas del cuidado del hogar y los hijos, así como de la preparación de los alimentos:

2 Actividad que consiste en quitarle al agave toda aquella hierba o vegetación nociva.

3 Esta actividad tiene como fin arrancar los hijuelos del agave que se emplearán en la creación de nuevas plantaciones. 
La mayoría de ellas se organizan con los hijos (as) y las abuelas, para llevar el alimento a los hombres en el lugar de trabajo. Lo anterior aun sin pretenderlo, va creando las condiciones para que las siguientes generaciones (de hombres y mujeres) vayan incorporando conocimientos empíricos relacionados con la tradición familiar de cultivar el agave azul. ${ }^{4}$

Tomando en cuenta lo anterior, se dice que cuando las madres llevan a los hijos e hijas a los campos agaveros, se da una especie de proceso de iniciación para ellos, como una forma de familiarizarse con lo que en un futuro será su principal actividad laboral remunerable, económicamente hablando. Aun así, muchos de los jóvenes hombres y mujeres que experimentaron este proceso de "socialización" en su niñez, hoy en día han optado por dedicarse a los estudios y buscar una forma de sustento y crecimiento personal, alejado de lo que sus padres y abuelos trataron de imponerles.

La inclusión directa de la mujer en la cadena industrial agave-tequila

A pesar de lo anterior, hoy en día muchas de las "mujeres agaveras" han logrado romper con los esquemas tradicionales e históricos que les impedían incorporarse a otros ámbitos laborales, y, poco a poco, se han ido incorporando a la vida laboral del municipio.

Hoy en día muchas de las mujeres se encuentran trabajando como obreras en fábricas de tequila, como oficinistas, recepcionistas, secretarías, traductoras, responsables de mercadotecnia, guías de turistas, o en programas de desarrollo comunitario como encargadas de destilación, envasado, empaque o comercialización entre otros empleos; todo ello dentro de la industria tequilera. Al respecto Valenzuela dice lo siguiente:

$4 \quad$ Op.cit. 19. 
Actualmente muchas mujeres de Tequila Jalisco y de otras partes en donde existe la cadena productiva agave-tequila, se han incorporado de forma directa y formal dentro de los procesos productivos del agave azul en distintas empresas; esto como parte de un proceso de igualdad y desarrollo propios de una sociedad moderna y cambiante. ${ }^{5}$

En ese sentido y en términos generales, se puede decir que en la actualidad, las mujeres de este municipio han ido dejando de lado dedicarse casi exclusivamente al apoyo de los procesos productivos del agave azul, y en su lugar, poco a poco se han ido incorporando a otras actividades dentro y fuera de la industria. Dicho de otra forma, muchas de ellas han salido del seno familiar para incorporarse a la vida laboral y económica de su lugar de origen.

\section{Las mujeres agaveras en la actualidad}

Si se considera lo señalado en los apartados anteriores, hoy en día se puede hablar incluso de una tipología no oficial de las mujeres agricultoras de agave azul que quedaría de la siguiente forma:

a) Agricultoras de agave azul tradicionales: son aquellas que ocasionalmente ayudan a los varones en el cultivo del agave azul, manteniendo aún labores casi exclusivas dentro del seno familiar.

b) Agricultoras de agave azul profesionistas: son aquellas que trabajan en los campos agaveros desempeñando una profesión (agrónomas y químicas principalmente).

5 A. Valenzuela y M. Gaytán, "La expansión tequilera y las mujeres en la industria: del símbolo al testimonio", Ensayos: Sociedades Rurales, Producción y Medio Ambiente, vol. 9, núm. 18 
c) Agricultoras de agave azul obreras técnicas: aquellas que desarrollan trabajos manuales de menor esfuerzo (hijas y/o nietas de agricultores de agave azul que aportan sus conocimientos empíricos). ${ }^{6}$

Tal y como se puede ver en el caso de las primeras, las que aún no han podido romper con esa tradición familiar mencionada anteriormente, su labor en los campos agaveros se limita a actividades de carácter sencillo y relativamente rápido; en cuanto a las segundas, normalmente son contratadas como responsables y/o supervisoras de cuadrillas en la aplicación de nuevas técnicas de cultivo y en el control de plagas y enfermedades; mientras que las últimas, debido a sus conocimientos y mano de obra calificada, normalmente son quienes verifican la calidad del trabajo hecho por los plantadores, muchos de ellos varones, y detectan plantas caídas, amontonamientos y espacios vacíos, entre otras funciones.

Por otra parte, cada una de estas mujeres cuenta con características particulares de acuerdo con su origen, edad y expectativas de vida, las cuales se describen a continuación.

\section{CARACTERÍSTICAS PARTICULARES DE LAS MUJERES AGRICULTORAS DE AGAVE AZUL}

Agricultoras de agave azul tradicionales

- $\quad$ Se trata de mujeres cuya edad oscila entre los 40 y los 65 años.

- Su nivel de estudios es escaso.

- La mayoría son esposas y/o hijas de agricultores de agave azul tradicionales.

- Comúnmente no desempeñan ningún otro tipo de trabajo remunerado y sólo se dedican al cuidado del hogar y los hijos.

- Únicamente en épocas de abundancia es cuando suelen in-

6 S. A. Sánchez, "Necesidades de información de las mujeres agaveras". 
corporarse en labores sencillas dentro de la producción de agave, aunque esta labor no es habitualmente remunerada.

Agricultoras de agave azul profesionistas

- Se trata de mujeres cuya edad oscila entre los 25 y los 35 años

- Cuentan con estudios profesionales.

- La mayoría son hijas, nietas o hermanas de agricultores de agave azul tradicionales.

- Algunas provienen de otros municipios de Jalisco en donde también se cultiva agave (Amatitán, Arandas, El Arenal).

- Su trabajo es bien remunerado por lo que no cuentan con ninguna otra forma de empleo.

Agricultoras de agave azul obrero-técnicas

- Son mujeres cuya edad oscila entre los 18 y los 40 años.

- Algunas cuentan con estudios básicos o de bachillerato.

- Son hijas, nietas o hermanas de agricultores de agave azul tradicionales.

- Algunas provienen de otros municipios de Jalisco en donde también se cultiva agave.

- Ocasionalmente suelen ayudar a sus progenitores en las labores de cultivo del agave azul.

- En épocas de escasez suelen emplearse en otros oficios (ventas, promoción turística o en otras actividades fuera del municipio).

Una vez definida la tipología de estas mujeres, así como sus características particulares, en el siguiente apartado se presentan sus necesidades de información desde tres perspectivas diferentes:

- Necesidades de información derivadas de su interacción con el entorno social en el que habitan.

- Necesidades de información derivadas de su entorno económico. 
- Necesidades de información derivadas de su interacción con el entorno familiar.

A continuación se presenta una descripción detallada de estas necesidades.

\section{NECESIDADES DE INFORMACIÓN DE LAS MUJERES AGAVERAS: LA INFLUENCIA DE LOS FACTORES SOCIALES, ECONÓMICOS Y FAMILIARES}

Necesidades de información de las agricultoras de agave azul tradicionales

- $\quad$ NIFS 7 : técnicas de cultivo de agave azul; enfermedades y plagas que afectan el agave azul; precios, compra y venta de agave azul; fertilizantes y pesticidas que se aplican en el agave azul; legislaciones agropecuarias; reglamentos de control del CRT; organizaciones de agaveros; créditos agrícolas; etc.

- $\quad \mathrm{NIFE}^{8}$ : precios de alimentos básicos (frijol, arroz, huevo, leche, carne, verduras); de artículos de cocina (aceite, especias, condimentos); de medicamentos; de aparatos electrodomésticos; de compra y venta de agave; de fertilizantes y pesticidas; de uniformes escolares; precios de útiles escolares, etc.

- NIFF9: salud familiar; salud de la mujer (prevención de embarazos, prevención y cuidado de enfermedades); violencia familiar; alcoholismo; machismo; derechos de las mujeres; tareas escolares, etc.

7 Necesidades de información derivadas del entorno social.

8 Necesidades de información derivadas del entorno económico.

9 Necesidades de información derivadas del entorno familiar. 
Necesidades de información de las agricultoras de agave azul profesionistas

- $\quad$ NIFS: nuevas técnicas de cultivo del agave azul; desarrollo sustentable; agroindustria; agroquímicos, bioquímica, biodiversidad; recursos humanos; administración de recursos humanos; administración de empresas; legislación agraria; normas de control CRT; derecho agrario; etc.

- NIFE: costos de escuelas de idiomas; de aparatos electrónicos (computadoras, iPhone, iPod, tablets); de autos; de la ropa; de artículos de uso personal (cosméticos, accesorios, calzado); de libros, eventos de esparcimiento y diversión, etc.

- NIFF: temas relacionados con tareas escolares (de hijos y hermanos menores); con antiguas técnicas en el cultivo de agave azul (debidas a la relación familiar con los agricultores tradicionales); con salud familiar y de la mujer; empleos; jubilaciones, etc.

Necesidades de información de agricultoras de agave azul obrero-técnicas.

- $\quad$ NIFS: nuevas y modernas técnicas de cultivo del agave azul; uso de fertilizantes y pesticidas; de maquinaria agrícola; cursos de capacitación; recursos humanos; temas sobre la industria agavera; el control fitosanitario; el desarrollo sustentable; la legislación agropecuaria; los reglamentos de control del CRT; la agronomía, ecología y biodiversidad.

- $\quad$ NIFE: costo de fertilizantes y pesticidas; de maquinaria agrícola; de aparatos telefónicos; de ropa; de artículos de uso personal; precios de alimentos básicos; de herramientas; de ropa de trabajo; de ofertas de trabajo, y de eventos de esparcimiento y diversión.

- NIFF: temas relacionados con antiguas técnicas en el cultivo de agave azul (debidas a la relación familiar con los agricultores tradicionales); servicios de salud familiares (principalmente orientados hacia los padres y los hijos); salud de 
la mujer; temas relacionados con las tareas escolares; derechos de la mujer.

\section{CONCLUSIÓN}

En conclusión se puede decir que en el caso de las mujeres agaveras, dado que su inclusión dentro de la cadena productiva agavetequila es relativamente reciente, ellas consideran al oficio como una oportunidad de desempeñar un trabajo relativamente bien remunerado; así como una opción de crecimiento personal, a diferencia de lo que sucedió en el pasado con sus abuelas, madres o hermanas mayores.

En ese sentido, este interés se pone de manifiesto en la mayoría de sus necesidades de información, ya que estas están abocadas hacia el conocimiento de las técnicas y los procedimientos adecuados para la correcta producción del agave azul: nuevas técnicas de cultivo del agave azul, enfermedades y plagas del agave azul, agroindustria, agroquímicos, uso de maquinaría agrícola, etc.

Por supuesto, estas mujeres no han perdido su esencia como tales y conservan su feminidad, manifestada a través de su forma de hablar, de vestir y de relacionarse con su entorno; asimismo se mantienen al cuidado de su hogar, sus hijos, sus padres o sus hermanos menores y propician así una interacción sana y productiva con el entorno que las rodea.

\section{BIBLIOGRAFÍA}

González, C. (2003). En las líneas del tiempo: el tequila. Cápsula 52. Radio Red. Grupo Radio Centro. Disponible en: $<$ http://radiocentro.com.mx/grc/redam.nsf/vwALL/MALZ -SPFSDN $>$ [Fecha de consulta: 23 de octubre 2010]. 
Hernández, J (2007). Más tradicional que el agave: la organización social de los agaveros alteños. Libro Técnico, núm. 4, 1-89.

(2012). "Presencia de mujeres en los campos agaveros. Tecnoagave: Revista de la Cadena del Agave y sus Derivados, año 2, núm. 20. (diciembre-enero): 1820. Disponible en: <http://www.tecnoagave.mx/sitio/ index.php/es/reportajes/141-presencia-de-mujeres-enlos-campos-agaveros $>$.

(2012). "Transmisión de conocimientos en campos agaveros" Disponible en: <http://www.tecnoagave.mx/ sitio/index.php/es/reportajes/172-la-transmision-de-co nocimientos-en-los-campos-agaveros $>$. [Fecha de consulta: 30 de febrero 2014].

Colunga, P. et al. (2007). En lo ancestral hay futuro: del tequila a los mezcales y otros agaves. México: CICY, CONACYT, CONABIO, SEMARNAT, INE.

Cruz, A. (2012). "Bajo porcentaje de jornaleros agrícolas capacitados en manejo de pesticidas". La Jornada, 14 de septiembre, 2012.

Dansac, Y. (2012). "Conceptualizaciones nativas y etnoconocimientos sobre vestigios prehispánicos en el folclore rural. Notas de la exploración del patrimonio etnológico de Teochitlán (México)”. Apuntes, vol. 25, núm. 1, 115-125.

Pérez, J. y J. Del Real (2007). "Conocimiento y prácticas agronómicas para la producción de Agave Tequilana Weber, en la zona de denominación de origen del tequila". Libro Técnico, núm. 4, 1-89.

Sánchez S. A. (2015). "Necesidades de información de las mujeres agaveras": Revista de la cadena del agave $y$ sus derivados. En prensa.

Tercero, M. (1999). "A caballo entre dos tiempos: el agave laborioso". Artes de México. El tequila: Arte tradicional de México, núm. 27, 37-45 
Valenzuela, A. (2006). "Agave azul: historia por venir". Patrimonio cultural y turismo 15. Cuadernos: Itinerarios culturales y rutas del patrimonio, 145-157. México: CONACULTA.

(2007). "Diagnóstico del sistema de producción ejidal de Agave Tequilana Weber, variedad azul en la región de origen: 20 años de expansión tequilera", en Primer Seminario Internacional del Tequila: ambiente, cultura y sociedad, 11-28. México: Universidad de Guadalajara.

Valenzuela, A. y M. Gaytan (2009). "La expansión tequilera y las mujeres en la industria: del símbolo al testimonio". Ensayos: Sociedades rurales, Producción y Medio ambiente. vol. 9, núm. 18.

Venegas, H. et al. (coord.). (2008). "Tequila, pueblo mágico: de pueblo rural a desarrollo turístico". Historia regional y local, las ciudades, su historia y su importancia en la región. VII Taller Internacional de Historia Regional y Local. Problemas teóricos y prácticos, México: IHC-CU Altos Universidad de Guadalajara, Universidad Autónoma de Chapingo.

Villalvazo, A. (1986). El cultivo del mezcal (Agave Tequilana Weber) en la región de Tequila, Jalisco. Tesis de licenciatura. Universidad Autónoma de Chapingo. 


\title{
El empleo de la tecnología por los docentes de escuelas secundarias: una aproximación
}

\author{
Angélica Guevara Villanueva \\ Universidad Nacioanl Autónoma de México
}

\section{INTRODUCCIÓN}

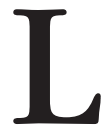

a presente investigación forma parte de un estudio de mayor dimensión, la cual representa un primer esfuerzo por descrillado por la comunidad de profesores de secundaria ante la información. Se considera el hecho de que como grupo social definido, esta comunidad tiene una misión propia y fundamental dentro de la sociedad, que le exige una formación académica y profesional que solo puede ser adquirida mediante el uso de la información.

Dada la importante labor educativa que tienen encomendada, su capacitación, actualización y preparación profesional se vuelven requisitos indispensables que deben poseer sus integrantes para poder adquirir las habilidades y competencias que les permitan ejercer con profesionalismo su actividad docente y, al mismo tiempo, cumplir con las políticas educativas imperantes en materia de evaluación. Esto la hace una comunidad interesante que nos lleva a dilucidar su comportamiento dentro de los estudios de usuarios de la información.

Para brindar esta primera aproximación, el presente estudio tiene como objetivo general analizar el comportamiento en la bús- 
queda de información de los docentes adscritos a dos escuelas secundarias públicas con modalidad general, circunscritas a la Delegación de Iztapalapa por ser la demarcación que concentra el mayor número de profesores en activo y que conforma la Ciudad de México. ${ }^{1}$ (Véase Gráfica 1)

Ante este panorama, para desarrollar el siguiente trabajo se comenzará por explicar lo que se entiende por comportamiento en la búsqueda de información para después, abordar a la comunidad académica, que es el objeto de estudio.

\section{EL COMPORTAMIENTO EN LA BÚSQUEDA DE INFORMACIÓN: SU CONCEPTUALIZACIÓN}

Antes de iniciar la examinación del concepto de comportamiento en la búsqueda de información, es importante comentar que hoy en día este comprende una fase plenamente diferenciada que implica un proceso cognitivo en el individuo, la cual ha sido analizada mediante la creación del Modelo de las Necesidades de Información (Modelo NEIN) elaborado por Calva González ${ }^{2}$ para explicar que el individuo solamente presenta un comportamiento si antes siente una necesidad.

Se ha definido al comportamiento de búsqueda de información de diferentes maneras, pero todas ellas coinciden en que esa búsqueda es una pieza fundamental dentro de dicho término. Por ello, Krikelas ${ }^{3}$ lo interpreta como "[...] la actividad del individuo dirigida a identificar un mensaje que satisfaga una necesidad percibida como tal". La actividad que refiere Krikelas tiene como objetivo principal cubrir los requerimientos de información que el

1 México. Secretaria de Educación Pública en el D. F. Estadísticas: 2011-2012. Secundarias.

2 Para profundizar sobre los elementos que conforman al Modelo de las Necesidades de Información véase la obra de Juan José Calva González, Las necesidades de información: fundamentos teóricos y métodos.

3 J. Krikelas," Information-Seeking Behavior: Patterns and Concepts” p. 6. 
individuo establece a través de una serie de procedimientos que se relacionan con las fuentes y recursos de información, mediante una acción dinámica por parte de quien desea satisfacer esa necesidad.

Para Cirigliano ${ }^{4}$ el comportamiento en la búsqueda de información comprende "[...] los hábitos, costumbres, actitudes, procedimientos y habilidades así como los modos de acción exhibidos por los sujetos en su relación de búsqueda y el empleo de las fuentes o documentos informativos". De acuerdo con este razonamiento establecido, el comportamiento se refiere a una línea conductual mediante la cual el individuo llega a poseer una serie de atributos y competencias capaces de conducirlo hacia la búsqueda y obtención de la información, a través de un eficiente manejo de las fuentes documentales, o también, acudiendo a la asistencia del profesional de la información cuando el interesado carece de habilidades.

Así, dentro de esta temática, Wilson ${ }^{5}$ define al comportamiento en la búsqueda de información como "[...] la totalidad del comportamiento humano en relación a los recursos y canales de información, abarcando la búsqueda de información, activa y pasiva, y el uso de información". Incluye, tanto la comunicación cara-a-cara con otros, como la recepción pasiva de información. De este modo, la explicación que proporciona Wilson hace presente la serie de procedimientos que debe realizar el sujeto para satisfacer su necesidad. Es decir, la expresión de cómo el usuario selecciona las fuentes y recursos, así como los servicios que más utiliza y la forma en que selecciona la información.

Finalmente, Calva establece que el individuo solo presenta un comportamiento si siente una necesidad; es decir, si se rompe momentáneamente el equilibrio entre el medio y su organismo. Por ello, una persona que tiene una necesidad de información presen-

4 G. F. Cirigliano, La conducta informativa en universitarios argentinos: investigación sobre la habilidad y capacidad de los jóvenes graduados universitarios para manejar y utilizar las fuentes de información bibliográfica, 26.

5 T. D. Wilson, "Human Information Behavior", Informing Science. Special Issue, 49. 
ta un comportamiento informativo que conlleva la idea de satisfacer tal necesidad y, de ese modo, planea cubrir la insuficiencia de conocimientos e información sobre algún fenómeno, hecho u objeto. ${ }^{6}$ De acuerdo con este concepto, se puede apreciar claramente la continuidad que se le da a la aparición de las necesidades de información en el sujeto que desarrolla el comportamiento de búsqueda o el comportamiento informativo que busca satisfacer la necesidad que dio origen a este proceso.

En suma, es posible afirmar que el comportamiento de búsqueda de información es una fase que forma parte de un proceso que orienta y se dirige a la satisfacción de necesidades en las que se pueden conocer las actitudes, hábitos y estrategias que realizan las personas para obtener información, y que no pueden explicarse de forma aislada, sino que encuentran su aplicación en comunidades de usuarios específicas como los docentes, que son objeto de análisis dentro de esta investigación. Razón por la cual a continuación se menciona a la comunidad docente.

\section{La comunidad docente en escuelas secundarias: su contexto}

Sin duda, la función docente que realiza la comunidad de profesores representa uno de los motores culturales en los que se basa el desarrollo de una nación. En este marco, su preparación profesional, actualización y superación, resultan factores que determinan la necesidad de recurrir a la utilización de la información. Y, con ello, el interés de investigar acerca de su comportamiento en la búsqueda de información se vuelve indispensable, no solo para poder crear, reformular e innovar servicios bibliotecarios y de información, sino para favorecer y lograr que el profesor adquiera las habilidades informativas que le permitan desarrollar nivel de competitividad exigido por los procesos de modernización y globalización, con el objetivo de hacer frente a los retos impuestos por las actuales exigencias internacionales en materia de evaluación.

6 J. J. Calva González, Las necesidades de información: fundamentos teóricos y métodos, op. cit., 102. 
Debido a que en nuestro ámbito disciplinar no se dispone de estudios que documenten el comportamiento de búsqueda de información de la comunidad de profesores de educación secundaria, específicamente en la Delegación de Iztapalapa, o bien, investigaciones que mencionen si el profesor recibe algún tipo de asesoría que lo capacite o prepare en relación con la búsqueda de información para cumplir con lo solicitado, este estudio representa la posibilidad de conocer nuevas líneas de investigación en torno a los estudios de usuarios en comunidades académicas dentro de nuestra disciplina bibliotecológica, con la intención fundamental de obtener un conocimiento particular de la colectividad de profesores respecto al comportamiento informativo que han desarrollado como resultado de su práctica profesional.

A pesar de que la Secretaría de Educación Pública (SEP) a nivel institucional asiste en la formación continua y preparación profesional de la comunidad docente por medio de la creación de espacios como los denominados Centros de Maestros, ${ }^{7}$ o mediante la posibilidad de obtener una beca para realizar estudios de especialización, maestría o doctorado en alguna de las instituciones formadoras del país, ${ }^{8}$ no se tienen datos objetivos que den cuenta sobre la existencia del comportamiento informativo por parte de los docentes a través de estas acciones institucionales.

Como consecuencia de esta serie de limitaciones, no se alcanza a percibir si efectivamente la información es un recurso determinante para la formación, el ejercicio profesional y la vida cotidiana de los educadores, pues hasta ahora sólo se han mencionado en di-

7 Su función sustantiva es ofrecer servicios, recursos e instalaciones de apoyo al desarrollo de las escuelas y los colectivos docentes de la educación básica, a través de la promoción y asesoramiento de actividades formativas y de desarrollo, así como la acreditación de sus conocimientos por medio de los exámenes nacionales para maestros en servicios. Para mayor información, véase la siguiente dirección electrónica: <http://formacioncontinua. sep.gob.mx/index.php?option=com_content\&view=article\&id=53\&Itemid= $81>$.

8 Véase: Formación continua y superación profesional para maestros de educación básica en servicio. Catálogo nacional 2012-2013. 
versos momentos los deficientes niveles de preparación, ${ }^{9}$ pero sin tener ni siquiera estudios exploratorios que indiquen las tendencias de esta comunidad hacia la información.

Precisamente en una época en que la información y el conocimiento son elementos fundamentales para el mejoramiento profesional e individual de los ciudadanos, todo indica que en apariencia, el sector de profesores de educación secundaria de la CDMX se encuentra alejado de esta serie de prácticas y, por lo tanto, se pueda llegar a suponer que estos no alcanzan los beneficios que la información y el conocimiento les ofrecen, y en cierta manera esto llegue a reflejarse en el reducido número de profesores que se inscriben para participar en los diversos programas de evaluación como el denominado Carrera Magisterial. ${ }^{10}$

En función de la problemática mencionada, se partirá de los siguientes supuestos que permitirán concretar el conocimiento del comportamiento de búsqueda de información en la comunidad docente:

9 "Según cifras de un reporte estadístico de la SEP, sobre la evaluación a 422860 profesores de educación básica en el país, en 2009, 90.42\% de ellos no aprobaron los exámenes, ni pudieron obtener los puntajes necesarios por la forma en que preparan y enseñan a los niños [...] por lo que no fueron promovidos para obtener ingresos adicionales a su salario". Nurit Martínez, "La SEP recompensa a maestros reprobados”, El Universal, diciembre 7, 2009.

La misma autora enfatiza que: "En México, cuatro de cada diez maestros no se han involucrado en cursos y talleres de actualización en los últimos años, mientras que $\mathbf{1 5 . 3 \%}$ del total de profesores no tiene una preparación formal para la docencia, por lo que eso genera que seis de cada diez maestros confiesen 'tener dificultades' para dominar los contenidos del plan de estudios, planear la clase y enseñar a los niños de preescolar, primaria y secundaria”, Martínez, Nurit. "Estudiar interesa poco a maestros: informes", El Universal, 26 de abril, 2010.

10 [...] a la convocatoria de la SEP se presentaron para inscripción 721366 maestros de todo el país; $41 \%$ de los maestros no concluyeron el trámite para someterse a la evaluación al no cumplir con la entrega de documentos [...], [...] sólo 58\% (422 860) de los profesores que tuvieron intención de examinarse y obtener ingresos adicionales a su salario, cumplieron con todos los requisitos para ser examinados [...] Nurit Martínez, "La SEP recompensa a maestros reprobados", El Universal, 7 de diciembre, 2009. 
- La modalidad general es un tipo de enseñanza que lleva al docente hacia el interés por utilizar determinadas fuentes y recursos informativos, como los materiales impresos y audiovisuales, y a dejar de lado el uso de Internet y otros medios electrónicos que no maneja.

- El procedimiento de búsqueda de información que los profesores han desarrollado se encuentra orientado principalmente hacia el uso de las unidades de información (Centros de Maestros), seguido de la comunicación entre colegas, y también, existe una mayor tendencia a recurrir a las monografías en formato impreso, como los denominados "libros para el maestro" y "libros de apuntes para el maestro"11 y una menor a usar recursos académicos electrónicos.

- Los profesores jóvenes ${ }^{12}$ emplean con mayor frecuencia las fuentes y recursos informativos electrónicos en comparación con aquellos colegas de mayor edad.

\section{Metodología}

A pesar de las diversas y muchas particularidades que pueden poseer los docentes, ${ }^{13}$ para fines del presente estudio se optó por de-

11 Materiales que incluyen un plan de trabajo para cada actividad: contenidos conceptuales, destrezas, actitudes, el trabajo que el alumno desarrolla en la actividad, los recursos informáticos con los que se trabaja en cada actividad, los materiales que deben llevar de casa o el trabajo realizado previamente.

12 De acuerdo con el Instituto Mexicano de la Juventud, se tipifica como joven a aquellas personas cuya edad fluctúa entre los 12 y los 29 años de edad. Para mayor información véase la siguiente dirección electrónica: <http:// www.imjuventud.gob.mx/quienes-somos-imjuve-31.html>.

13 Por ejemplo: formación académica (normalista, universitario, etc.); funciones asignadas en la escuela (profesor de asignatura, de laboratorio, de taller o de actividades tecnológicas, asesor de grupo o tutor de alumnos); lugar de trabajo (profesor con horas concentradas en una misma escuela secundaria o desconcentradas en dos o más planteles, profesor de asignatura en secundaria y con plaza en una primaria, etc.). 
terminar como rasgos característicos los siguientes: tener dos años de antigüedad como mínimo, desempeñar su función en la modalidad general y encontrarse en activo.

Por otra parte, fueron elegidas al azar las escuelas secundarias públicas generales 194 "Nicolás Copérnico" y 266 "Teotihuacán" ubicadas en la delegación de Iztapalapa, debido a que esta es considerada como la entidad más grande territorialmente y que concentra la mayor cantidad de profesores (véase Gráfica 1).

Gráfica 1. Población de profesores en cada delegación del Distrito Federal

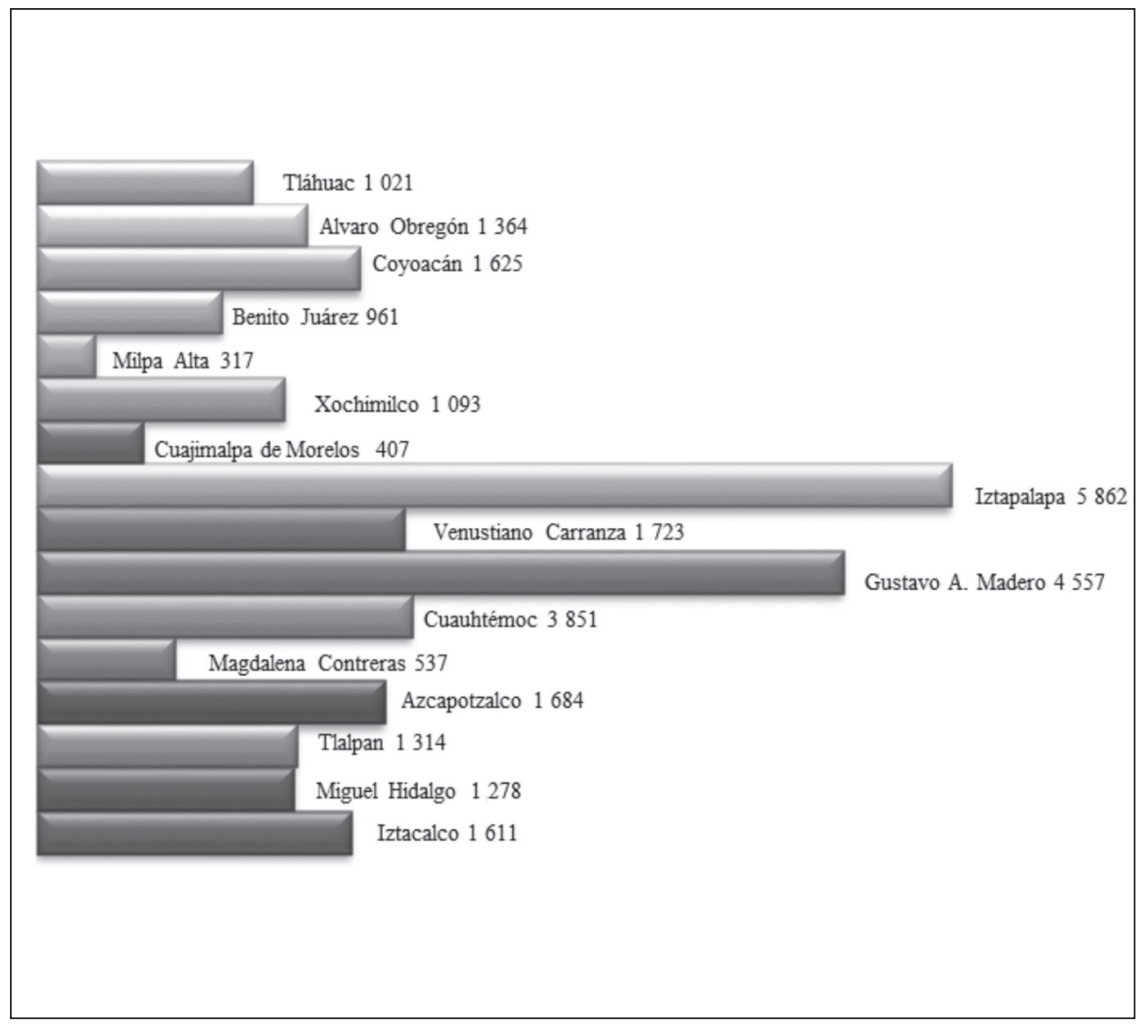

Fuente: Elaboración propia con base en los siguientes documentos. México. Secretaria de Educación Pública en el D. F. Estadísticas: 2011-2012. Secundarias. 
Teniendo en cuenta las consideraciones anteriores, es necesario indicar que para poder investigar a la comunidad de docentes se seleccionaron como estrategias (método, técnica e instrumento): el método directo, ${ }^{14}$ la técnica de investigación y la encuesta, y como instrumento, la cédula de entrevista, la cual contempló 21 preguntas, de las cuales, 19 fueron cerradas y 2 abiertas ( Anexo 1).

Así, a través del proceso anterior, se logró entrevistar a 75 docentes de ambos turnos. Es importante añadir que en el momento de aplicar el instrumento (cédula de entrevista) algunos docentes no se pudieron entrevistar porque tenían incapacidad, habían solicitado una licencia económica o, bien, no desearon participar.

\section{Resultados}

Para dar inicio a la presentación de los resultados es importante señalar que se comenzará por dar a conocer algunas generalidades de la comunidad de docentes, para después mostrar las cifras obtenidas acerca del conocimiento sobre la búsqueda de información que llevan a cabo los profesores.

\section{Datos generales}

En cuanto al género, en las secundarias generales impera el femenino (48) ( Tabla 1). Y en tanto a su estado civil, se obtuvo que la mayor parte de los profesores se encuentran casados (38); sin embargo, también hay profesores solteros (21), divorciados (6), viudos (8), o en unión libre (2) ( Tabla 2).

14 El método directo dentro de la línea de investigación denominada "estudios de usuarios" comprende estar cara a cara con nuestro sujeto de investigación, con el fin de lograr que responda a las preguntas en tiempo real. 
Tabla 1. Género

\begin{tabular}{|l|l|}
\hline Femenino & 48 \\
\hline Masculino & 27 \\
\hline Total & 75 \\
\hline
\end{tabular}

Tabla 2. Estado civil

\begin{tabular}{|l|c|}
\hline Casada(o) & 38 \\
\hline Soltera(o) & 21 \\
\hline Divorciada(o) & 6 \\
\hline Viuda(o) & 8 \\
\hline Unión libre & 2 \\
\hline Total & 75 \\
\hline
\end{tabular}

En relación con su edad, la (Tabla 3) muestra que son pocos los profesores jóvenes ${ }^{15}$ de la modalidad general (8) ya que la mayoría (67) rebasa los 31 años de edad. En lo concerniente a la antigüedad laboral se puede ver (Tabla 4) que el número de profesores que tienen una antigüedad menor a cinco años es reducido debido a que el rango mayor de docentes en activo se encuentra entre los 6 y los 25 años de antigüedad, siendo muy escasos (7) los docentes que tienen más de 26 años laborando.

Tabla 3. Edad

\begin{tabular}{|l|c|}
\hline De 20 a 25 años & 1 \\
\hline De 26 a 30 años & 7 \\
\hline De 31 a 40 años & 22 \\
\hline De 41 a 50 años & 25 \\
\hline Más de 50 años & 20 \\
\hline Total & 75 \\
\hline
\end{tabular}

15 Cabe aclarar que de acuerdo con el Instituto Mexicano de la Juventud, se tipifica como joven a aquellas personas cuya edad fluctúa entre los 12 y los 29 años de edad. Para mayor información véase la siguiente dirección electrónica: <http://www.imjuventud.gob.mx/quienes-somos-imjuve-31.html>. 
Tabla 4. Antigüedad laboral

\begin{tabular}{|l|c|}
\hline Menos de 5 años & 5 \\
\hline Entre 6 a 10 años & 19 \\
\hline Entre 11 a 15 años & 19 \\
\hline Entre 16 a 20 años & 13 \\
\hline Entre 21 a 25 años & 12 \\
\hline Más de 26 años & 7 \\
\hline Total & 75 \\
\hline
\end{tabular}

Por otra parte, en lo que respecta al número de horas laborables, se tiene que todos los profesores de esta modalidad trabajan de 10 a 20 horas semanalmente. En lo que corresponde a la pregunta 6 del instrumento de investigación (entrevista) sobre la asignatura o asignaturas que imparten los profesores, la Tabla 5 muestra el número de docentes que tiene cada una de ellas.

Tabla 5. Asignaturas que imparten los docentes

\begin{tabular}{|l|c|}
\hline Matemáticas & 13 \\
\hline Español & 9 \\
\hline Ciencias (énfasis en biología) & 6 \\
\hline Ciencias (énfasis en física) & 5 \\
\hline Ciencias (énfasis en química) & 7 \\
\hline Geografía de México y el Mundo & 2 \\
\hline Historia & 10 \\
\hline Formación cívica y ética & 10 \\
\hline Lengua extranjera & 6 \\
\hline Educación física & 2 \\
\hline Asignatura estatal & 4 \\
\hline Orientación vocacional & 1 \\
\hline Tecnología (Informática) & 4 \\
\hline Artes plásticas y/o artísticas & 4 \\
\hline Taller & 6 \\
\hline Total & 89 \\
\hline
\end{tabular}

Es importante mencionar que hay profesores que no solo se limitan a impartir una asignatura, sino que pueden estar asignados a dos o más en la misma secundaria, por lo que las cantidades que 
se presentan son superiores a la comunidad investigada. En relación con los talleres que se ofrecen, se encuentran los siguientes: ofimática, administración contable, electricidad, diseño de circuitos, informática, industria del vestido, diseño arquitectónico, dibujo técnico y preparación y conservación de alimentos.

Ahora bien, con respecto al grado en el que los profesores imparten su o sus asignaturas sucede algo similar en la Tabla 5, debido a que algunos de ellos dan su materia no solo en primer grado, sino que pueden hacerlo en dos e incluso en los tres grados (Gráfica 2). Por ello, sucede que en las secundarias generales en el primer grado hay 36 docentes, en el segundo 40 docentes y en el tercero 46.

Gráfica 2. Grado en el que los docentes imparten su asignatura

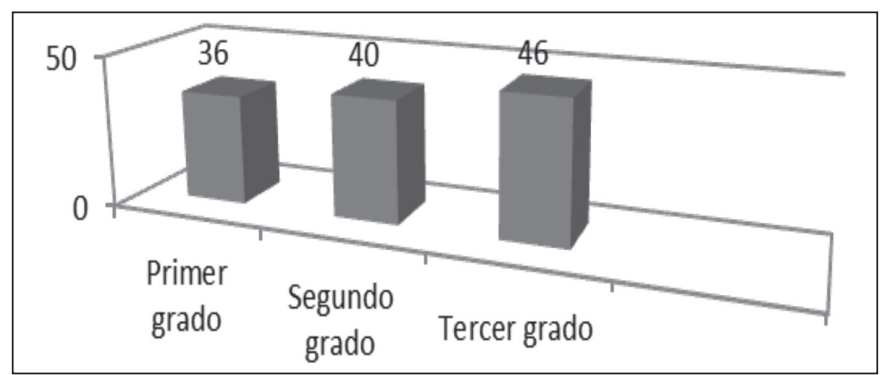

Otro elemento característico que se investigó fue la institución de la cual egresaron los docentes, y a continuación se muestran los siguientes datos:

Tabla 6. Institución de donde egresaron los docentes

\begin{tabular}{|l|c|}
\hline Colegio de Pedagogía (UNAM) & 26 \\
\hline Universidad Pedagógica Nacional & 6 \\
\hline Escuela Normal Superior de México & 1 \\
\hline Otra & 42 \\
\hline Total & 75 \\
\hline
\end{tabular}


En cuanto a los docentes que contestaron "otra" se encontró que han sido preparados en las siguientes instituciones educativas:

\begin{tabular}{|c|c|c|c|}
\hline $\begin{array}{l}\text { Colegio de } \\
\text { Bachilleres Núm. } 6\end{array}$ & UPIICSA, IPN & $\begin{array}{l}\text { Centro Universitario } \\
\text { San Ángel }\end{array}$ & ENEP, Aragón \\
\hline $\begin{array}{l}\text { FES, Zaragoza, } \\
\text { UNAM }\end{array}$ & UAM, Xochimilco & Universidad Latina & $\begin{array}{l}\text { Facultad de Contaduría } \\
\text { y Administración, UNAM }\end{array}$ \\
\hline UAM, Iztapalapa & $\begin{array}{l}\text { Universidad } \\
\text { Iberoamericana }\end{array}$ & CONALEP & $\begin{array}{l}\text { Facultad de Derecho, } \\
\text { UNAM }\end{array}$ \\
\hline $\begin{array}{l}\text { Centro de Bachillerato } \\
\text { Tecnológico } \\
\text { Agropecuario Núm. } 35\end{array}$ & $\begin{array}{l}\text { Escuela Superior de } \\
\text { Educación Física }\end{array}$ & $\begin{array}{l}\text { Centro de Estudios } \\
\text { Tecnológico y de } \\
\text { Servicio No. } 153\end{array}$ & Universidad del Valle \\
\hline $\begin{array}{l}\text { Tecnológico de } \\
\text { Estudios Superiores } \\
\text { Monterrey }\end{array}$ & FES, Acatlán, UNAM & $\begin{array}{l}\text { ENAP, Xochimilco, } \\
\text { UNAM }\end{array}$ & $\begin{array}{l}\text { Facultad de Medicina, } \\
\text { UNAM }\end{array}$ \\
\hline $\begin{array}{l}\text { Escuela de Bailes y } \\
\text { Tradiciones }\end{array}$ & $\begin{array}{l}\text { Facultad de Ciencias } \\
\text { Políticas y Sociales, } \\
\text { UNAM }\end{array}$ & $\begin{array}{l}\text { Instituto Tecnológico } \\
\text { de Acapulco }\end{array}$ & ESCA, IPN \\
\hline $\begin{array}{l}\text { Escuela Nacional } \\
\text { de Maestros para } \\
\text { la Capacitación del } \\
\text { Trabajo Industrial }\end{array}$ & $\begin{array}{l}\text { Escuela Nacional } \\
\text { Preparatoria, UNAM }\end{array}$ & Universidad ICEL & UNITEC \\
\hline $\begin{array}{l}\text { Escuela Particular } \\
\text { Normal Superior del } \\
\text { Estado }\end{array}$ & $\begin{array}{l}\text { Escuela Nacional } \\
\text { de Antropología e } \\
\text { Historia }\end{array}$ & $\begin{array}{l}\text { Universidad } \\
\text { Autónoma del } \\
\text { Estado de México }\end{array}$ & $\begin{array}{l}\text { Facultad de Ciencias, } \\
\text { UNAM }\end{array}$ \\
\hline $\begin{array}{l}\text { Facultad de } \\
\text { Ingeniería, UNAM }\end{array}$ & $\begin{array}{l}\text { Escuela Nacional de } \\
\text { Música }\end{array}$ & Universidad Marista & $\begin{array}{l}\text { Conservatorio } \\
\text { Nacional }\end{array}$ \\
\hline $\begin{array}{l}\text { Facultad de } \\
\text { Psicología, }\end{array}$ & $\begin{array}{l}\text { Centro de Artes } \\
\text { Musicales }\end{array}$ & & \\
\hline
\end{tabular}

Adicionalmente, se les preguntó a los profesores si estudian actualmente, y las respuestas obtenidas al respecto fueron que 27 se encuentran estudiando, y 48 no (véase Gráfica 3). De quienes contestaron que se encuentran estudiando, ellos cursan lo siguiente (Tabla 7). 
Gráfica 3. Profesores que estudian

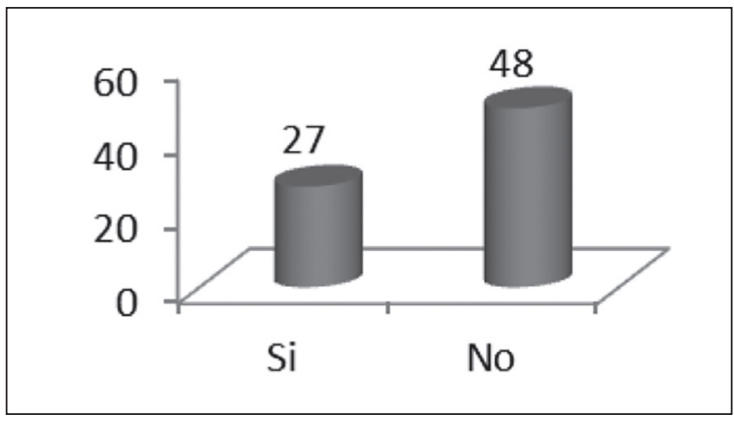

Tabla 7. Estudios que cursan

\begin{tabular}{|l|c|}
\hline Curso & 15 \\
\hline Diplomado & 7 \\
\hline Especialización & 1 \\
\hline Licenciatura & -- \\
\hline Maestría & 4 \\
\hline Doctorado & -- \\
\hline Total & 27 \\
\hline
\end{tabular}

Por último, con respecto a sus generalidades, se les preguntó acerca de su participación en el Programa de Carrera Magisterial y el año en que iniciaron su participación, los datos arrojados se muestran enseguida (Tablas 8 y 9).

Tabla 8. Participación en Carrera Magisterial

\begin{tabular}{|l|l|}
\hline Sí & 29 \\
\hline No & 46 \\
\hline Total & 75 \\
\hline
\end{tabular}

Tabla 9. Año de inicio de participación

\begin{tabular}{|l|l|}
\hline $1993-1999$ & 8 \\
\hline $2000-2006$ & 3 \\
\hline
\end{tabular}


El empleo de la tecnología...

\begin{tabular}{|l|c|}
\hline $2007-2013$ & 12 \\
\hline $2014-$ & 6 \\
\hline Total & 29 \\
\hline
\end{tabular}

Por los números mostrados, se puede comentar que existe un mediano interés en la modalidad general de estar incorporados al Programa de Carrera Magisterial. Asimismo, se puede observar ( $\mathrm{Ta}$ bla 9) que su incorporación en total ha variado; sin embargo, existe un mayor interés entre los años 2007-2013.

\section{COMPORTAMIENTO EN LA BÚSQUEDA DE INFORMACIÓN}

Con respecto al comportamiento que manifiestan estos docentes en su búsqueda de información, se obtuvo que lo primero que hacen cuando tienen una necesidad informativa es recurrir básicamente a las secundarias generales a consultar Internet (34), seguido, de la comunicación con sus colegas (17) y en tercer lugar, consultar su colección personal (15) (Gráfica 4). Pocos son los profesores que asisten como primera opción a la biblioteca, la librería o a eventos (Tabla 10).

Gráfica 4. Recurso informativo que más utiliza el docente

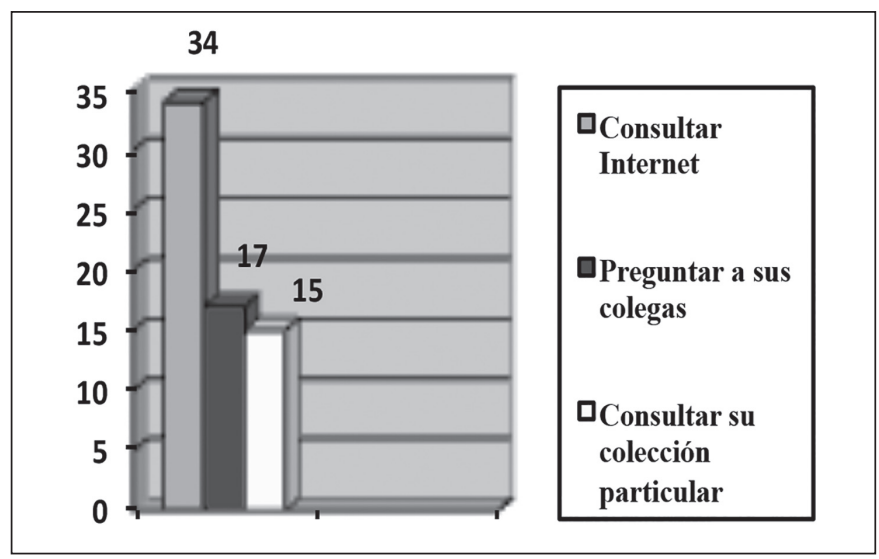


Tabla 10. Recurso informativo más utilizado

\begin{tabular}{|l|c|}
\hline Consultar Internet & 34 \\
\hline Preguntar a sus colegas & 17 \\
\hline Consultar su colección particular & 15 \\
\hline Asistir a la biblioteca & 5 \\
\hline Asistir a una librería & 2 \\
\hline Recurrir a eventos & 2 \\
\hline Total & 75 \\
\hline
\end{tabular}

En lo que corresponde a la frecuencia de utilizar la primera acción de la Gráfica 4 que comentaron, Consultar internet, los profesores de la modalidad general manifestaron que lo emplean diariamente 25, algunas veces a la semana 6 y, solo, los fines de semana 3 .

Otros datos sobre el comportamiento que nos interesa. También se les cuestionó sobre los materiales que más emplean para desarrollar sus actividades. Las respuestas obtenidas fueron las siguientes: 26 docentes recurren principalmente a los libros de carácter general; 15 de ellos a los libros para el maestro; 13 a los avances programáticos, y 8 , hace uso de los libros de texto del alumno (Gráficas 5 y 0 ).

Gráfica 5. Materiales que más utilizan

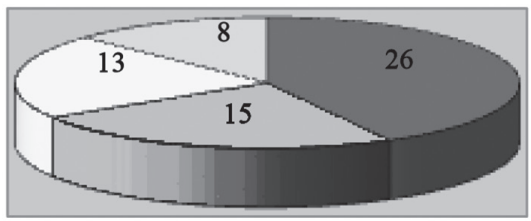

๑Libros de carácter general

口Libros para el maestro

$\square$ Avances programáticos

$\square$ Libros de texto del alumno

A su vez, resultó interesante conocer la frecuencia con que estos profesores emplean los materiales. Los resultados indican que en las secundarias generales 38 de ellos recurren siempre a estos 
materiales; 36 ocasionalmente, y 1 raramente. De igual manera, se les preguntó cómo prefieren consultar esos materiales. Con sus respuestas, se supo que 37 profesores de la modalidad general se inclinan por consultarlos tanto en formato impreso como electrónico; 24 profesores sólo en papel y 14 de ellos en electrónico.

En otro orden de ideas, también se quiso saber sobre el uso de los Centros de Maestros y para ello se les preguntó qué tan comúnmente asistían a ellos. Los datos nos indican que en general asisten poco (Tabla 11), y esto se fundamenta acudiendo a las exposiciones y talleres (22) u otros cursos de actualización (21), que son impartidos en estas unidades como un requisito para que los docentes puedan participar y ser evaluados en el Programa de Carrera Magisterial (Tabla 12).

Tabla 11. Asistencia a los Centros de Maestros

\begin{tabular}{|l|c|}
\hline Mucho & 8 \\
\hline Poco & 59 \\
\hline Nada & 8 \\
\hline Total & 75 \\
\hline
\end{tabular}

Tabla 12.. Razón por la cual asisten a los Centros de Maestros

\begin{tabular}{|l|c|}
\hline A consultar algún libro, revista, etc. & 17 \\
\hline A sacar copias & 1 \\
\hline A hacer trabajos escolares & 2 \\
\hline A pedir asesoría sobre un tema & 4 \\
\hline A consultar las convocatorias & 7 \\
\hline A asistir a exposiciones, talleres, etc. & 22 \\
\hline A formar círculos de estudio & 1 \\
\hline Otra & 21 \\
\hline Total & 75 \\
\hline
\end{tabular}

Además de lo anterior, también se les preguntó a los maestros si consideraban pertinente la organización de cursos dentro de los Centros de Maestros o en otras bibliotecas que los pudieran apoyar en su búsqueda de información (Tabla 13). A este respecto los docentes 
aludieron lo siguiente: 57 de ellos estuvieron a favor y 18 no consideran necesarios los cursos.

Tabla 13. Considera indispensable que se impartan cursos en los Centros de Maestros y en otras bibliotecas

\begin{tabular}{|l|c|}
\hline Sí & 57 \\
\hline No & 18 \\
\hline Total & 75 \\
\hline
\end{tabular}

Algunas de las razones que mencionaron los profesores que respondieron tanto "sí" como "no" son las siguientes.

\begin{tabular}{|c|c|}
\hline Sí & No \\
\hline $\begin{array}{l}\text { - Para recomendarnos títulos de obras o darnos referencias. } \\
\text { - Despejaría la mayoría de dudas con la información que me } \\
\text { ofrezcan. } \\
\text { - Para saber a quién se puede recurrir. } \\
\text { - Para complementar la información para la clase. } \\
\text { - Porque es importante utilizar diversas herramientas para } \\
\text { informarnos. } \\
\text {-Porque son muchos los diversos títulos y autores y uno se } \\
\text { pierde. } \\
\text {-Para saber en concreto dónde buscar y ahorrar tiempo. } \\
\text {-Para estar mejor informados y actualizados. } \\
\text { - Ayudaría a reforzar nuestra práctica docente. } \\
\text {-Para encontrar otros materiales y contenidos. } \\
\text {-Porque algunas informaciones son difíciles de conseguir. } \\
\text { - Así sería más fácil obtener información y tendríamos un } \\
\text { panorama general de los materiales. } \\
\text {-Porque es una competencia básica de los docentes. } \\
\text {-Porque no todos los maestros tienen el conocimiento y } \\
\text { dominio de los temas. } \\
\text {-Para conocer más bibliografía y agilizar la búsqueda. }\end{array}$ & $\begin{array}{l}\text { - Tengo otros medios } \\
\text { para hacerlo. } \\
\text { - Existen otras formas de } \\
\text { capacitarse. } \\
\text { - Hay otros espacios para } \\
\text { buscar información. }\end{array}$ \\
\hline
\end{tabular}

Finalmente, al preguntarles si consideraban importante que dentro de los planes de estudios de las instituciones que se dedican a la formación de docentes debería existir una asignatura que les brinde la adquisición de los conocimientos sobre diversos recursos y fuentes de información, los profesores indicaron lo siguiente: 


\section{3 consideran indispensable esta práctica y 12 contestaron que no}

\section{(Tabla 14).}

Tabla 14. Consideran importante que exista una asignatura sobre los planes de estudio

\begin{tabular}{|l|l|}
\hline Sí & 63 \\
\hline No & 12 \\
\hline Total & 75 \\
\hline
\end{tabular}

Entre los motivos que mencionaron los docentes que dijeron "sí" y los que señalaron "no", se encuentran los siguientes:

\begin{tabular}{|c|c|}
\hline Sí & No \\
\hline $\begin{array}{l}\text { - La investigación se deja de lado. } \\
\text { - Ayudaría a especificar más nuestros } \\
\text { conocimientos. } \\
\text { - Ayudaría mucho más y así podría apoyar a } \\
\text { mis alumnos a adquirir conocimiento. } \\
\text { - Considero que la Internet es muy importan- } \\
\text { te pero debe enseñarse a enseñar. } \\
\text { - No sabemos utilizar adecuadamente los } \\
\text { recursos. } \\
\text { - Yo saldría capacitada y todo sería más } \\
\text { rápido teniendo o contando con dicha } \\
\text { habilidad. } \\
\text { - Serían más accesibles los conocimientos. } \\
\text { - Permitirían que se visualizara todo el } \\
\text { potencial. } \\
\text { - Actualmente existe tanta información que } \\
\text { hay que tener una forma sistemática para } \\
\text { buscarla. } \\
\text { - En la actualidad la tecnología ha superado } \\
\text { los niveles de preparación de los docentes. } \\
\text { - Es indispensable mejorar nuestra prepara- } \\
\text { ción integral educativa. } \\
\text { - No existen cursos referentes a la música. }\end{array}$ & $\begin{array}{l}\text { - Esto ya existe en las escuelas para } \\
\text { maestros. } \\
\text { - Existe, creo yo. Hay una metodología de la } \\
\text { investigación o algo similar. } \\
\text { - Porque a través de los años de estudio se } \\
\text { aprende a investigar. } \\
\text { - Ya se tienen materias como metodología } \\
\text { de la investigación. } \\
\text { - Actualmente existen muchos y diversos } \\
\text { medios de acceso a la información. }\end{array}$ \\
\hline
\end{tabular}




\section{CONCLUSIONES}

Con base en los datos descritos anteriormente, se puede determinar que los rasgos que caracterizan a la comunidad de docentes de nivel secundaria de la modalidad general durante el proceso de búsqueda de información son los siguientes:

- El recurso informativo que más usan para desarrollar sus actividades es la consulta a Internet, y luego la comunicación con sus colegas.

- La mayoría de los profesores emplea diariamente Internet.

- La fuente informativa a la que más acuden para realizar sus actividades son los libros de carácter general y los libros para el maestro.

- Emplean siempre los libros de carácter general y los libros para el maestro al desarrollar sus actividades laborales.

- Los docentes prefieren consultar los materiales que están en formato impreso y electrónico.

- Su asistencia a los Centros de Maestros es baja.

- Consideran indispensable el desarrollo de cursos en los Centros de Maestros y en otras bibliotecas para adquirir nuevas habilidades en la búsqueda de información.

- Del mismo modo, manifiestan su interés por que exista una asignatura en los planes de estudio que les brinde las habilidades y conocimientos para ayudarlos en su búsqueda de información.

Cabe señalar que los resultados muestran que la comunidad de docentes de secundaria de la modalidad general adscrita a la Delegación de Iztapalapa requiere mucha información para realizar sus labores profesionales y académicas; sin embargo, hay que resaltar otros aspectos importantes que permitan corroborar las hipótesis elaboradas, como las siguientes:

La edad no es un factor interno que influye sobre el uso de las fuentes y recursos informativos electrónicos, debido a que la mayo- 
ría de los docentes que se encuentran en las secundarias son adultos que hacen uso del formato electrónico.

La modalidad de enseñanza en la que se encuentra el profesor no lo lleva por sí mismo hacia el uso de determinadas fuentes y recursos informativos impresos o audiovisuales, puesto que la comunidad mostró una tendencia hacia el uso de Internet y también hacia el empleo electrónico de otras fuentes informativas: libros de carácter general y los libros para el maestro.

La búsqueda de información que los profesores han desarrollado en su mayoría, como ya se ha mencionado, se encuentra orientada principalmente hacia el uso de Internet y de los libros de carácter general. Los Centros de Maestros no son primordiales para ellos, ni tampoco recurrir a la comunicación con sus colegas.

\section{Recomendaciones}

Como las secundarias generales que se estudiaron presentan un mismo patrón de comportamiento informativo, sería deseable realizar otras investigaciones que analicen un número mayor de secundarias tomando como referencia a otras delegaciones, con el propósito de profundizar acerca del objeto de estudio, sobre todo debido a la ausencia de este tipo de investigaciones en nuestro país. En este ánimo y considerando que nuestra profesión es de vital importancia para que los servicios de información y bibliotecarios tengan como finalidad satisfacer las necesidades de los usuarios, sugiero que los Centros de Maestros y las Bibliotecas Públicas tomen en cuenta la importancia de aplicar estudios de usuarios a sus comunidades, para conocer mejor el nivel de satisfacción hasta hoy alcanzado y determinar sí los servicios, colecciones e instalaciones ofrecidos satisfacen las necesidades de información de sus comunidades.

También cabe destacar, que debido al gran desarrollo tecnológico que se presenta en nuestro siglo y en los sistemas de recuperación de información, existe la necesidad de tener al frente de las unidades de información a profesionales preparados y actualizados que ofrezcan servicios bibliotecarios y de información que 
tengan presente el mejoramiento continuo de las colecciones $\mathrm{y}$, desde luego, de los servicios y el equipo en las distintas unidades de información, y que desarrollen cursos de alfabetización informativa que les permita a los docentes contar con las habilidades, capacidades y destrezas necesarias para buscar y localizar la información que requieren.

\section{BiBLIOGRAFÍA}

Calva González, J. J. (2014). Las necesidades de información: fundamentos teóricos y métodos, México: UNAM, Centro Universitario de Investigaciones Bibliotecológicas.

Ciriglilano, G. F. (1974). La conducta informativa en universitarios argentinos: investigación sobre la habilidad y capacidad de los jóvenes graduados universitarios para manejar y utilizar las fuentes de información bibliográfica. Buenos Aires: Universidad de Buenos Aires, Facultad de Filosofía y Letras. Centro de Investigaciones Bibliotecológicas.

Krikelas, J. (1983). "Information-Seeking Behavior: Patterns and Concepts". Drexel Library Quarterly, vol. 19, núm. 2, 5-20.

Martínez N. (2009). "La SEP recompensa a maestros reprobados”. El Universal, 7 de diciembre, 2009.

- (2010). "Estudiar interesa poco a los maestros". $E l$ Universal, 26 de abril, 2010.

SEP. Subsecretaría de Educación Básica (2010). Dirección General de Formación Continua de Maestros en Servicio. Formación continua y superación profesional para maestros de educación básica en servicio. Catálogo nacional 2012-2013. México: SEP, DGFCMS. 
SEP. Secretaria de Educación Pública en el D. F. (2011). Estadísticas: 2011-2012. Secundarias. Disponible en: <http:// www2.sepdf.gob.mx/inf_sep_df/estadisticas/ei2011_ 2012.jsp $>$. [Fecha de consulta: 9 de marzo 2014].

Wilson, T. D. (2000). "Human Information Behavior". Informing Science. Special Issue, vol. 3, núm. 2, 49-55. 


\section{Anexo}

\section{CÉDULA DE ENTREVISTA}

Objetivo: Conocer el comportamiento en la búsqueda de información que se encuentra presente en la comunidad de docentes de nivel secundaria en la Delegación de Iztapalapa.

\section{Nombre de la escuela:}

Modalidad:

Número de entrevista:

I) Datos Generales

1. Género:

$\square$ Femenino

$\square$ Masculino

2. Estado civil:

$\square$ Casada (o)

$\square$ Soltera (o)

$\square$ Divorciada (o)

$\square$ Viuda (o)

$\square$ Unión libre

3. ¿Entre qué rango se encuentra su edad?

$\square 20$ años a 25 años

$\square 26$ años a 30 años

$\square 31$ años a 40 años

$\square 41$ años a 50 años

$\square$ Más de 50 años

4. ¿Cuántos años tiene laborando dentro del sistema educativo?

$\square$ Menos de 5 años

$\square$ Entre 6 a 10 años

$\square$ Entre 11 a 15 años

$\square$ Entre 16 a 20 años

$\square$ Entre 21 a 25 años

$\square$ Más de 26 años 
5. ¿Cuál es el número de horas que labora semanalmente?

$\square$ Menos de 10 horas

$\square$ De 10 a 20 horas

$\square$ De 20 a 30 horas

$\square$ De 30 a 42 horas

6. ¿Cuál o cuáles son las asignaturas que imparte?

$\square$ Matemáticas

$\square$ Español

$\square$ Ciencias (énfasis en biología)

$\square$ Ciencias (énfasis en física)

$\square$ Ciencias (énfasis en química)

$\square$ Geografía de México y el Mundo

$\square$ Historia

$\square$ Formación cívica y ética

$\square$ Lengua extranjera

$\square$ Educación física

$\square$ Asignatura estatal

$\square$ Orientación vocacional

$\square$ Tecnología (Informática)

$\square$ Artes plásticas y/o artísticas

$\square$ Taller (¿Cuál?)

7. ¿En qué grado se encuentra impartiendo su(s) asignatura(s)?

$\square$ Primer Grado

$\square$ Segundo Grado

$\square$ Tercer Grado

8. ¿De qué institución es egresada(o)?

$\square$ Escuela Normal Superior de México

$\square$ Colegio de Pedagogía (UNAM)

$\square$ Universidad Pedagógica Nacional

$\square$ Otra. Especifique

9. ¿Estudia actualmente?

$\square$ Sí

$\square$ No

Si su respuesta fue afirmativa:

10. ¿Qué estudia y en dónde se encuentra estudiando? 


\section{Usuarios de la Información...}

11. ¿Se encuentra participando en el programa de carrera magisterial?

$\square \mathrm{Si}$

$\square$ No

Si su respuesta fue afirmativa:

12. ¿En qué año inició su participación?

II) Con respecto a su búsqueda de información

13. Cuando en ud. se origina una necesidad de información, ¿qué acción realiza en un primer momento? Por favor indique con el número (1), la que emplea como primera instancia y, con el número (8), la que menos emplea.

- Preguntar a sus colegas

- Consultar Internet.

- Consultar su colección particular.

- Asistir a la biblioteca (Biblioteca escolar, Biblioteca Pública, Centro de Maestros). ..( )

- Confiar en su experiencia y conocimientos personales.

- Recurrir a eventos (congresos, reuniones, talleres, encuentros, etc

- Asistir a una librería.

- Acudir a un puesto de periódicos..

- Otra. Especifique

14. ¿Con qué frecuencia realiza la acción que indicó con el número (1)?

$\square$ Diariamente

$\square$ Algunas veces a la semana

$\square$ Solo los fines de semana

$\square$ Solo cuando tengo una necesidad o inquietud

15. ¿Indique del (1) al (10) los materiales que utiliza con mayor frecuencia para desarrollar sus actividades laborales? El número (1) indica el material que más emplea y el número (10) el que menos emplea.

- Libros de carácter general.

- Libros para el maestro

- Libros de apuntes para el maestro.

- Libros de texto del alumno.

- Ficheros de actividades didácticas..

- Avances programáticos................................................................................ ( )

- Notas de clase....................................................................................... ( )

- Notas de cursos, seminarios, ponencias, talleres, reuniones, congresos etc. 
- Material No impreso como: bases de datos, audiocintas, videocintas, discos compactos, televisores, etc.

- Artículos de revistas.

- Boletines informativos.

- Anuarios.

- Informe.

- Manuales.

- Enciclopedias.

- Diccionarios.

- Atlas.

- Periódicos

- Folletos.

- Otro. Especifique

16. ¿Qué tan frecuente emplea el material que señaló con el número (1)?

$\square$ Siempre

$\square$ Ocasionalmente

$\square$ Raramente

17. ¿De qué manera prefiere consultar el material que señaló con el número (1)?

$\square$ Impreso

$\square$ Electrónico

$\square$ Ambos

18. ¿Qué tan asiduo es a asistir a los Centros de Maestros?

$\square$ Mucho

$\square$ Poco

$\square$ Nada Pasar a la pregunta 21

19. ¿A qué ha asistido a los Centros de Maestros?

$\square$ A consultar algún libro, revista, etc.

$\square$ A sacar fotocopias

$\square$ A hacer trabajos escolares

$\square$ A pedir asesoría sobre un tema

$\square$ A consultar las convocatorias

$\square$ A asistir a exposiciones, talleres, etc.

$\square$ A formar círculos de estudio

$\square$ Otra. Especifique: 
Usuarios de la Información...

20. ¿Considera indispensable que se desarrollen cursos dentro de los Centros de Maestros o en otras bibliotecas que le asistan para la búsqueda de la información que necesita?

$\square$ Sí

$\square$ No

$\square$ Porque

21. ¿Cree usted que sería importante que dentro de los planes de estudio de las instituciones que se dedican a la formación de los docentes exista una asignatura que posibilite la adquisición de conocimientos sobre diversos recursos y fuentes para la búsqueda y recuperación de información?

$\square$ Sí

$\square$ No

$\square$ Porque

¡Gracias por su participación! 


\title{
La comunidad de docentes de educación básica y su investigación dentro de los estudios de usuarios de la información
}

\author{
Angélica Guevara Villanueva \\ Universidad Nacional Autónoma de México
}

\section{INTRODUCCIÓN}

$\tau$ a educación, de acuerdo con Zorilla, "[...] es un proceso cultural por el cual una sociedad transmite a las nuevas generaciones su modo de ver el mundo, sus conocimientos y anhelos...[lo que permite] el desarrollo de la individualidad, a través de la interacción con otros seres humanos.1

Como sistema educativo, la educación suele variar de acuerdo con el contexto de cada país. Por ejemplo, la UNESCO señala que más allá del nivel primaria, la duración de la escolarización obligatoria muestra una gran variabilidad entre las naciones; mientras que en 35 países sólo se exigen 7 años de educación obligatoria, en 55 estados este requisito asciende a 8 o 9 años, en tanto que en 105 regiones fluctúa entre 10 y 12 años. $^{2}$

1 M. Zorrilla Fierro y M. T. Férnández Lomelín, "Conceptos y contexto. Elementos que orientan el estudio". 48.

2 Compendio Mundial de la educación 2011. Comparación de las estadísticas de educación en el mundo, 18. 
En México, la educación básica que satisface las necesidades educativas elementales se encuentra integrada por los niveles de preescolar, primaria y secundaria. ${ }^{3}$ Aunque, en febrero del 2012, se dio a conocer mediante decreto la reforma a los Artículos 3 y 31 constitucionales donde se aprueba la obligatoriedad en la educación desde el nivel preescolar hasta el bachillerato. ${ }^{4}$

En el nivel secundaria de nuestro país, con la firma del Acuerdo Nacional para la Modernización Educativa de la Educación Básica en el año de 1992, se emprendieron diversas acciones para mejorar y elevar la calidad de la educación, una de las cuales fue la

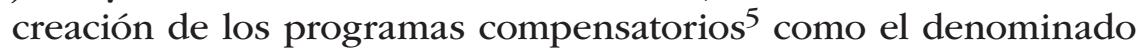
Carrera Magisterial en 1993, y cuyos objetivos específicos señalan:

- Fomentar en los docentes el desarrollo de estrategias educativas y procedimientos didácticos para mejorar el aprendizaje.

- Reconocer las actividades extra-clase que realizan los docentes para favorecer el desarrollo integral del alumno.

- Privilegiar la capacitación, actualización y superación profesional del docente, mediante su participación en procesos de formación continua que contribuyan a mejorar su desempeño. ${ }^{6}$

Así, y como consecuencia de este hecho, la comunidad de docentes de nivel secundaria, objeto de estudio de este ensayo, requirió reforzar sus conocimientos teóricos-prácticos debido a que el programa mencionado evalúa los siguientes factores: antigüedad, grado

3 C. Vélaz de Medrano Ureta, Los retos de la educación básica en América Latina, 13.

4 J. Ramos Pérez,"Publican decreto sobre bachillerato obligatorio". El Universal, 9 de febrero del 2012.

5 Algunos programas fueron: el Programa para Abatir el Rezago Educativo (PARE) en 1992; el Programa para Abatir el Rezago en Educación Básica (PAREB) en el periodo 1994-1999, que sustituyó al PARE y el Programa Integral para Abatir el Rezago Educativo (PIARE) que comenzó en 1995 con una proyección hacia el año 2000; R. Mercado, "La evaluación de profesores de educación básica en México: la carrera magisterial", Avance y perspectiva, 57-68.

6 Programa Nacional de Carrera Magisterial: Lineamientos generales, 7. 
académico, preparación, actualización y superación profesional, desempeño profesional y aprovechamiento escolar.

Precisamente en su preparación, actualización, superación profesional y desempeño docente se hace evidente el uso de la información y, con ello, la oportunidad de investigar acerca de las necesidades de información y el comportamiento informativo que desarrollan los profesores de educación secundaria, como resultado de su actividad laboral y el de las políticas educativas imperantes en materia de evaluación.

Derivado de lo anterior, surgió la inquietud por realizar una primera aproximación que explorara las investigaciones llevadas a cabo hasta el momento a nivel internacional, lo cual permitirá observar las experiencias que tratan de explicar la manera en que actúa la comunidad de profesores de nivel secundaria ante la información, y de este modo, determinar sus necesidades y comportamientos informativos, todo ello con la finalidad de brindar alternativas que favorezcan los servicios bibliotecarios y de información que comúnmente utilizan los docentes.

Surgieron así las siguientes interrogantes para el desarrollo del trabajo: ¿Existen investigaciones en nuestro ámbito disciplinar que se interesen por estudiar las necesidades de información y el comportamiento informativo en la comunidad de docentes de nivel secundaria?

¿Cuáles han sido los resultados más relevantes que han contribuido a conocer estas necesidades y el comportamiento dentro de la comunidad de profesores de educación básica del nivel secundaria?

En función de lo planteado, los objetivos que se persiguen son los siguientes:

- Identificar las investigaciones efectuadas en torno a las necesidades de información y el comportamiento informativo a nivel mundial.

- Determinar el grado de desarrollo de las investigaciones realizadas con relación a las necesidades de información y el comportamiento informativo. 
Con base en estos argumentos, el trabajo se desarrollará de manera deductiva mediante la realización de una investigación documental vinculada hacia el conocimiento de las necesidades de información y el comportamiento informativo de la comunidad de docentes de educación secundaria, lo cual forma parte de una investigación más profunda que se realiza dentro de los estudios de doctorado en el Posgrado de Bibliotecología y Estudios de la Información de la Facultad de Filosofía y Letras de la UNAM.

Para estructurar este contenido, se parte de los conceptos desarrollados sobre las necesidades de información y el comportamiento informativo. Enseguida, se ofrece una descripción de la comunidad de docentes de educación básica del nivel secundaria; posteriormente se dan a conocer algunos datos cuantificables de las investigaciones realizadas dentro de esta comunidad a nivel internacional y, por último, se presentan las consideraciones finales.

\section{CONCEPTUALIZACIÓN DE LOS TÉRMINOS: NECESIDADES DE INFORMACIÓN Y COMPORTAMIENTO INFORMATIVO}

\section{Antecedentes Generales}

A manera de antecedente, se puede hablar sobre las necesidades de información y el comportamiento informativo, lo que significa recorrer un largo camino desde décadas atrás; hecho que se puede confirmar a través de la literatura especializada publicada en torno a estas líneas de investigación.

Los referentes históricos que marcan el inicio con relación a esta temática se pueden ubicar con la consideración de Sánz, ${ }^{7}$ quien subraya que los primeros estudios de usuarios se comenzaron a realizar hacia 1920 en el ámbito norteamericano. La década de los cincuenta se vio fuertemente favorecida con la elaboración de in-

$7 \quad C f r$. E. Sánz Casado, "La realización de estudios de usuarios: una necesidad urgente", 158; Manual de estudios de usuarios, 45-46. 
vestigaciones que contemplaban las necesidades de información como un objeto de estudio esencial para la bibliotecología. ${ }^{8}$

En los años setenta del siglo pasado se marca el punto donde los estudios se dirigieron a examinar el uso de sistemas particulares de información: su eficiencia y efectividad. ${ }^{9}$ En los años noventa, la ampliación de teorías conceptuales acerca del fenómeno de estas necesidades de información continuó en la misma dirección creciente de investigaciones vinculadas con las tecnologías de información y su utilización en la recuperación de información.

Concretamente en Latinoamérica, los estudios han sido escasos y no fue sino hasta finales de la década de los noventa cuando se detectan trabajos consolidados, cuyas líneas de investigación se acercan más decididamente a la rigidez para abordar el estudio de las necesidades de información. Países como Uruguay, Cuba, Costa Rica, Brasil, Argentina, Colombia y México dan cuenta de la atención orientada hacia las investigaciones del tema. Una prueba evidente de lo anterior fue la elaboración del Modelo NEIN. ${ }^{10}$

8 Un ejemplo de esto se puede apreciar en los trabajos de E. Tornudo, "Professional Reading Habits of Scientists Engaged in Research as Revealed by an Analysis of 130 Questionnaires", M.S Thesis, Carnegie Institution of Technology, 1953; R. R. Shaw, Pilot Study on the Use of Scientific Literature by Scientists, Washington, DC: National Science Foundation, 1956; R. E. Maizell, Information Gathering Patterns and Creativity. New York: Columbia University.

9 Véanse los trabajos de: D. Crane, "Information Needs and Uses", Annual Review of Information Science and Technology, vol. 6, 1971, 3-29; J. Martin, "Information Needs and Uses", Annual Review of Information Science and Technology, vol. 9, 1974, 3-23; S. Crawford, "Information Needs and Uses", Annual Review of Information Science and Technology, vol. 13, 1978, 61-81.

10 Véanse las obras de J. J. Calva González, Las necesidades de información: fundamentos teóricos y métodos, México: UNAM, Centro Universitario de Investigaciones Bibliotecológicas; "La investigación sobre las necesidades de información en comunidades de usuarios" Investigación bibliotecológica: Archivonomía, Bibliotecología e Información, 22-55. 


\section{Conceptos}

En lo que corresponde a los conceptos de necesidades de información y comportamiento informativo, es preciso reconocer que estos ya han sido tratados por diferentes especialistas dentro de la bibliotecología, (Krikelas, 1993; Sanz, 1994; Izquierdo, 1998; Wilson, 2000; Hernández, 2001 y Calva, 2004) lo que ha conducido a superar definiciones nominales ${ }^{11}$ que han implicado el desarrollo de estudios más complejos con un rigor indispensable dentro del trabajo científico y cuyos resultados han dado cabida a la creación de una línea temática vinculada al estudio del usuario y al fenómeno de las necesidades de información. ${ }^{12}$

Por esto mismo, dentro del ámbito bibliotecológico se entiende como necesidad de información:

La carencia de conocimientos e información sobre un fenómeno, objeto, acontecimiento, acción o hecho que tiene una persona,

11 "Una definición nominal solamente orienta acerca del sentido que tiene la palabra definida utilizando sinónimos o palabras más usuales que aproximen al significado. El procedimiento es recurrir a la etimología de la palabra”. R. Gutiérrez Sáenz, Lógica: conceptos fundamentales, 85.

12 Para profundizar con relación a esta temática, véanse los trabajos de J. J. Calva González: "Las necesidades de información: la importancia de su estudio", Biblioteca Universitaria. Boletín Informativo de la Dirección General de Bibliotecas", vol.9, núm. 3, 1994, 33-38; "Surgimiento y manifestación de las necesidades de información en los investigadores”, Investigación Bibliotecológica: Archivonomía, Bibliotecología e Información, vol.9, núm. 19, 1995, 17-29; "Las necesidades de información del usuario en la automatización de unidades de información", Biblioteca Universitaria. Boletín Informativo de la Dirección General de Bibliotecas, vol. 1, núm. 1, 1998, 15-20; "El comportamiento en la búsqueda de información de los investigadores del área de humanidades y ciencias sociales", Investigación Bibliotecológica: Archivonomía, Bibliotecología e Información, vol. 1, núm. 30, 2001, 29-64; Las necesidades de información: fundamentos teóricos y métodos. México: UNAM, Centro Universitario de Investigaciones Bibliotecológicas, 2004. "La investigación sobre las necesidades de información en comunidades de usuarios, Investigación Bibliotecológica: Archivonomía, Bibliotecología e Información, vol. 18, núm. 37, 2004, 23-55. 
producidos por factores externos e internos, que provocan un estado de insatisfacción, misma que el sujeto se ve motivado a satisfacer a través de presentar un comportamiento para buscar la satisfacción. ${ }^{13}$

Asimismo, González expresa que es:

El estado del usuario que refleja la falta de correspondencia de sus conocimientos respecto a las condiciones de su actividad. En este punto de vista se expresa la existencia de la relación entre el conocimiento y la información. ${ }^{14}$

En las definiciones asentadas sobresalen algunos aspectos como carencia, uso, información y sujeto, los cuales son puntos de partida para profundizar en el estudio de las necesidades de información y, con ello, en el interés por la estructuración de un marco teórico requerido para el desarrollo de la disciplina bibliotecológica.

Vinculado a las necesidades de información se encuentra el término comportamiento informativo, el cual se puede ubicar como la segunda fase del fenómeno de las necesidades de información. Así, dentro de esta perspectiva, Krikelas menciona que el comportamiento este es la actividad que realiza un individuo para identificar un mensaje que satisfaga una necesidad percibida como tal. ${ }^{15}$

Por su parte, Izquierdo lo conceptualiza como:

Aquellas actitudes y valores del usuario con respecto a la información en general y a las relaciones con las unidades de información en particular; también, contribuye a valorar los fundamentos del desarrollo de la búsqueda y de comunicación; es decir, la manera como el usuario selecciona las fuentes, la formulación de sus pre-

13 J. J. Calva González, Las necesidades de información: fundamentos teóricos y métodos, 68.

14 E. González Suárez, "Sistema de factores de la conducta del usuario", 11.

15 J. Krikelas, "Information-Seeking Behavior: Patterns and Concepts, 6. 
guntas, cómo elige la información y la preferencia por ciertos medios de información. ${ }^{16}$

En síntesis, el comportamiento informativo comprende la suma de la conducta humana en relación con las fuentes y recursos de información, incluidos en una búsqueda de información activa y pasiva. Pero la comprensión del comportamiento informativo no es tarea fácil, pues los patrones son muy diversos tal y como la personalidad del ser humano es diversa y multifacética, por ello existen varios comportamientos en la búsqueda de información que depende de los sujetos y los grupos que estos conforman, y por lo cual se puede entender que cada comunidad tiene necesidades de información específicas y comportamientos informativos concretos.

\section{COMUNIDAD DE PROFESORES}

La educación secundaria contempla objetivos particulares mediante los cuales se reconoce su trascendencia dentro del Sistema Educativo Nacional, entre los que destacan:

a) Constituirse como un ciclo de naturaleza comprensiva y conciliar su original carácter propedéutico.

b) Adecuarse a las características y necesidades del adolescente.

c) Establecer una continuidad efectiva con la primaria y constituirse en el último nivel del ciclo básico. ${ }^{17}$

Operativamente estos objetivos requieren de la participación de recursos materiales, infraestructura, programas y, ante todo, de una comunidad de docentes capaz de transmitir, orientar y conso-

16 M. Izquierdo Alonso, J. Ruíz Abellán y J. T. Pinera Lucas, Los estudios de usuarios en los programas de gestión de calidad. Propuesta de un marco teórico integrador para el estudio del usuario de información.

17 A. I. Santos del Real, La educación secundaria: perspectivas de su demanda, 19 . 
lidar los conocimientos necesarios dentro de este ciclo educativo para, de esta manera, contribuir al desarrollo educativo nacional y, en consecuencia, a la evolución social de quienes acuden a las aulas. Este grupo social de profesores es tan importante que ha propiciado en miles de alumnos, a lo largo de varias generaciones, un pensamiento crítico y preparado para tener una vida propia, y representa uno de los motivos que ha generado el interés para hacer su análisis.

Es necesario reconocer que su intervención en el proceso de enseñanza-aprendizaje en la educación secundaria, lo vuelve una figura protagónica en donde su preparación y actualización se convierten en dos actividades que resultan ineludibles en la conformación de este profesional de la enseñanza dentro de un contexto educativo cada vez más competitivo. Por ello, resulta esencial que los docentes posean un perfil para el adecuado aprovechamiento de sus capacidades, en beneficio de quienes reciben el aprendizaje. Entre las cualidades que mayormente destacan entre los docentes, se encuentran las siguientes:

- Trabajar de forma contraria a la tradicional.

- Comprender los nuevos contenidos de las propuestas curriculares.

- Saber analizar la realidad en que se desarrolla la tecnología.

- Comprender los aspectos didácticos para su enseñanza.

- Aprender nuevas formas de planificación educativa de las propuestas curriculares para la enseñanza-aprendizaje en el aula.

Es fundamental contar con un nuevo profesor que exprese su necesidad de acuerdo con los retos y avances de las nuevas tecnologías y el proceso de la información, con el fin de responder con idoneidad a las perspectivas económicas, nacionales y globales de nuestra actualidad. Estos son algunos factores que nos permitirán cumplir ciertos indicadores con los docentes para el nuevo milenio, tomando en cuenta las situaciones actuales hacia una nueva revolución tecnológica, con características diferentes a las anterio- 
res, y que representa a lo que se ha definido como la sociedad de la información.

En este entorno, los profesores deben propiciar que las capacidades de los alumnos cuyas edades fluctúan entre los 11 y 15 años impulsen el saber-hacer y el saber-ser, lo que define a un profesor con nuevas perspectivas, con una formación científica, humanística, tecnológica y pedagógica para trabajar en los espacios educativos en donde se imparten la distintas actividades formativas, para de este modo ofrecer respuesta a la realidad en la que se encuentran sus alumnos.

Para alcanzar lo anterior, se necesita el dominio del conocimiento del docente en aspectos relacionados con la interpretación y aplicación de propuestas curriculares y planeación didáctica, así como de formas de organización para el trabajo que sean utilizadas para solucionar, a partir de la educación elemental, las exigencias de un mundo globalizado en el que la competitividad y la calidad son normas que deben ser cubiertas. ${ }^{18}$

Pero además de las anteriores expectativas sobresale un rasgo que figura como eje rector para el cumplimiento de los propósitos que los maestros de nivel secundaria deben ser capaces de cubrir, específicamente me refiero al uso y manejo de la información, donde aparecen como recursos que se encuentra incorporados en cada uno de los procesos que laboral, profesional y académicamente realizan los profesores.

Más concretamente, dentro de la dinámica de la búsqueda, manejo y uso de la información se esclarece la manera en cómo identifican sus necesidades de información así como la actitud, la metodología y las fuentes que utilizan para satisfacer estas necesidades de información.

En un mundo como el actual, la información como recurso se encuentra en cada una de las actividades que desarrolla la comu-

18 Para el caso de los educadores de nivel secundaria en México, existen requisitos que deben ser cumplidos para ejercer de manera formal en las instituciones educativas en nuestro país. Véase: Concurso Nacional para el otorgamiento de plazas docentes 2012-2013. 
nidad docente del sector educativo que se está analizando, aunque en nuestro país, en comparación con otros, el interés por investigar las necesidades de información y el comportamiento informativo de este sector, pareciera no mantener una atención que conduzca a determinar el análisis de la problemática con la que se enfrentan los profesores de secundaria en las líneas de investigación —necesidades y comportamiento- mencionados.

Tal vez la ausencia de este tipo de investigaciones imposibilita no solo el reconocimiento de las necesidades y la manera en cómo son cubiertas, sino la generación adecuada de decisiones que fortalezcan el diseño y la aplicación de políticas educativas que les permitan a los docentes asegurar el uso y manejo correcto de la información en cada uno de los procesos y actividades que realizan en su práctica docente; consecuentemente, esto conduce a realizar el análisis de las diversas investigaciones hechas a nivel mundial y cuyos resultados pueden favorecer tanto a los docentes como los alumnos, a las unidades de información y al sistema educativo en general.

Identificación de las investigaciones realizadas a nivel internacional acerca de las necesidades de información y comportamiento informativo en los profesores de educación secundaria

En este apartado se dan a conocer las investigaciones que se han hecho a nivel mundial con referencia a las necesidades de información y comportamiento informativo de la comunidad de docentes de nivel secundaria. De este modo, se establecen algunos indicadores con el propósito de describir de manera más adecuada la información obtenida, siendo estos los siguientes: cronología de las investigaciones, distribución geográfica, líneas temáticas, tipos de fuentes, técnicas e instrumentos empleados e idioma.

Para identificar las investigaciones que se han elaborado dentro de esta comunidad académica de secundaria, cabe mencionar que 
primero se determinaron varios descriptores ${ }^{19}$ con la ayuda de algunos tesauros especializados en la disciplina bibliotecológica y en la educación. ${ }^{20}$

Posteriormente se procedió a identificar los recursos bibliográficos que pudiesen ayudar en la pesquisa. Así, los recursos de información que se utilizaron para realizar la labor de búsqueda fueron las bases de datos Library and Information Science Abstracts (LISA), Library and Information Science and Technology Abstract (LISTA) $y$ Library Literature and Information Science, debido a su cobertura internacional, su especialización en el área y la diversidad de fuentes de información que contienen.

Asimismo, fueron consultadas otras bases de datos como Education Resources Information Center (ERIC), que proporciona acceso a la literatura relacionada con la educación y la base de datos Información Bibliográfica y Latinoamericana (INFOBILA) que contiene la literatura en bibliotecología que se produce en América Latina y el Caribe.

Por otra parte, se consideró importante consultar la Red de Revistas Científicas de América Latina y el Caribe, España y Portugal: DIALNET y REDALYC, por ser portales bibliográficos que dan visibilidad a la literatura científica hispana en Internet y acceso a una base de datos exhaustiva, interdisciplinar y actualizada que

19 Los descriptores que se seleccionaron fueron los siguientes con su respectivo término en inglés: necesidades de información, comportamiento informativo, comportamiento en la búsqueda de información, profesores de secundaria y/o docente de secundaria, escuelas secundarias, fuentes de información y/o recursos de información, uso de la información y patrones de comportamiento.

20 Los tesauros utilizados fueron los siguientes: S. Peniche de Sánchez McGregor, (comp), Vocabulario controlado en bibliotecología, ciencia de la información y temas afines, México: UNAM, Centro Universitario de Investigaciones Bibliotecológicas, 1992; C. Naumis Peña et. al., Tesauro latinoamericano en ciencia bibliotecológica y de la información, México: UNAM, Centro Universitario de Investigaciones Bibliotecológicas, 1999; Tesauro de la UNESCO, Disponible en: <http://databases.unesco.org/thessp/2011)>. [Fecha de consulta: 13 de octubre 2012]. 
aborda áreas en las que se encuentran la educación y las ciencias de la información. Por último, se recurrió a realizar una búsqueda en la Web con el motor de Google.

A continuación, se presentan en la Tabla 1 el número de artículos recuperados en las fuentes seleccionadas.

Tabla 1

\begin{tabular}{|l|c|}
\hline \multicolumn{1}{|c|}{ Recurso bibliográfico } & Resultados \\
\hline LISA & 26 \\
\hline LISTA & 39 \\
\hline Library Literature \& Information Science & 6 \\
\hline ERIC & 13 \\
\hline DIALNET & 2 \\
\hline REDALYC & 10 \\
\hline Google & 12 \\
\hline Total & 108 \\
\hline
\end{tabular}

Posteriormente, a los 108 documentos recuperados e identificados se les hizo una revisión selectiva con base en algunos criterios que se determinaron, estos fueron:

- Investigaciones específicas de la comunidad de profesores de secundaria.

- Estudios de las necesidades de información y del comportamiento informativo publicados en cualquier país del orbe.

- Documentos en idioma español, inglés, francés y portugués.

- Investigaciones teóricas o aplicadas.

Finalmente, la cantidad de documentos seleccionados fue de 45; mismos que se presentan a continuación.

Cronología de las investigaciones

Con respecto al año en que fueron publicadas las investigaciones, es importante resaltar que hubo una mayor propensión de productividad en la década del 2000, esto obedece a que durante este periodo 
se alcanzó $60 \%$ de investigaciones con relación a los estudios realizados anteriores a este lapso (Véase Tabla 2).

Tabla 2

\begin{tabular}{|c|c|c|}
\hline Década & Número de investigaciones & Porcentaje \\
\hline 1960 & 4 & $8.8 \%$ \\
\hline 1970 & 4 & $8.8 \%$ \\
\hline 1980 & 4 & $8.8 \%$ \\
\hline 1990 & 6 & $13.3 \%$ \\
\hline 2000 & 27 & $60.0 \%$ \\
\hline Total & 45 & $100 \%$ \\
\hline
\end{tabular}

A manera de contraste, en la década de los noventa, las investigaciones dieron a conocer un porcentaje del $13.3 \%$, que si bien, no deja de ser bajo en comparación con la década del 2000, resulta muy significativo para comprender el momento de transición existente que atrae la atención de los estudios de usuarios y, con esto, incorpora a la comunidad de profesores en investigaciones relacionadas con sus necesidades y comportamiento informativo.

\section{Distribución geográfica}

Dentro de este indicador, se logra apreciar que los continentes en los cuales se han elaborado investigaciones referentes a las temáticas de interés comprenden al europeo, americano, africano y asiático. Sin embargo, específicamente en cuanto a países, los Estados Unidos sostienen una gran ventaja por encima de otros como Argentina, Suecia, Grecia, por mencionar algunos, con un total de $44.4 \%$ de investigaciones, seguidos a una distancia lejana por Canadá con 8.8\%. En el tercer lugar aparecen dos naciones (Brasil y España) con $6.6 \%$ respectivamente y en cuarto lugar se encuentran Escocia, Australia y México, con 4.4\%, cada uno en cuanto a productividad de investigaciones (Véase Tabla 3). 
Tabla 3

\begin{tabular}{|l|c|c|}
\hline \multicolumn{1}{|c|}{ País } & Número de investigaciones & Porcentaje \\
\hline África Subsahariana* & 1 & $2.2 \%$ \\
\hline Argentina & 1 & $2.2 \%$ \\
\hline Australia & 2 & $4.4 \%$ \\
\hline Brasil & 3 & $6.6 \%$ \\
\hline Canadá & 4 & $8.8 \%$ \\
\hline Escocia & 2 & $4.4 \%$ \\
\hline España & 3 & $6.6 \%$ \\
\hline Estados Unidos & 20 & $44.4 \%$ \\
\hline Grecia & 1 & $2.2 \%$ \\
\hline Malasia & 1 & $2.2 \%$ \\
\hline México & 2 & $4.4 \%$ \\
\hline Nigeria & 1 & $2.2 \%$ \\
\hline Nueva Zelanda & 1 & $2.2 \%$ \\
\hline Reino Unido** & 1 & $2.2 \%$ \\
\hline Sudáfrica & 1 & $2.2 \%$ \\
\hline Suecia & 1 & $2.2 \%$ \\
\hline Total & 45 & $100 \%$ \\
\hline
\end{tabular}

* África subsahariana también denominada África Negra está integrada por lo siguientes países: República Democrática del Congo, República del Congo, República Centroafricana, Ruanda, Burundi, Chad, Camerún, Gabón, Guinea Ecuatorial, Kenia, Tanzania, Uganda, Yibuti, Eritrea, Etiopía, Somalia, Sudán del Sur, Angola, Botsuana, Lesoto, Malaui, Mozambique, Namibia, Sudáfrica, Suazilandia, Zambia, Zimbabue, Benín, Burkina Faso, Camerún, Chad, Costa de Marfil, Guinea Ecuatorial, Gabón, Gambia, Ghana, Guinea, Guinea-Bissau, Liberia, Malí, Mauritania, Níger, Nigeria, Senegal, Sierra Leona, Sudán y Togo.

** El estudio incluyó a los países de Escocia, Gales e Inglaterra.

Geográficamente, este dato revela que Estados Unidos aparece como líder en estudios con referencia a las temáticas en las que prolifera, lo que significa, entre otras razones, que le otorgan un alto nivel de importancia al uso de la información para su progreso, así como al avance tecnológico que forma parte de esta evolución, y, por supuesto, al interés que le dan a las unidades de información y a los usuarios en todos sus niveles.

No obstante, esto no quiere decir que el resto de los países no realicen investigaciones al respecto, sino más bien, es casi imposi- 
ble saber de ellos porque no hacen públicas sus investigaciones en medios formales de comunicación.

\section{Líneas temáticas}

Bajo este parámetro se puede apreciar que la línea temática, también llamada de fases del Modelo NEIN, ${ }^{21}$ que se desarrolla con mayor frecuencia en la comunidad de profesores, es la referente al comportamiento informativo $(77.7 \%)$ y en un segundo nivel, están las necesidades de información con un porcentaje de $17.7 \%$, sumamente menor a la descrita inicialmente. En cuanto a los estudios que integran las dos fases, se tiene $4.4 \%$ de investigaciones, que resultan todavía menores que las realizadas con referencia a las necesidades de información (Véase Gráfica 1).

Gráfica 1. Línea temática

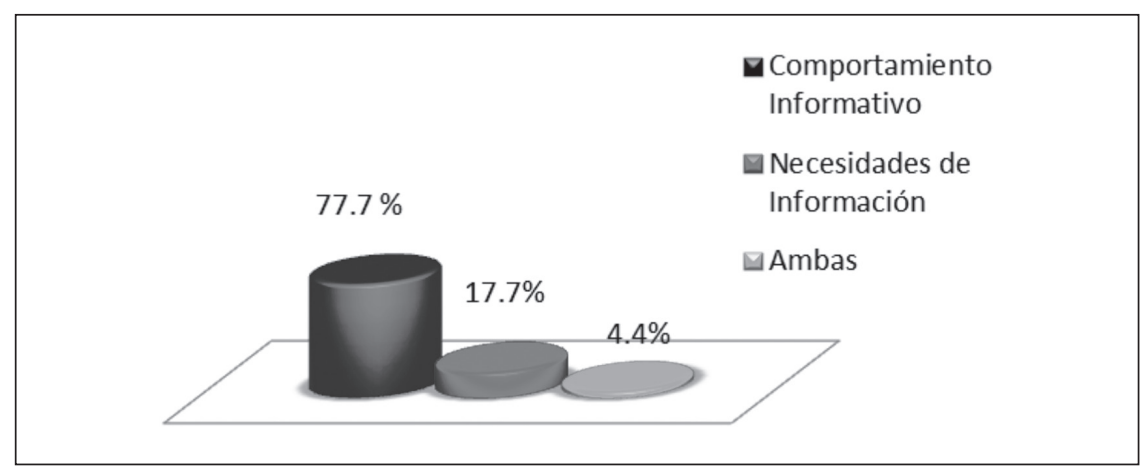

Por lo datos obtenidos, se puede pensar en la importancia que tiene, por ejemplo en la actualidad, el comportamiento informativo dentro de los estudios de usuarios como producto de la incorporación de las tecnologías de la información y en los procedimientos de búsqueda, localización y recuperación de la información

21 Cfr. J. J. Calva González, Las necesidades de información: fundamentos teóricos y métodos, op. cit., 155 
mediante recursos y fuentes no solamente bibliográficos, sino electrónicos; es decir, el impulso que le dan estas tecnologías al uso de la información se encuentra fuertemente vinculado con el adecuado desarrollo de un comportamiento informativo, un caso patente de este testimonio está representado en el desarrollo de cursos en habilidades informativas, en los cuales el comportamiento informativo se ve reflejado de manera constante.

Tipos de fuentes de información

En este rubro se encuentran tendencias interesantes; por una parte se observa la ausencia de investigaciones que aparezcan en una fuente monográfica, y por otra, se advierte una proliferación de artículos de investigación que se publican en revistas especializadas y que alcanzan un porcentaje del $62.2 \%$; lo cual indica que este tipo de investigaciones tienden a publicarse en revistas pero no así en monográficas, cuya aparición, como se sabe, sería más lenta (Véase Gráfica 2).

Gráfica 2. Tipos de fuente

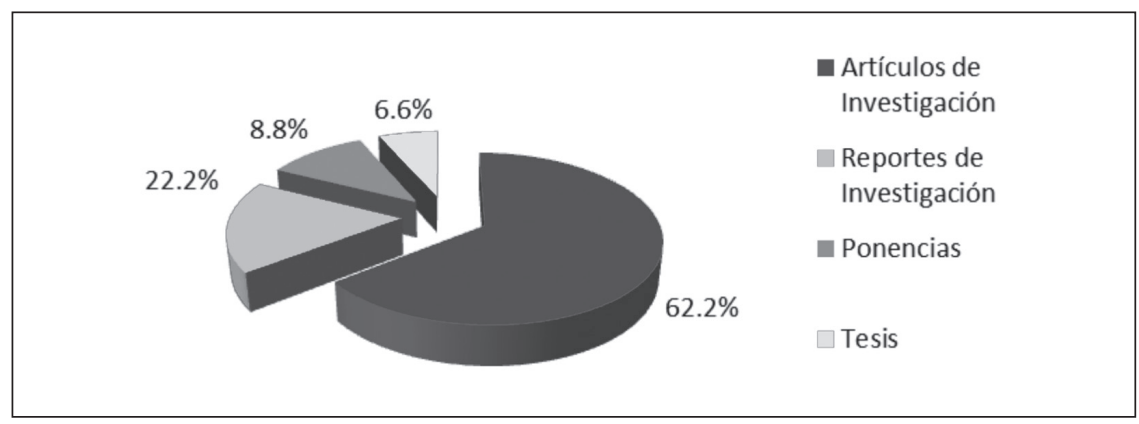

En segundo lugar se encuentran los reportes de investigación con $22.2 \%$, y en tercero, con $8.8 \%$, figuran las ponencias que se presentan en foros donde participan especialistas de nuestra área y que también suelen mostrar los avances de las investigaciones que se realizan. Por último, están las disertaciones, que son el tipo de fuen- 
te con menor desarrollo, debido a que alcanzan un $6.6 \%$, dato que revela la falta de interés en hacer estudios escolares relacionados con las necesidades de información y el comportamiento informativo en comunidades de profesores de nivel secundaria.

Técnicas e instrumentos de estudio

Otro indicador que resulta determinante para comprender las investigaciones que tienen que ver con las necesidades de información y el comportamiento informativo en las comunidades de profesores de secundaria, se encuentra relacionado con las técnicas e instrumentos que fueron empleados en las investigaciones seleccionadas. De acuerdo con lo identificado, sucede que son los cuestionarios los instrumentos que más se utilizan en los estudios de usuarios, con 48.9\% (Véase Gráfica 3). Lo cierto es que este tipo de instrumento refleja no solamente la preferencia, sino que al parecer es un recurso metodológico que brinda mayor confianza y certeza en cuanto a la obtención de resultados y la cobertura de objetivos en los estudios obtenidos. En segundo lugar, con $26.5 \%$ se encuentran las entrevistas, que gradualmente están siendo utilizadas, al menos en los estudios relacionados con la comunidad de profesores. Con $10.2 \%$ se ubican los grupos de discusión y con $2 \%$ el análisis de referencias, cuyos porcentajes indican que en un futuro pueden llegar a ser técnicas o instrumentos de investigación capaces de proporcionar información confiable para aplicarse en los estudios, aunque hasta el momento, esto sigue poniéndose a prueba. Mención aparte merecen los ensayos que se han realizado con base en teorías y cuyo porcentaje alcanza $12.2 \%$, lo que de alguna forma demuestra una atención inmediata a la preocupación de crear conocimiento teórico con respecto a esta comunidad de usuarios de la información. 
Gráfica 3. Técnicas e instrumentos empleados en las investigaciones

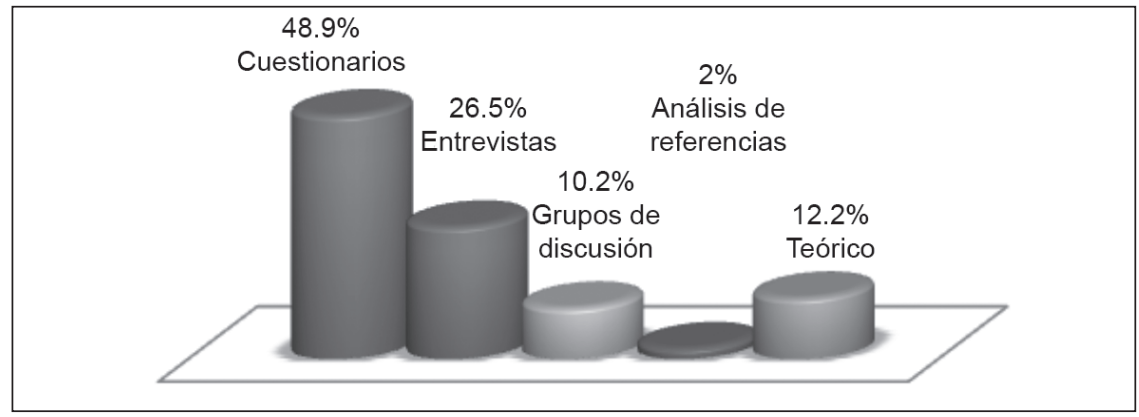

Idioma

Con relación a este punto se puede apreciar que existe una alta incidencia del idioma inglés (82.2\%) en los estudios que se han llevado a cabo dentro de esta comunidad, y que esto supera con mucho a los artículos que son publicados en español (5) con un porcentaje del $11.1 \%$; resulta mayor en portugués (3) con $6.6 \%$, lo que permite explicar el alto posicionamiento que tiene el inglés en la comunicación de conocimientos especializados de la bibliotecología (Véase Gráfica 4). Pero este porcentaje también se vincula con el dominio que mantienen los Estados Unidos en este tipo de investigaciones y cuyo sitio destacado les permite determinar la utilización de un lenguaje como el inglés, y con esto plantear un requisito casi obligado para que las investigaciones se presenten preferentemente en este idioma en las revistas especializadas.

Sin embargo, no se puede dejar de lado el avance lento pero gradual que va teniendo el español, lo cual también puede tener explicación por el aporte que hace en los distintos países de Iberoamérica interesados en la problemática de las necesidades de información y del comportamiento informativo; lo que en consecuencia demuestra la intención de crear estudios originales en su respectivos países que tienen problemáticas específicas y por lo mismo resultados propios también susceptibles de publicarse en su idioma original. 
Gráfica 4. Idioma

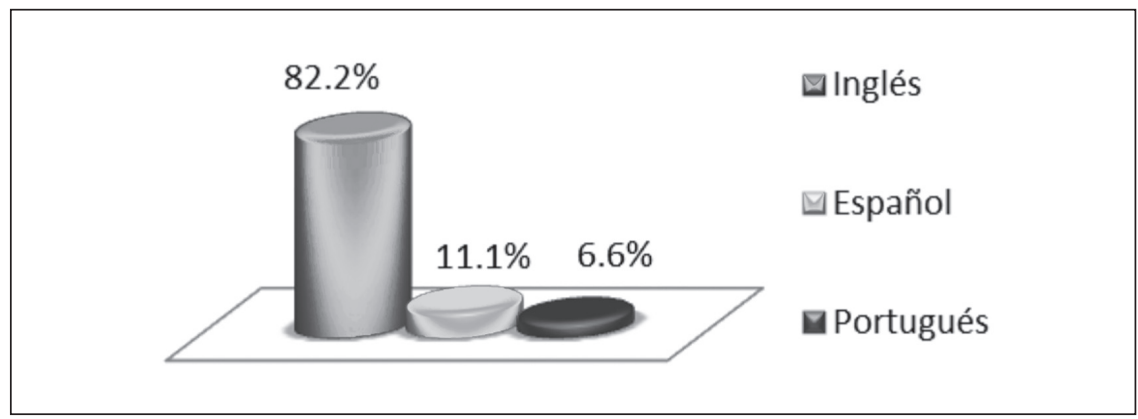

\section{CONSIDERACIONES FINALES}

La comunidad de profesores de secundaria a nivel mundial conforma un grupo de profesionistas en los cuales cae la responsabilidad de educar a los alumnos desde una perspectiva muy distinta a la que tradicionalmente se ha realizado desde más de tres décadas. En la actualidad, los profesores de secundaria requieren la utilización y el manejo de la información, no solamente para resolver sus problemas cotidianos, sino para aplicarlos en su práctica docente, y también en la formación permanente de la que son objeto debido a la globalización de la información actual.

Frente a lo anterior, aparecen las necesidades de información y el comportamiento informativo que resultan determinantes para obtener logros profesionales y laborales; sin embargo, se han realizado escasas investigaciones que exploren la problemática por la que suele atravesar la comunidad docente.

Como se logró apreciar, incluso a nivel mundial, los profesores de secundaria son pocas veces visibles para ser abordados en relación con las necesidades de información y el comportamiento informativo, y es en los países de habla inglesa donde ha habido un mayor interés para formular estrategias que inciten a identificar y fortalecer sus necesidades de información y su comportamiento informativo. 
Paralelamente, este primer acercamiento deja entrever que es a partir del nuevo milenio cuando surge la tendencia por plantear las temáticas sobre las necesidades de información y el comportamiento informativo, aunque con un fuerte vínculo hacia las habilidades informativas; pero pese a esto, sí se han seguido líneas temáticas definidas en las que el comportamiento informativo destaca como el de mayor transcendencia.

En términos generales, tanto las necesidades de información como el comportamiento informativo, de acuerdo con los datos obtenidos en el estudio, todavía no logran posicionarse como una línea de investigación cuyo interés se traduzca en investigaciones que revelen formal y públicamente sus resultados y establezcan los marcos teóricos necesarios para expandir los estudios hacia esa temática.

También es notoria la utilización frecuente de instrumentos de investigación que resultan clásicos para estos estudios, pero que de alguna manera evidencian la necesidad de buscar e incorporar técnicas e instrumentos distintos e innovadores que favorezcan el fortalecimiento metodológico de investigaciones futuras. Esto se logrará en la medida en que se multipliquen las experiencias con referencia a estas temáticas y se establezcan fundamentos teóricos que den origen a metodologías diferentes.

En suma, esta investigación forma parte de estudios de mayor dimensión que revelan las tendencias existentes en rubros específicos y representan un primer esfuerzo por clarificar, describir y explicar la problemática existente entre la comunidad de profesores de nivel secundaria a nivel mundial, en relación con las necesidades de información y el comportamiento informativo, y que subrayan el hecho de que en nuestro país este tipo de comunidad (profesores de secundaria) no ha sido objeto de una investigación de tal naturaleza y, por lo mismo, persiste un vacío de estudios que atienda a esta comunidad. 


\section{BIBLIOGRAFÍA}

Calva González, J. J. (2004). Las necesidades de información: fundamentos teóricos y métodos. México: UNAM, Centro Universitario de Investigaciones Bibliotecológicas.

- (2004). "La investigación sobre las necesidades de información en comunidades de usuarios". Investigación Bibliotecológica: Archivonomía, Bibliotecología e Información. vol. 18, núm. 37 (julio-diciembre): 22- 55.

Compendio Mundial de la educación 2011. Comparación de las estadísticas de educación en el mundo. París: UNESCO.

Concurso Nacional para el otorgamiento de plazas docentes 2012-2013, Disponible en" <http://concursonaci onalalianza.sep.gob.mx/CONAPD12/pdfs/convocatoria 2012-2013_DS.pdf>. [Fecha de consulta: 16 de febrero 2012].

Crane, D. (1974). "Information Needs and Uses". Annual Review of Information Science and Technology, vol. 6, 3-29.

Crawford, D. (1978). "Information Needs and Uses". Annual Review of Information Science and Technology, vol. 13, 61-81.

González Suárez, E. (2000). "Sistema de factores de la conducta del usuario”. Forinf@: Revista Iberoamericana de Usuarios de Información, núm. 9 (julio-septiembre): 3- 17.

Gutiérrez Sáenz, R. (2006). Lógica: conceptos fundamentales, México: Esfinge.

Hernández Salazar, P. (2001). "La producción del conocimiento científico como base para determinar perfiles de usuarios". Investigación Bibliotecológica: Archivonomía, Bibliotecología e Información, vol. 1, núm. 30 (enero-junio): 29-64. 
Izquierdo Alonso, M., J. Ruiz Abellán, Joaquín y J. T. Piñera Lucas (1998). Los estudios de usuarios en los programas de gestión de calidad. Propuesta de un marco teórico integrador para el estudio del usuario de información Disponible en: <http://fesabid98.florida-uni.es/co municaciones/m_izquierdo $>$. [Fecha de consulta: $10 \mathrm{de}$ marzo 2012].

Krikelas, J. (1993). "Information-Seeking Behavior: Patterns and Concepts". Drexel Library Quarterly, vol. 19, núm. 2 (spring): 5-20.

Maizell, R.G. (1957). "Information Gathering Patterns and Creativity". New York: Columba University.

Martin, J. (1974). "Information Needs and Uses". Annual Review of Information Science and Technology, vol. 9, 3-23.

Mercado, R. (2005). "La evaluación de profesores de educación básica en México: la carrera magisterial". Avance y perspectiva, vol. 24, (enero-marzo): 57-68.

Naumis Peña, C. et. al. (1999). Tesauro latinoamericano en ciencia bibliotecológica y de la información. México: UNAM, Centro Universitario de Investigaciones Bibliotecológicas.

Peniche de Sánchez McGregor, S. (1992). (comp.) Vocabulario controlado en bibliotecología, ciencia de la información y temas afines. México: UNAM, Centro de Investigaciones Bibliotecológicas.

Ramos Pérez, J. (2012). "Publican decreto sobre bachillerato obligatorio". El Universal, 9 de febrero.

Programa Nacional de Carrera Magisterial: Lineamientos Generales (2011). México: SEP, SNTE.

Santos del Real, A. I. (2001). La educación secundaria: perspectivas de su demanda, Aguascalientes: Universidad Autónoma de Aguascalientes, Tesis (Doctorado Interinstitucional en Educación). 
Sánz Casado, E. (1993). "La realización de estudios de usuarios: una necesidad urgente". Revista General de Información y Documentación, vol. 3, núm. 1, 154-166.

Sánz Casado, E. (1994). Manual de estudios de usuarios. Madrid: Fundación Germán Sánchez Ruipérez, Pirámide.

Shaw, R. R. (1956). Pilot Study of the Use of Scientific Litera ture by Scientists. Washington, DC National Science Foundation.

Tesauro de la UNESCO (2011). Disponible en: <http://databa ses.unesco.org/thessp/2011>. [Fecha de consulta: 13 de octubre 2012].

Tornudo, G. (1953). "Professional Rending Habits of Scientists Engaged in Research as Revealed by An analysis of 130 Questionnaires, M. S Thesis. Carnegie Institution of Technology.

Vélaz de Medrano Ureta, C. (2005). Los retos de la educación básica en América Latina, Documento de trabajo núm. 1, Madrid: Fundación Carolina.

Wilson, T. D. (2000). "Human information behavior". Informing Science. Special Issue, vol. 3, núm. 2, 49-55.

Zorrilla Fierro, M. y M. T. Fernández Lomelín (2003). "Conceptos y contexto. Elementos que orientan el estudio". La evaluación de la educación básica en México 19902000: una mirada a contra luz,. Aguascalientes: Universidad Autónoma de Aguascalientes, 47-111. 


\title{
Estudios de usuarios en diversas comunidades productoras principalmente de Vitis vinifera
}

\author{
JuAn José Calva GonzÁlez \\ Universidad N acional Autónoma de México
}

\section{INTRODUCCIÓN}

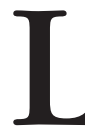

as personas tienen necesidades de diferentes tipos: fisiológicas, primarias o básicas como son el hambre, la sed, el sueño, etc; así como necesidades de salud, de protección o seguridad, de empleo y otras de niveles más altos, entre las que se pueden encontrar las de información.

Debido a que las personas presentan necesidades de información y que por lo tanto es un fenómeno recurrente en el hombre, en relación con sus múltiples facetas de actividad docente, investigativa o de producción, estos temas, pueden ser investigados.

Por otro lado, como cada unidad de información o biblioteca atiende a un sector distinto de la sociedad como investigadores, niños, estudiantes, agricultores, vitivinicultores, ganaderos, productores de leche, productores de lana, tequila, etc., para satisfacer sus necesidades de información, primeramente, conocer cuáles son esas necesidades. Así, el personal de la biblioteca debe detectarlas, identificarlas, analizarlas y luego desarrollar los mecanismos necesarios para satisfacerlas. 
De este modo se puede afirmar que el usuario, a través de sus necesidades de información, está vinculado recíprocamente con la unidad de información y también con el documento que la tiene registrada.

Pero la información que necesita el usuario para satisfacer su necesidad puede no estar incluida en el acervo documental de la unidad informativa, por lo que le tocaría a esta vincular al usuario con la información que necesita, aunque se ubique en algún otro documento no bibliográfico o en otro tipo de unidad de información, como un museo, una zona arqueológica o un archivo.

La investigación sobre la información que necesitan los usuarios y el sitio donde se localiza, tanto en bibliotecas como en otros lugares que manejen recursos informativos, enriquece de manera sustancial las bases o principios para seguir conformando la "[...] teoría sobre las necesidades de información"1 y de esta forma, crear y enriquecer los modelos teóricos, como el modelo NEIN (Modelo sobre las Necesidades de Información), en el que se relacionan las variables que intervienen, de modo que estas puedan ser de utilidad para describir, explicar y predecir, al ser aplicadas en la práctica con una metodología rigurosa.

El análisis de investigaciones llevadas a cabo en diversas comunidades de usuarios de diversos sectores sociales permitirá adentrarse en la existencia de las relaciones entre varios elementos (variables) para seguir y continuar con la creación de bases y así, desarrollar el marco teórico del fenómeno de las necesidades de información. ${ }^{2}$

Por todo lo cual, el presente trabajo es una introducción a la presentación del proyecto PAPITT IN404408 "Desarrollo de la industria vitivinícola en México: información para la producción de

1 D. I. Blyumenau, "Refining Initial Concepts in Information Need Theory", Nauchno Tekhinicheskaya informatsiya, 1986, serie 2, núm. 2, 49. Texto en inglés. Teoría de las necesidades de información es un término empleado por este autor para decir que sí es posible que exista una teoría acerca de las necesidades de información.

2 D. I. Blyumenau, "Refining Initial Concepts...", 49. 
Vitis vinifera", en el cual participan varias investigaciones derivadas que culminarán en la formación de recursos humanos en licenciatura y en el Posgrado en Bibliotecología y Estudios de la Información.

\section{LA INVESTIGACIÓN SOBRE EL FENÓMENO DE LAS NECESIDADES DE INFORMACIÓN}

El hombre, al ir evolucionando, ha recurrido a la herencia cultural de una generación a otra, la cual consiste en la transmisión acumulativa de los descubrimientos y conocimientos adquiridos por los seres humanos a lo largo de generaciones.

El mecanismo fundamental de transmisión de la información y el conocimiento es, por supuesto, el lenguaje, tanto el oral como el escrito. Pero es esencial tomar en cuenta que el primer mecanismo de comunicación utilizado fue el lenguaje oral, y por lo tanto la información transmitida por ese medio era fugaz, difusa y no retenía el sentido exacto con el cual era expresada la primera vez. Así es como podemos especular que las primeras sociedades agrícolas, en el desarrollo de la humanidad, transmitían su conocimiento de manera oral de una generación a otra; es decir, la información y el conocimiento de cómo realizar la siembra y la cosecha de diversas plantas se transmitía de padres a hijos, como ocurría en la prehistoria con los primeros grupos sedentarios.

Probablemente la escritura ocupe el segundo lugar, después del lenguaje, como el mayor invento del hombre en términos de comunicación; y sus orígenes, como los del lenguaje, surgieron en el paleolítico. ${ }^{3}$ Así el conocimiento de la agricultura quedaba plasmado en la información registrada en las primeras escrituras que utilizó el hombre en su largo desarrollo hacia su estado actual.

Después de la aparición del lenguaje como medio de comunicación, surgió también la escritura, con la ventaja de que a través de

3 J. Shera, Fundamentos de la educación bibliotecológica, 32. 
esta se puede acumular la información y el conocimiento que ha adquirido la especie humana a través de las generaciones, y quedar registrada en algún soporte:

- piedra

- tablillas de arcilla

- papiro

- pergamino

- papel

- cintas magnéticas

- disquetes

- discos compactos

- en discos magnéticos de computadoras

- $\quad$ y otros soportes que se utilizarán en el futuro.

En la actualidad, el lenguaje verbal y no verbal puede ser plasmado en algún medio al grabarlo en un documento fotográfico, en cintas de cine, en discos láser y en medios magnéticos o electrónicos. Así, no solo la información escrita puede ser preservada en algún soporte, como había sido durante muchos años, sino que ahora la tecnología permite preservar el sonido y la imagen, además de darle un mayor número de soportes a la escritura. Lo cual incluye también la posibilidad de registrar los propios sonidos de los que se vale el lenguaje, e incluso incluir imágenes y texto como se hace en el cine, en los discos láser, en las cintas magnetofónicas, en la memoria de las grandes computadoras o en Internet.

En el largo desarrollo de la humanidad, al pasar del lenguaje oral al escrito, el ser humano, se fue dando cuenta de la necesidad de acumular los conocimientos generados para ser retenidos por él mismo, y luego ser transmitidos a otros sujetos. Pero tener el conocimiento registrado significa tenerlo fuera del cuerpo; es decir, en otro lugar que no es el cerebro.

Por lo tanto, el ser humano, en la restringida y más reciente fase de su largo devenir biológico-intelectivo, se ha procurado no solo información extragenética, sino también conocimientos extrasomá- 
ticos; es decir, información acumulada fuera de nuestro cuerpo, fenómeno del que la escritura constituye el ejemplo más significativo. ${ }^{4}$ Como afirma Sagan :

Al ir avanzando el individuo de la infancia a la madurez y aún en la vejez, asimila constantemente en su propio sistema mental, elementos que desde su origen son externos a él, los cuales incluyen representaciones simbólicas de objetos ambientales, las normas de su cultura y los rasgos, tanto reales como ideales, de aquellos con quiénes tiene ligas emocionales." 5

Actualmente el cerebro humano de un sujeto genera información y conocimiento para ser consumidos por el cerebro humano de otro sujeto diferente; es decir, esto forma un ciclo.

La necesidad del cerebro de recibir y procesar constantemente nueva información es una característica inherente, cuando menos, de los animales superiores. Sólo una pequeña porción del sistema nervioso central se desarrolla en el nacimiento, la mayor parte crece continuamente por medio de la estimulación y la experiencia; a través de la absorción, organización y procesamiento de toda la información que llega al cerebro por medio de la percepción sensorial. ${ }^{6}$

Pero es indudable que el sistema nervioso humano y su órgano regulador, el cerebro, a través de su larga evolución, han desarrollado la capacidad de procesar la información que perciben y, además, de almacenarla fuera del propio cerebro. Esto lo ha logrado utilizando:

- símbolos,

- figuras y

- $\quad$ sonidos.

4 C. Sagan, op. cit, 16.

5 Idem., 14.

6 J. Shera., op. cit., 8. 
Como indicaciones de lo anterior se pueden citar, entre otras:

- las pinturas rupestres

- construcciones monolíticas

- los jeroglíficos

- los papiros

- las tablillas de arcilla

- los libros

- los medios audiovisuales

- los medios electrónicos (computadoras)

- los discos compactos

La utilización de estos elementos le ha permitido al cerebro, trabajar de forma activa y a su vez generar nuevas formas de símbolos y figuras, y también conservar los sonidos para su posterior utilización por los cerebros de otros sujetos, pero de forma relacional, conjunta, no de forma lineal. Así:

El cerebro - escribe Shera- puede hacer algo más que procesar o manipular información que le es telegrafiada por los sentidos, más que conceptualizar, distinguir y agrupar; puede generar información nueva de estímulos recibidos por medio de indicios y analogías; puede resolver problemas, según parece, fragmentándolos en partes manejables que tienen connotaciones familiares y luego haciendo participar a todos sus recursos (como la memoria) para relacionarse con cada fragmento uno por uno, puede recordar visiones, sonidos, gustos, olores y contactos físicos y puede ser entrenado para recordarlos lo mejor de lo que naturalmente está inclinado a hacerlo; puede imaginar y dirigir la creación de cosas que nunca antes han existido aplicando o relacionando, de nuevos modos, algo de su conocimiento almacenado[... $]^{7}$

$7 \quad$ J. Shera., op. cit., 11 
Por lo anterior, Morales Campos afirma que:

Para todo lo que hacemos requerimos información, desde la antigüedad hasta nuestros días, la necesidad ha sido constante; muchas veces, para las tareas cotidianas es un acto inconsciente ya que la información se ha transmitido de manera natural de padres a hijos, de adultos a niños; pero no todo en la vida es satisfacer necesidades básicas, ya que una vez cubiertas éstas, trascendemos a otras culturas, otros niveles de dificultad, ya unos buscamos información para poder afrontar el nuevo reto, y otros tenemos interés en difundir nuevas ideas y proponer al público temas de reflexión sobre la realidad científica, cultural y sociopolítica. ${ }^{8}$

De ello se puede deducir, como lo afirma López con una visión enmarcada en la información; que el documento en donde está registrada, es un instrumento de cultura, de conocimiento y fijación de la realidad, y de comunicación en el proceso documental, así como una fuente de nuevo conocimiento científico.?

La información que el propio ser humano ha generado es precisamente para utilizarla nuevamente, por eso la registra en algún medio. Ella:

Se produce en la sociedad en alguno de sus estratos y grupos; existe un interés consciente o inconsciente de transmitirla, ya sea de manera individual o colectiva; puede ser información de tipo secreto concentrada en un selecto grupo, o del dominio público; también en los dos casos la sociedad puede estar interesada en conocerla y participar en los mecanismos de su difusión; a su vez los grupos de poder, llámese Estado, consorcio comercial, grupo político les interesa tener la información y utilizarla. ${ }^{10}$

8 E. Morales Campos, "Sociedad e información”, 83.

9 J. López Yepes, "Reflexiones sobre el concepto de documento ante la revolución de la información: ¿un nuevo profesional del documento?”, 11-30. 
Blyumenau considera que existe una necesidad social de conocimiento que luego se transforma en necesidad de información. ${ }^{11}$

En suma, el desarrollo del propio ser humano y su órgano rector, el cerebro, tuvo la necesidad de conservar y transmitir el conocimiento que fue generado paulatinamente a través de su larga evolución, para sobrevivir como especie y seguir desarrollándose como un organismo vivo y evolutivo, pero una vez que contó con el lenguaje escrito y encontró los soportes que lo ayudaran a conservarlo para la posteridad, pudo avanzar más rápido en su camino hacia su completo crecimiento como ser humano.

\section{LOS ESTUDIOS REALIZADOS}

Con el fin de presentar un desarrollo de los estudios realizados acerca de las tres fases de fenómenos de las necesidades de información que correspondan con su surgimiento, con el comportamiento informativo y satisfacción, a través de un recorrido por la producción hecha en América Latina y el Caribe, se utilizó la base de datos de INFOBILA para llevar a cabo el rastreo de documentos que traten sobre algunas de las tres fases:

- Surgimiento de las necesidades de información.

- Comportamiento en la búsqueda de información.

- Satisfacción de las necesidades de información.

Se analizaron los documentos recuperados que trataban sobre el tema o alguna de sus fases; y de no ser así, no se tomaba en cuenta para este análisis. Se incluyeron únicamente aquellos documentos que trataban sobre necesidades, comportamiento y satisfacción.

11 D. I. Blyumenau, op. cit., 51. 
Al mismo tiempo, se contó con la recuperación de un total de 253 documentos, y tras su análisis se descartaron 86 debido a que trataban sobre temas no pertinentes, como:

- Evaluación de servicios bibliotecarios.

- Opinión sobre el personal de la biblioteca.

- Opiniones sobre el edificio de la biblioteca.

- Aspectos relativos a las características de una comunidad de usuarios en específico como cantidad, edades, género, etc.

Tras el descarte anterior, se contó con 212 documentos, los cuales quedaron distribuidos de la siguiente forma en cada una de las tres fases estudiadas:

\begin{tabular}{|l|c|}
\hline Necesidades de información & 121 \\
\hline Comportamiento informativo & 53 \\
\hline Satisfacción & 32 \\
\hline
\end{tabular}

Necesidades de información

Al observar con mayor atención lo encontrado en cada una de ellas se observó lo siguiente: entre los años 1981, año de creación del CUIB, y 1994, únicamente se contó con 15 estudios realizados sobre esta fase; en cambio, a partir de 1995 se tienen 93 documentos. Dentro de este mismo periodo se tienen los niveles más altos en 1997, con 14 documentos, y en los años del 2000 al 2003 se tienen más de diez en cada uno de ellos.

\section{COMPORTAMIENTO INFORMATIVO}

En cuanto al comportamiento informativo se encontró que se concentra en dos partes principalmente: 
- La primera en el periodo de 1981 a 1993, con 13 documentos.

- La segunda en el periodo de 1998 a 2006, con 20 estudios.

Cabe señalar que existe un espacio en blanco con cero estudios realizados entre 1994 y 1997. Los estudios se concentran entonces en el segundo periodo, y el valor más alto se concentra en el 2003.

Satisfacción de usuarios

Los estudios sobre la satisfacción se centran entre los años de 1995 y 2005 que aunque pocos, corresponden a 21 estudios. Se puede decir que en años anteriores no existen estudios.

\section{ESTUDIOS POR PAÍS}

En lo que corresponde a la distribución por país en cuanto a los estudios tenemos que el mayor número está en México, seguido de Brasil y después por Chile. Aunque también hay otros países.

En lo que respecta al comportamiento informativo, se tiene que los estudios se desarrollaron en México y luego fueron seguidos por Brasil, Cuba y Argentina aunque existen más países, su número es mínimo.

En cuanto a la satisfacción de las necesidades, los estudios se centran en México y son seguidos principalmente por Brasil y cinco países más.

Pero, ¿qué sucede en las comunidades estudiadas en cualquiera de estos tres momentos en los que se dan: la necesidad de información, el comportamiento informativo y la satisfacción informativa?

Se puede decir que se han efectuado investigaciones en una gran variedad de comunidades, pero principalmente en las académicas, como son:

- Profesores e investigadores de diferentes áreas: historia, arqueología, sociología, medicina, física, química, biología, biotecnología, geología, etc. 
- Estudiantes de primaria, universitarios, y por área específica; estudiantes de arte, de sociología, economía, etc.

También se han estudiado otros sectores sociales, como las comunidades indígenas, discapacitados, tercera edad, y hay otros estudios que se han efectuado en Estados Unidos.

En cuanto a los sectores productivos, en este rubro todavía es poco el trabajo que se ha llevado a cabo, como en la industria lechera, ganadera y pesquera, o en el comercio. Pero existen sectores productivos que no han sido investigados, como la industria vitivinícola, la restaurantera, etc.

Es, pues, poco lo que la bibliotecología ha investigado en lo que se refiere a los sectores productivos e industriales de México y considero que esto es lo que sucede en América Latina en general.

Es así como surgió la idea de realizar este proyecto colectivo sobre el desarrollo de la industria vitivinícola en México, ya que la bibliotecología debe acercarse al ámbito de la producción de Vitis vinifera para darles la mejor información posible.

Los antecedentes para la realización de este proyecto colectivo se ubican en la investigación que se pensó hacer sobre lo relacionado con la información (necesidades, comportamiento y satisfacción) de los vitivinicultores en México, pero la cual no se ha llevado a cabo. Igualmente, tampoco se cuenta con antecedentes respecto a las fuentes y recursos de información que utiliza esta colectividad y que puedan brindarle apoyo para aumentar la producción y calidad de los viñedos y los productos derivados de ellos.

Los materiales publicados abordan los siguientes aspectos principales:

a) La historia del desarrollo de la industria vitivinícola mexicana a partir de la llegada de los europeos a Mesoamérica.

b) El desarrollo logrado por las diferentes marcas o bodegas que producen vino a partir de la Vitis vinífera como por ejemplo: La Cetto y Domecq.

c) La llegada de vitivinicultores europeos a las diferentes regiones donde se cultiva la Vitis vinífera, y la descripción de 
sus bodegas y los productos que le ofrecen a la sociedad mexicana.

d) Los problemas económicos que presenta el desarrollo de la industria vitivinícola mexicana en algunas regiones, como sucede en Sonora.

e) La descripción de los procesos de producción de la Vitis vinífera, y también de la elaboración de los diferentes tipos de vinos en México (tintos, blancos y espumosos), presentados como textos elaborados principalmente por la Universidad Autónoma Metropolitana para apoyar la materia de enología (que no es una licenciatura que pueda estudiarse).

Por otro lado, existe mucha literatura sobre otras regiones del mundo principalmente la francesa y la española, pero no para la mexicana.

En realidad, existe bastante literatura sobre el producto final que es el vino y la forma de servirlo en y con los alimentos, sobre todo aquella que se enfoca a la industria restaurantera y turística (elementos que no forman parte, de esta investigación).

Los antecedentes generales de la producción de Vitis vinífera para producir vino adquieren visibilidad hacia finales de los años ochenta, lo que incluyó no solo a los mexicanos, sino también a los argentinos y chilenos, y a otras regiones como Nueva Zelanda y Australia, como los principales actores.

En el caso mexicano, la introducción en nuestro país se logró con la participación de varios actores, entre ellos los productores establecidos en diferentes regiones del país, así como a los enólogos y vitivinicultores expertos que en algún momento decidieron iniciar una nueva aventura y se lanzaron a producir vinos de alta calidad capaces de competir con los vino extranjeros.

Hoy en día, el vino mexicano está siendo reconsiderado, y cada vez con más frecuencia, entre los mejores del mundo. Y ese reconocimiento, tanto nacional como internacional, en la actualidad estimula mucho los esfuerzos de sus protagonistas

La industria vitivinícola en México goza actualmente de muy buena salud; es decir, sigue desarrollándose, por lo cual es tan im- 
portante estudiarla a profundidad desde una perspectiva bibliotecológica y de la información, así como geográfica.

Las actividades propias de los vitivinicultores y del producto que generan, el vino en sus tipos ya mencionados, los llevan a cuestionarse sobre los siguientes problemas de investigación:

Los vitivinicultores de México cuentan con la información necesaria y el acceso a la misma para desarrollar su industria y su producto final en sus diferentes tipos. Y si quieren, pueden averiguar si existe alguna relación entre el acceso a la información que necesitan y la producción de la vid y del vino que producen. Pero también es preciso que puedan seguir indagando cuáles son aquellas necesidades de información que tienen como vitivinicultores para poder producir cada vez, una más alta calidad de vid y de vino.

A la vez, se puede tomar en cuenta que si la industria vitivinícola en México ya ha iniciado su ascenso, es posible profundizar sobre esas fuentes y recursos de información que están accesibles en cada región de vitivinicultores.

Debido a los muy escasos acercamientos desde la parte bibliotecológica hacia esta comunidad de usuarios de la información, el estudio se basará en los siguientes modelos teóricos que contemplan los aspectos de las necesidades de información, el comportamiento de búsqueda de la información y la satisfacción de las necesidades informativas:

- Modelo NEIN (UNAM)

- Modelo de Krikelas (University of Wisconsin)

- Modelo de Applegate (The College of St. Scholastica Library)

Estos modelos brindarán algunas de las variables que se manejarán, como son:

a) El entorno físico donde se ubican los usuarios y el producto que elaboran.

b) Las características del usuario de la información (vitivinicultores): 
- Experiencia

- Conocimiento previo

- Forma de buscar la información (uso de fuentes de información)

c) Información que necesitan para desarrollar su industria.

d) Recursos de información disponibles en México para esta comunidad de usuarios.

El objetivo principal de toda la investigación será la identificación de las necesidades de información y el comportamiento informativo de los vitivinicultores de México, distribuidas entre las cinco grandes regiones donde existe o se desarrolla esta industria. Tomará en consideración la descripción de las regulaciones o normas aplicables en México para la producción de Vitis vinifera y sus derivados. Asimismo, en la medida de sus posibilidades, describirá la situación geográfica de las regiones productoras de uva que pudieran posibilitar el diseño de un sistema de información para el desarrollo de bibliotecas, centros de información y documentación que apoyen la producción vitivinícola mexicana.

Partiendo del supuesto de que los vitivinicultores presentan necesidades de información para desarrollar su industria, así como de los planteamientos presentados en los apartados anteriores, se tienen las siguientes hipótesis:

a) El acceso a los recursos informativos existentes en México interviene como una variable más en la producción, proceso y elaboración de los productos obtenidos en las regiones vitivinícolas mexicanas, aparte de las ya conocidas y propias de esta industria, como son el suelo, el clima, la variedad de uva, la forma de cultivo y las regulaciones propias del producto.

b) La información es un factor determinante para que el trabajo de los productores vitivinícolas de México se mantenga en el mercado competitivo con los demás productores mexicanos y con los extranjeros. 
c) Si la información que necesitan los productores vitivinícolas mexicanos es una variable que determina su producción, proceso y elaboración de productos, entonces la existencia de sistemas de información, como bibliotecas u otros, aumentarán las posibilidades de que estos vitivinicultores tengan mejores oportunidades para competir, incluso con los vinos extranjeros.

d) Que la identificación de la situación geográfica de cada una de las regiones vitivinícolas mexicanas pueda ser incluida en una biblioteca o sistema de información puede favorecer el acceso a la información y por tanto el aumento de la producción, el proceso y la elaboración de los productos obtenidos por cada productor vitivinícola.

\section{Metodología}

La presente investigación tiene como unidades de análisis:

a) Las necesidades de información de los productores vitivinícolas (de la vid y de sus productos) mexicanos ubicados en las regiones donde se cultiva la Vitis vinifera en México.

b) Los recursos y fuentes informativas sobre la producción de Vitis vinifera y sus derivados utilizados por los vitivinicultores.

c) Las regulaciones o normas para la producción de Vitis vinifera en México.

Para llevar a cabo la investigación sobre sus tres objetos se hará lo siguiente:

a) Una investigación documental.

b) Un análisis crítico de los recursos informativos identificados.

c) Una investigación de campo, directamente con los productores de Vitis vinifera en las regiones donde se cultiva en el país para la producción de vino. 
La investigación de campo se llevará a cabo a través de una entrevista semiestructurada. Tomando en cuenta los objetos de investigación que se persiguen y la manera en que serán abordados, los instrumentos que se utilizarán para hacer la recolección de los datos que permitan su análisis e interpretación serán los siguientes:

a) Una cédula para la descripción y el análisis de los recursos informativos mexicanos tanto impresos como de otro tipo (electrónicos, audiovisuales, reales).

b) Una cédula de entrevista.

Las diferentes regiones serán investigadas por los participantes en este proyecto; es decir, a cada tesista adscrito al proyecto se le designará una de las diferentes regiones que cultivan la Vitis vinifera involucrada; por lo regular la casa productora se encuentra ubicada en sus propios viñedos o en sus cercanías.

La distribución de las regiones vitivinícolas se hará con base en el siguiente esquema aproximadamente:

- Baja California

- Querétaro

- Guanajuato

- Coahuila

- Zacatecas, Aguascalientes y Durango

\section{Algunas CONCLUSIONES}

La realización de estudios sobre el fenómeno de las necesidades de información en relación a sus fases de surgimiento, comportamiento informativo y satisfacción, se desarrolla principalmente desde mediados de la década de los años noventa.

Igualmente, aunque la cantidad es limitada, los estudios de satisfacción también están presentes después de la segunda década de los noventa en adelante. 
El país más interesado en que se lleven a cabo estos estudios es México seguido muy de cerca por Brasil. También hay mucho interés en otros países de América Latina y el Caribe por esta línea de investigación.

La actividad en la producción de estudios y documentos sobre el tema parece haber aumentado en la década posterior a 1995. Asimismo todo parece indicar que México sigue siendo el país que lleva la vanguardia en esta temática e inicia un acercamiento hacia otro tipo de comunidades de usuarios, como es el sector productivo conformado por los vitivinicultores.

Las comunidades de usuarios estudiadas hasta ahora han tendido a ser mayormente comunidades académicas; esto es, estudiantes, docentes e investigadores de diferentes áreas del conocimiento, como psicólogos, matemáticos, geógrafos, etc. Pero comunidades como las de pescadores, comerciantes o agricultores, o incluso como los productores de Vitis vinifera de las cinco regiones vitivinícolas de México, no han sido investigadas con la atención debida.

\section{BIBLIOGRAFÍA}

Atherton, P. (1978). Manual para sistemas y servicios de información. París: UNESCO.

Blyumenau, D. I. (1986). "Refining Initial Concepts in Information Need Theory". Nauchno Tekhinicheskaya informatsiya, serie 2, núm.2, 49.

Frants, V., Op. cit., 86.

Hill, H. K. (1987). Methods of Analysis of Information Need, Denton. Texas: H. K. Hill. Tesis (Master of Arts), School of Library and Information Studies, 1.

López Yepes, J. (1997). "Reflexiones sobre el concepto de documento ante la revolución de la información: ¿un nuevo profesional del documento?". Scire, (enero-junio): vol. 3, núm. 1, 11-30. 
Morales Campos, E. (1990). "Sociedad e información". OMNIA: Revista de la Coordinación General de Estudios de Posgrado, (septiembre): año 6, núm. 20, 83.

Negrete Gutiérrez, M. del C. (1988). La selección de materiales documentales en el desarrollo de colecciones. México: UNAM, Centro Universitario de Investigaciones bibliotecológicas, 1988, 23.

Norman, D. A. (1972). El procesamiento de la información en el hombre. Buenos Aires: Paidós.

Sagan, C., Cosmos Op. cit, 16.

Shera, J (1990). Fundamentos de la educación bibliotecológica. México: UNAM, Centro Universitario de Investigaciones Bibliotecológicas, 32. 


\title{
Necesidades de información del personal académico del Instituto de Geografía para publicar en revistas indexadas
}

\author{
Antonia SANTOS Rosas \\ Universidad Nacional Autónoma de México
}

\section{INTRODUCCIÓN}

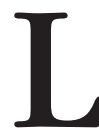

os usuarios de toda biblioteca son el motor que debe dirigir a esta hacia el tipo de información que debe adquirir, en qué idioma, de qué editorial, de qué país y en qué formato, por lo que es muy importante que las diversas instituciones realicen estudios sobre sus usuarios para conocer las necesidades de información de estos y poder satisfacerlas.

Como es sabido, las necesidades de información son transitorias, es decir, conforme se van cubriendo unas van surgiendo otras.

Las necesidades de información de las comunidades científicas son diversas; sin embargo, presentan una en común, y esta es: ¿en qué fuentes de información primaria (revistas) pueden publicar sus productos de investigación?, pero se necesita también que estas fuentes sean consideradas como adecuadas para evaluar la producción científica. Por lo que la Coordinación de la Investigación Científica, en su folleto titulado Criterios Generales para la Evaluación del Personal Académico del Subsistema de la Investigación Científica, menciona que, "[...] los nuevos conocimientos 
deben ser publicados en revistas arbitradas de circulación internacional, [y un] ejemplo de ellas son las revistas indizadas". ${ }^{1}$

Una vez aceptados los criterios de evaluación del personal académico del Instituto de Geografía, es necesario insistir en la necesidad de que todo el personal publique en estas fuentes de información, las cuales, para esta comunidad en particular, se encuentran indizadas en la base de datos Web of Science "[...] en función de las políticas de evaluación del Consejo Técnico de la Investigación Científica"; ${ }^{2}$ cabe mencionar que SCOPUS también es otra base de datos de alcance multidisciplinario que le asigna factor de impacto a las revistas que monitorea, pero con otra denominación que es, JSR (SCImago Journal Rank). Para este trabajo nos enfocaremos en la base de datos Web of Science.

En la medida en que los investigadores cubran estos criterios de evaluación esto les permitirá, entre otros aspectos, aspirar a ascensos, asistir a eventos y participar en el Programa para Primas de Desempeño del Personal Académico de Tiempo Completo, PRIDE.

Asimismo, ante la necesidad de conocer en qué revistas deben publicar los investigadores y que estas a su vez tengan un factor de impacto, se presenta este documento en el que se mencionan las líneas de investigación, lo que traducido a usuarios de la información, nos refleja la necesidad de información, el conocimiento del título de la revista en donde se puede publicar y el propio factor de impacto.

Estos datos le ayudan al investigador a valorar el sitio adonde enviará su artículo, con la confianza de que cuando su producción científica sea evaluada, será aceptada si se cumplen los requisitos de publicación que pide la Investigación Científica en la UNAM.

Es necesario que los resultados obtenidos en este trabajo se difundan entre la comunidad geográfica, ya que es un requerimiento

1 Criterios generales para la evaluación del personal académico del Subsistema de la Investigación Científica, 16

2 Primer Informe de Actividades 2012. Universidad Nacional Autónoma de México, Instituto de Geografía. 
que se les pide a los investigadores para su evaluación, y que algunos de ellos desconocen cómo buscar en la base de datos.

Los objetivos que se persiguen en este trabajo son:

- Conocer las necesidades de información de los investigadores del Instituto de Geografía a través de sus propias líneas de investigación.

- Elaborar un listado de revistas indizadas en la base datos Web of Science con su factor de impacto en la base de datos Science Citation Index y el Social Citation Index.

- Dar a conocer estos resultados entre los investigadores del Instituto de Geografía.

\section{INSTITUTO DE GEOGRAFÍA}

El Instituto de Geografía de la UNAM es el instituto de investigación académica de índole geográfica más grande y de mayor tradición en México y, por lo mismo, ejerce un liderazgo y marca rutas y tendencias en materia científica y docente. Realiza investigación básica y aplicada encaminada a conocer el territorio y sus recursos, y a diagnosticar su estado y su aprovechamiento actual y potencial. Su principal objeto de estudio es el espacio y sus diferentes formas de organizar los elementos que lo componen, tanto físicos como socioeconómicos. ${ }^{3}$

Una de las misiones del Instituto de Geografía es organizar, llevar a cabo y difundir investigaciones científicas originales, tanto básicas como aplicadas", así como promover la divulgación de los resultados de investigación geográfica, utilizando medios impresos y electrónicos, conferencias y otras acciones complementarias y alternativas que sean pertinentes. ${ }^{4}$

Debido a que la geografía estudia el espacio geográfico y las relaciones con el medio social, económico y físico, el Instituto está

$\begin{array}{ll}3 & \text { Ibid., } 50 . \\ 4 & \text { Ibid., } 50 .\end{array}$ 
estructurado con base en los departamentos de Geografía Física, Geografía Social y Geografía Económica; además de contar con un Laboratorio de Análisis Geoespacial.

A continuación se mencionan a grandes rasgos las actividades que se realizan en cada departamento.

\section{Departamento de Geografía Física}

El Departamento de Geografía Física se encarga del estudio de las relaciones espaciales que guardan entre sí los fenómenos que actúan sobre la superficie de la Tierra. Esto comprende tanto la esfera puramente física como la biológica, sin olvidar las relaciones con la actividad humana. El estudio de estas relaciones permite la planeación de las actividades económicas y el ordenamiento del territorio. ${ }^{5}$

\section{Departamento de Geografía Social}

El Departamento de Geografía Social analiza los cambiantes esquemas sociales del mundo moderno, e interpreta así a la sociedad dentro de su marco geográfico. El estudio de los grupos sociales en el territorio establece tres conjuntos de problemas para la Geografía Social: la definición de grupos sociales significativos en el espacio, el análisis de sus actividades y la evaluación de sus impactos como producto de las interacciones sociales. ${ }^{6}$

\section{Departamento de Geografía Económica}

El Departamento de Geografía Económica examina la estructura territorial de las actividades económicas, entendidas como parte medular del proceso de producción de bienes y servicios que la sociedad demanda. La Geografía Económica juega un papel fun-

5 Primer Informe 1997-1998, 1998, Universidad Nacional Autónoma de México. Instituto de Geografía.

6 Op. cit., 18. 
damental en los estudios relacionados con la planeación, la evaluación del impacto ambiental y el ordenamiento territorial. ${ }^{7}$

\section{Personal Académico}

La plantilla de investigadores está constituida por: ${ }^{8}$

\begin{tabular}{|l|c|}
\hline Personal académico & - \\
\hline Investigadoras Eméritas & 2 \\
\hline Investigadores & 46 \\
\hline Técnicos Académicos & 35 \\
\hline Total & 86 \\
\hline
\end{tabular}

\section{ACADÉMICOS POR DEPARTAMENTO}

\begin{tabular}{|l|c|c|c|}
\hline \multicolumn{1}{|c|}{ Departamento } & Investigadores & Técnicos Académicos & Total \\
\hline Geografía Económica & 9 & 5 & 14 \\
\hline Geografía Física & 21 & 6 & 27 \\
\hline Geografía Social & 10 & 4 & 14 \\
\hline Laboratorio de Análisis Geoespacial & 4 & 10 & 14 \\
\hline
\end{tabular}

Grado Académico del personal investigador

\begin{tabular}{|l|c|}
\hline Grado de Doctor & 47 \\
\hline Grado de Maestro & 1 \\
\hline
\end{tabular}

7 Op. cit., 20.

8 Primer Informe de Actividades 2012. Universidad Nacional Autónoma de México, Instituto de Geografía. 


\section{Sistema Nacional de Investigadores}

\begin{tabular}{|l|c|}
\hline Nivel I & 19 \\
\hline Nivel II & 19 \\
\hline Nivel III & 2 \\
\hline Investigadora Emérita & 1 \\
\hline Fuera del sistema & 6 \\
\hline
\end{tabular}

Nivel de estímulo

\begin{tabular}{|c|c|c|c|}
\hline 19 PRIDE “D” & 40 PRIDE "C" & 15 PRIDE “B” & 6 PAIPA \\
\hline
\end{tabular}

\section{PRODUCCIÓN PRIMARIA}

Se publicaron 542 productos primarios

\begin{tabular}{|c|c|c|c|}
\hline $\begin{array}{c}\text { Artículos en revistas } \\
\text { internacionales }\end{array}$ & $\begin{array}{c}\text { Artículos } \\
\text { nacionales }\end{array}$ & Libros & $\begin{array}{c}\text { Capítulos } \\
\text { de libros }\end{array}$ \\
\hline $24.5 \%$ & $10.9 \%$ & $10.3 \%$ & $54.2 \%$ \\
\hline
\end{tabular}

Es necesario señalar que existe una diferencia importante en cuanto al tipo de publicaciones de los diferentes departamentos del instituto, ya que la tendencia a publicar en artículos o libros y capítulos de libros varía de acuerdo con el área a la que pertenecen los investigadores.

A continuación se muestra un ejemplo de la tendencia que tienen los investigadores a publicar en artículos, libros o capítulos de libros.

\begin{tabular}{|l|c|c|}
\hline & $\begin{array}{c}\text { Geografía Física } \\
\text { 202 Productos generados }\end{array}$ & $\begin{array}{c}\text { Geografía Económica } \\
\text { 104 Productos Generados }\end{array}$ \\
\hline Artículos internacionales & $40.1 \%$ & $12.5 \%$ \\
\hline Artículos nacionales & $12.4 \%$ & $17.3 \%$ \\
\hline
\end{tabular}


Necesidades de información...

\begin{tabular}{|l|c|c|}
\hline Libros & $8.9 \%$ & $11.5 \%$ \\
\hline Capítulos de libros & $38.6 \%$ & $58 \%$ \\
\hline
\end{tabular}

En esta tabla se observa claramente la tendencia de los investigadores a publicar en determinadas fuentes de información, los del área de Geografía Física prefieren publicar en revistas internacionales que estén indizadas en la Web of Science en idioma inglés, mientras que los del área de Geografía Social y Económica prefieren publicar en artículos nacionales y escritos en español.

Por lo anterior, las necesidades de información se encuentran relacionadas con las actividades que realiza el individuo y el entorno en el que se desenvuelve, siendo estas las principales generadoras de las necesidades cognitivas.

Calva ${ }^{9}$ define la necesidad de información como la carencia de conocimiento e información sobre un fenómeno, objeto, acontecimiento, acción o hecho que tiene una persona, lo cual es producido por factores externos o internos que provocan un estado de insatisfacción, misma que el sujeto se ve motivado a satisfacer a través de un comportamiento que busca la satisfacción.

Como bibliotecólogos es importante conocer las necesidades de información de la comunidad a la que atendemos, puesto que es fundamental para planear los servicios bibliotecarios, lo que nos permitirá realizar un adecuado desarrollo de las colecciones, entendiéndose por esto el hecho de adquirir el material que el usuario requiere en el idioma, formato y en la actualidad que necesita, o en una mirada retrospectiva.

A continuación se presentan las líneas de investigación de esta comunidad, que nos llevarán a detectar las necesidades de información.

\begin{tabular}{|l|}
\hline \multicolumn{1}{|c|}{ Geografía Económica } \\
\hline Geografía minera y de los energéticos \\
\hline Geografía agraria \\
\hline Geografía del transporte \\
\hline Geografía de los servicios \\
\hline
\end{tabular}

9 J. J. González Calva, 69. 
Usuarios de la Información...

\begin{tabular}{|l|}
\hline Geografía del turismo \\
\hline Geografía regional \\
\hline
\end{tabular}

\begin{tabular}{|l|}
\hline \multicolumn{1}{|c|}{ Geografía Física } \\
\hline Geomorfología \\
\hline Hidrogeografía y estudios de las aguas subterráneas \\
\hline Climatología \\
\hline $\begin{array}{l}\text { Vegetación, Ecología del paisaje y dinámica de cambios de } \\
\text { uso del suelo }\end{array}$ \\
\hline
\end{tabular}

\begin{tabular}{|l|}
\hline \multicolumn{1}{|c|}{ Geografía Social } \\
\hline Geografía de la población \\
\hline Geografía histórica \\
\hline Geografía urbana \\
\hline Geografía cultural \\
\hline Geografía de la salud \\
\hline Pobreza \\
\hline
\end{tabular}

\begin{tabular}{|l|}
\hline Laboratorio de Análisis Geoespacial (LAGE) \\
\hline Métodos de análisis espacial \\
\hline $\begin{array}{l}\text { Desarrollo de tecnologías de percepción remota e } \\
\text { información geográfica }\end{array}$ \\
\hline Métodos de análisis ambiental y regional \\
\hline
\end{tabular}

\section{A manera de ejemplo el siguiente cuadro muestra cómo quedó estructurada la información, para cubrir cada necesidad de infor- mación.}

\begin{tabular}{|l|l|l|c|}
\hline $\begin{array}{c}\text { Necesidades de } \\
\text { Información }\end{array}$ & \multicolumn{1}{|c|}{ Revista indizada } & Titulo abreviado & Factor de Impacto \\
\hline Geografía Económica & $\begin{array}{l}\text { Journal of Economic } \\
\text { Geography }\end{array}$ & J. Econ. Geogr. & 2.6 \\
\hline & Economic Geography & Econ. Geogr. & 3.389 \\
\hline & $\begin{array}{l}\text { Eurasian Geography } \\
\text { and Economic }\end{array}$ & $\begin{array}{l}\text { Eurasian Geogr. } \\
\text { Econ. }\end{array}$ & 2.63 \\
\hline
\end{tabular}


Necesidades de información...

\begin{tabular}{|c|c|c|c|}
\hline & \begin{tabular}{|l|} 
Tijdschrift voor \\
Economische en \\
Sociale Geografie
\end{tabular} & $\begin{array}{l}\text { Tijdschr. Econ. Soc. } \\
\text { Geogr. }\end{array}$ & 0.753 \\
\hline \multirow[t]{3}{*}{ Geografía agraria } & Agrociencia & Agrociencia & 0.312 \\
\hline & $\begin{array}{l}\text { Revista Ciencia } \\
\text { Agronómica }\end{array}$ & Rev. Cienc. Agron. & 0.713 \\
\hline & $\begin{array}{l}\text { Revista Chapingo Serie } \\
\text { Ciencias Forestales y } \\
\text { del Ambiente }\end{array}$ & $\begin{array}{l}\text { Rev. Chapingo Ser. } \\
\text { Cienc. For. Am. }\end{array}$ & 0.128 \\
\hline
\end{tabular}

Los puntos que se cubrieron en este listado fueron la necesidad de información, la(s) revistas en donde pueden publicar los productos primarios de su investigación, el titulo abreviado y el factor de impacto; asimismo, el sitio en donde se obtiene esta información es en la base de datos Web of Science, la página es la siguiente: <http: //admin-apps.webofknowledge.com/JCR/JCR?SID=3FEhqfrr5DkJ5 OFqI5L $>$.

Esta base de datos proporciona otros elementos que también pueden ser de interés para la comunidad académica, como es el alcance del artículo, el idioma, la periodicidad, el país y las citas de los trabajos publicados, entre otras cosas.

Ahora bien, ¿por qué se decidió cubrir únicamente las variables: líneas de investigación; revistas en donde puede publicar el investigador; título abreviado de la revista, y el factor de impacto?, pues porque se considera preguntas frecuentes de esta comunidad.

Como se puede apreciar, los datos que se consideraron son básicos, pero también sirven de gancho para que el personal académico explore qué otra información de interés puede obtener de esta base de datos, que es requerida por CONACyT para evaluar la producción científica del personal académico. 


\section{BIBLIOGRAFÍA}

Criterios generales para la evaluación del personal académico del Subsistema de la Investigación Científica (2003). Coordinación de la Investigación Científica, Universidad Nacional Autónoma de México, p.

Primer Informe 1997-1998 (1998). Universidad Nacional Autónoma de México. Instituto de Geografía. Disponible en: <http://www.igg.unam.mx/sigg/utilidades/docs/ pdfs/instituto/inf_act/inf_38_97-98.pdf $>$. [Fecha de consulta: 7 de octubre, 2013].

Primer Informe de Actividades 2012, Universidad Nacional Autónoma de México. Instituto de Geografía. Disponible en: <http://www.igg.unam.mx/sigg/utilidades/ docs/pdfs/instituto/inf_act/informe_2012.pdf $>$. [Fecha de consulta: 07 de octubre 2013].

Santos Rosas, A. (2013). "Usuarios de la Revista Investigaciones Geográficas. El caso del personal académico del Instituto de Geografía”. Estudios de Usuarios en diferentes comunidades: necesidades de información y comportamiento informativo. México: UNAM, Instituto de Investigaciones Bibliotecológicas y de la Información. 


\title{
Niveles de usuarios de los sistemas de información geográfica
}

\author{
Antonia Santos Rosas \\ Universidad Nacional Autónoma de México
}

T a información geográfica es requerida por todo tipo de personas; así, tenemos a quienes usan esta información con fines meramente informativos, como sería para disipar una duda de ese momento, como por ejemplo, conocer la distancia que hay entre dos lugares, o conocer el clima, la vegetación o el tamaño de la población en un determinado lugar; en fin, cada individuo tiene necesidades específicas de información según su situación.

Igualmente, el valor que cada sujeto le da a la información varía dependiendo de para qué la requiere; en este sentido, ejerce gran influencia el medio ambiente social, económico, político y cultural en el que se encuentra inmerso el individuo ante la manifestación de las necesidades de información.

Seguramente, la necesidad del individuo de conocer el espacio geográfico lo ha llevado a investigar las características del lugar que le interesa en diversas fuentes de información, para posteriormente plasmarlo en mapas temáticos, por ser la fuente de información exacta que utilizan los diversos profesionales para delimitar el territorio, así como para conocer los atributos del lugar. 
Longhron $^{1}$ menciona que la información geográfica es un conjunto de datos espaciales y sus atributos (objetos, características, eventos, aspectos físicos, sociales, etc.), que pueden ser representados en dos, tres, o cuatro dimensiones ( $\mathrm{y}$ tiempos $\mathrm{x}, \mathrm{y}, \mathrm{z}$ ) en sistemas de referencia (sistemas de coordenadas, direcciones) y de una manera espacial (basada en el lugar), lo que permite hacer el análisis de las relaciones.

Para McMaster, ${ }^{2}$ la información geográfica provee las bases para tomar decisiones, en tanto que permite ver y ordenar el manejo de las tareas complejas, así como predecir las características del lugar en donde cada dato que es ingresado en el sistema es utilizado.

Las definiciones anteriores nos dan un panorama de lo que se entiende por información geográfica y la importancia de conocerla para poder ejecutar acciones en un fenómeno de estudio, por lo que conviene mencionar que la información geográfica a la que se refiere este trabajo es a la necesidad de información que tiene el individuo de conocer el territorio, con el fin de investigar y de obtener información para tomar decisiones.

Entonces, la necesidad de almacenar grandes volúmenes de información para facilitar el análisis de información geográfica sobre problemas complejos en el trabajo científico fue lo que desarrollaron los Sistemas de Información Geográfica.

Los antecedentes de los Sistemas de Información Geográfica se desarrollaron en tres etapas ${ }^{3}$ :

1ª Etapa. Era de la Innovación de 1957 a 1977

\begin{tabular}{|l|l}
\hline 1950 & $\begin{array}{l}\text { Waldo Tobler plantea la posibilidad de automatizar los procesos de la } \\
\text { cartografía. } \\
\text { Ésta es utilizada por agencias militares con fines de orientación }\end{array}$ \\
\hline
\end{tabular}

1 R. A. Longhron, Geographic Information: Value, Pricing, Production, and Consumption, 5.

2 R. A. McMaster y E. L., Usery A Research Agenda for Geographic Information Science, 17.

3 P. A. Longley, Geographic Information Systems \& Science, 17. 


\begin{tabular}{|l|l|}
\hline 1962 & $\begin{array}{l}\text { Tomlinson, Padre de los GIS - SIG. } \\
\text { Canada Geographic Information System (CGIS). }\end{array}$ \\
\hline 1965 & $\begin{array}{l}\text { The Harvard Laboratory for Computer Graphics desarrolla SYMAP. } \\
\text { A partir de este programa se crearon otros más desarrollados. }\end{array}$ \\
\hline 1970 & $\begin{array}{l}\text { Dual Independent Map Encoding “DIME", para el censo de los años seten- } \\
\text { ta en Estados Unidos. }\end{array}$ \\
\hline 1970 & Se extiende a Estados Unidos y en Europa. \\
\hline
\end{tabular}

El origen de los SIG se da a finales de los años cincuenta, cuando Waldo Tobler ${ }^{4}$ plantea la posibilidad de automatizar los procesos de la cartografía. Las primeras en utilizar la cartografía automatizada fueron las agencias militares de los Estados Unidos impulsadas por la necesidad de conocer la orientación precisa para hacer el lanzamiento de los misiles balísticos intercontinentales. Pero el manejo de los sistemas de información geográfica como tal se originó en la década de los años sesenta en dos grandes organismos: The Canadian GIS (CGIS) y The Harvard Laboratory for Computer Graphics.

En "1962 Tomlinson creó de manera conjunta con el gobierno de Canadá el primer inventario forestal de los recursos naturales de ese país y como resultado de ese esfuerzo se desarrolló el primer Sistema de Información Geográfica llamado también 'Canada Geographic Information System (CGIS)', por lo que debido a esta gran aportación se le considera a Tomlinson' como el 'Padre de los SIG.'”

En 1965 en el Harvard Laboratory for Computer Graphics, el arquitecto Howard Fisher diseñó el programa Mapping Package (SYMAP), un programa muy fácil de usar para esa época, por lo que fue adquirido por más de 500 instituciones universitarias. Esta aportación también demostró el potencial que tenía la elaboración de la cartografía automatizada, y por eso sentó la pauta para crear Sistemas de Información Geográfica más sofisticados.

El segundo SIG importante surgió a finales de los setenta en el Buró de Censos de los Estados Unidos para el Censo de la Pobla-

\footnotetext{
4 A. Buckley y D. Watkins, Automated Map Production Workflows.

5 R. Tomlinson, Thinking About Geographic Information System Planning for Managers, 12.
} 
ción de 1970, en donde se creó el programa "Dual Independent Map Encoding" (DIME), diseñado para crear archivos digitales de las calles que soportaran referencia automática y agregaran los registros del censo de población utilizando el nombre de la calle, el número y la ciudad". 6 Es decir, se establecía así la relación entre una representación geoespacial y sus atributos.

En los años setetenta, se incrementó el avance de esta tecnología porque en esa época se le dio gran importancia a la generación de publicaciones, principalmente las relacionadas con la resolución de problemas ambientales. Al mismo tiempo, los SIG siguieron creciendo y siendo desarrollados principalmente por empresas privadas de Norte América y Europa, por lo que se vendían a precios muy elevados

\section{2ª . Etapa. Era de la Comercialización de 1981 a 1999}

\begin{tabular}{|l|l|}
\hline 1980 & Bajó el precio del hardware; podía ser rentable. \\
\hline & Clientes: empresas forestales, agencias de recursos naturales. \\
\hline & $\begin{array}{l}\text { Se desarrolló Arclnfo, GIS que fue ampliamente aceptado por las universidades, } \\
\text { para la investigación y la educación. } \\
\text { Arclnfo fue desarrollado por Environmental Systems Research Institute. }\end{array}$ \\
\hline 1985 & $\begin{array}{l}\text { Fue utilizado por especialistas de Ciencias de la Tierra. } \\
\text { los recursos de las cuencas hidrográficas. }\end{array}$ \\
\hline 1990 & Se crearon diversas versiones de los SIG. \\
\hline
\end{tabular}

A principios de los años ochenta se crearon los Sistemas de Información Geográfica en otras partes del mundo con diferentes grados de complejidad y que fueron diseñados con diferentes propósitos, pero bajo los mismos principios: el análisis geográfico.

En esos mismos años, el precio del hardware bajó de costo a tal grado que lo volvió rentable. Entre los primeros clientes estuvieron empresas forestales y agencias de recursos naturales, impulsa-

6 I. Gregory y P. Ell, Historical GIS: Technologies, Methodologies and Scholarship, 12. 
das por la necesidad de realizar el seguimiento de la tala inmoderada de los recursos madereros y para regular su uso eficaz.

También, a principios de los años ochenta se desarrolló un paquete de software comercial conocido como ArcInfo, creado por Environmental Systems Research Institute, GIS que fue ampliamente aceptado en el mercado durante las dos próximas décadas así como en las universidades y en institutos de investigación y educación.

Durante esta década la utilización de los SIG se reflejó en varias áreas del conocimiento "[...] destacando los especialistas de Ciencias de la Tierra", 7 que le dieron gran importancia al uso de los SIG en áreas con mayor recurrencia de desastres naturales, como fue el caso de la Bahía de San Francisco en Estados Unidos, en donde por medio del SIG se conocieron los intervalos de recurrencia de terremotos; sus epicentros e intensidades, y por lo tanto de las zonas de riesgo.

A finales de 1985, el Instituto Internacional para Levantamientos Aeroespaciales y Ciencias de la Tierra (ITC) ${ }^{8}$ de los Países Bajos, inició un proyecto cuyo objetivo fue desarrollar un SIG que sirviera para aplicarse en la delimitación de unidades de uso de suelo, y en la planeación del uso de recursos de las cuencas hidrográficas.

A mediados de los años noventas se crearon diversos SIG, tales como: MapInfo, ESRI, ArcView; aquí es importante destacar que aunque estos programas fueron utilizados para crear sistemas de información geográfica, no eran compatibles entre sí, por lo que resultó complicado para el usuario cambiar a otro programa que no conocía, por lo que tampoco podía migrar datos a otros programas de SIG.

7 A. Alcántara, "Los sistemas de información geográfica en la prevención de desastre: realidades y perspectivas", 150.

8 Idem. 
$3^{a}$. Etapa. Era de la Explotación

Los SIG se siguen perfeccionando.

Ya se han generado diversos software comerciales y software libres.

Además se difunde la enseñanza de los cursos que se imparten en facultades y centros de investigación, diplomados, y cursos de SIG.

Se siguen publicando diversas fuentes de información en torno a esta tecnología desde diversos enfoques y aplicaciones.

Cada vez es mayor el número de usuarios que utilizan estas tecnologías.

Crece la importancia del bibliotecólogo al frente de las diferentes unidades de información.

A partir de este periodo, los SIG se siguen perfeccionando y generando diversos softwares comerciales y libres; se difunde el uso de esta enseñanza; se imparten cursos en facultades y centros de investigación, diplomados y cursos de SIG para aplicaciones diversas, y también se siguen publicando distintas fuentes de información en torno a esta tecnología desde diversos enfoques y aplicaciones, y por consiguiente, se aprovechan ampliamente los SIG para diseñar y generar mapas temáticos, así como para publicar diversos atlas.

\section{USUARIOS DE LOS SIG}

Esta tecnología inicialmente utilizada por geógrafos les ha resultado muy útil a diversas comunidades de usuarios, desde los técnicos en tecnologías de la información, que son quienes conocen el uso del sistema y quienes constituyen el personal operativo, hasta los investigadores, quienes se apoyan en el SIG para analizar el fenómeno de estudio, y también, otro tipo de usuarios como los gerentes y directivos, que son los encargados de tomar las decisiones en las instituciones gubernamentales y privadas. Por ello, los usuarios de los SIG van desde especialistas técnicos, quienes diseñan y mantienen el sistema, hasta aquellos que los utilizan para realizar trabajos escolares, o simplemente para explorar el sistema. 


\section{DEFINICIÓN DE USUARIOS}

Con respecto al uso y manejo de los Sistemas de Información Geográfica, Tomlinson ${ }^{9}$ menciona cuatro niveles de usuarios que son: usuarios profesionales, especialistas de SIG de escritorio; usuarios empresariales, y usuarios de servidores de mapas de Internet.

Usuarios profesionales de SIG son aquellos que contribuyen a hacer los estudios de la tecnología, el almacenamiento de datos espaciales y a efectuar operaciones de datos. En este nivel se encuentran los ingenieros en computación.

Los especialistas de SIG de escritorio son quienes contribuyen a la recopilación y captura de la información, proporcionan consultas para propósitos generales y participan en la producción de mapas simples. Es el nivel de usuario operativo.

Los usuarios empresariales son los que requieren producción de información SIG para responder a necesidades de negocios específicas. Estos son usuarios finales quienes no tiene necesidad de tener conocimientos geográficos para usar los productos informativos en respaldo de funciones empresariales estándar. En este nivel de usuarios se encuentran los investigadores responsables de proyectos de investigación

Usuarios de servidores de mapas de Internet e intranet, son quienes usan asistentes de publicación, y son los clientes y navegadores de intranet e Internet.

Tomlinson considera cuatro niveles de usuarios; sin embargo, es preciso tomar en cuenta la existencia de un nivel más, el cual es el de los usuarios estudiantes.

Usuarios estudiantes, son el tipo de usuarios que se encuentra en proceso de enseñanza, por lo que se puede considerar como el tipo de usuario explorador que está indagando los diversos softwares que existen en el mercado tanto de uso libre como comercial.

9 R. Tomlinson. Pensando en el SIG. Planificación de sistemas de información geográfica dirigida a gerentes, 76. 
Por lo tanto el nivel de usuario que exista, dependerá del concepto que se tenga acerca de lo que es un sistema de información geográfica.

En un estudio realizado en la World Wide Web respecto al uso de los SIG que hacen los diversos campos se encontró lo siguiente: ${ }^{10}$

\begin{tabular}{|l|c|}
\hline Cartografía & $4 \%$ \\
\hline Ciencias biológicas & $9 \%$ \\
\hline Geo ciencias & $16 \%$ \\
\hline Geopolítica & $6 \%$ \\
\hline Infraestructura & $7 \%$ \\
\hline Negocios & $9 \%$ \\
\hline Suelo & $21 \%$ \\
\hline Utilerías & $28 \%$ \\
\hline
\end{tabular}

Aunque este estudio no menciona el tamaño de la muestra, los porcentajes sí dan un panorama del uso que hacen los diversos actores sociales, y como resultado el $57 \%$ de la muestra corresponde a profesionales de diversas disciplinas científicas del área de ciencias puras y ciencias sociales, con lo cual es de esperarse que utilerías obtenga el mayor porcentaje, esto debido a que aquí entran en juego los profesionales de las tecnologías de la información.

A continuación, se dan algunas definiciones que han originado los diversos profesionales en torno a los sistemas de información geográfica.

\begin{tabular}{|l|l|l|}
\hline \multicolumn{1}{|c|}{ Autor } & \multicolumn{1}{|c|}{ Nivel } & \multicolumn{1}{c|}{ Definición } \\
\hline Devine y Field(1) $^{(1)}$ & Sistemas & $\begin{array}{l}\text { Sistema que permite el despliegue de } \\
\text { información general. }\end{array}$ \\
\hline Chuvieco(2) $^{(\text {Sistemas }}$ & $\begin{array}{l}\text { Bases de datos informatizadas con algún } \\
\text { componente espacial. }\end{array}$ \\
\hline Maguire(3) & Geógrafo & $\begin{array}{l}\text { Representa características definidas de } \\
\text { acuerdo con dos elementos: el de localización } \\
\text { y el de no localización (información). }\end{array}$ \\
\hline
\end{tabular}

10 G. B. Korte, The Gis Book: Updated and Expanded, 43. 


\begin{tabular}{|l|l|l|}
\hline Quintero $^{(4)}$ & $\begin{array}{l}\text { Geógrafo - Proyectos } \\
\text { académicos }\end{array}$ & $\begin{array}{l}\text { Herramienta de análisis espacial para resolver } \\
\text { problemas por medio de modelos. }\end{array}$ \\
\hline Tomlinson(5) & Geógrafo - Gerencia & $\begin{array}{l}\text { Tecnología que almacena datos espaciales que } \\
\text { se distinguen por la presencia de un vínculo } \\
\text { geográfico, como son carreteras, ríos o edificios, } \\
\text { los cuales se representan por puntos, líneas } \\
\text { o polígonos e información no espacial, como } \\
\text { nombres de carreteras, temperaturas, etcétera. }\end{array}$ \\
\hline
\end{tabular}

(1) H. A. Devine y R. C. Field, citados en Maguire, 1986, 11.

(2) C. E. Chuvieco, Fundamentos de teledetección espacial, 397.

(3) D. J. Maguire, M. F. Goodchild y D. M. Rhind, Geographical Information Systems: Principles, 11.

(4) P. J. A. Quintero, "Definición y origen de los sistemas de información geográfica", 118.

(5) Tomlinson, op.cit., 1.

Devine y Field, se refieren al SIGL "[...] como un sistema para el manejo de información (SMI) que permite el despliegue de mapas de información general".

Por su parte Chuvieco define a los SIG:

Como bases informatizadas de datos en algún tipo de componente espacial. Esto significa que la información que almacenan esta referenciada geográficamente, ya sea que se trate de mapas, estadísticas o datos climáticos, sobre un territorio concreto, por lo que todas estas variables pueden relacionarse mutuamente de formas muy diversas.

Maguire en su definición indica que un GIS, "[...] es representado como una serie de características geográficas definidas acorde con dos elementos. El geográfico (de localización), y el elemento usado para proporcionar la referencia al atributo (llamado estadístico, no de localización)".

Quintero marca, “[...] es una herramienta de análisis espacial para resolver problemas por medio de modelos que permiten encontrar patrones y entender cuáles son los eventos que dan origen a los fenómenos que se estudian".11

11 P. J. A. Quintero, op. cit., 118. 
Tomlinson agrega que es una tecnología que almacena datos espaciales que son datos sin procesar que se distinguen por la presencia de un vínculo geográfico como son carreteras, ríos, edificios, los cuales se representan por puntos, líneas o polígonos e información no espacial como nombres de carreteras, temperaturas estacionales entre otros datos que se almacenan en tablas y a los cuales se les llama atributos. ${ }^{12}$

Como se puede observar en las definiciones anteriores, los autores seleccionados dan una definición de Sistemas de Información Geográfica que va de acuerdo con su formación profesional.

Así tenemos el enfoque que dan Devine y Field en donde se menciona que el sistema sirve para generar mapas de información general, por lo que se puede considerar que la definición de estos dos autores queda muy corta, porque un sistema de información geográfica va más allá de elaborar mapas; si tal fuera el caso, a las comunidades científicas y empresariales el sistema no les sería de utilidad, ya que para elaborar mapas generales esta tecnología estaría subutilizada.

Con respecto a la definición que dan Maguire y Tomlinson, ellos marcan dos tipos de componentes, el geográfico y el no geográfico, y dentro de este último se encuentran datos y estadísticas que sirven para conocer el comportamiento del fenómeno estudiado

En la definición de Quintero, este marca el uso final del SIG, que es el de análisis y elaboración de modelos para conocer las causas.

Por lo que, estrictamente hablando, ninguna definición de las antes mencionadas da una idea completa de lo que es un SIG; sin embargo, todas en su conjunto nos permiten comprender el sistema.

Asimismo, se puede observar que mientras para los ingenieros en sistemas un SIG es una base de datos informatizada que almacena información georreferenciada, para los investigadores es un sistema altamente especializado y confiable que da respuesta a preguntas tales como: ¿Qué hay en...? ¿Qué sucede si...? ¿Cuál es la mejor ruta para...? las cuales les permiten analizar el fenómeno

12 R. Tomlinson, op. cit., 1-3. 
de estudio. Las comunidades empresariales presentan un comportamiento similar ya que requieren información para dar respuesta a sus necesidades de negocios, y también las instituciones gubernamentales, las cuales necesitan la información para apoyar a la población a resolver alguna necesidad social.

En conclusión, no existe una definición única de los sistemas de información geográfica, debido a que cada usuario la genera desde la perspectiva de su uso, como es el caso del investigador, que a través del sistema de información analiza la información, o el del personal operativo, que es quien la captura; entonces, de acuerdo con el uso que le de cada individuo, será la percepción que este tenga del sistema, y, como menciona Quintero "[...] mientras que para el público en general no es más que un contenedor de mapas digitales que se confunden con paquetería de dibujo y diseño, para los grupos de planeación es una herramienta para la toma de decisiones, y la comunidad científica los utiliza para revelar lo que de otra forma les sería invisible a simple vista".

\section{BIBLIOGRAFÍA}

Aguirre, R. (coord) (2009) Conceptos de Geomática y estudios de caso en México. UNAM, Instituto de Geografía.

Alcántara A. I. (2009). Los sistemas de información geográfica en la prevención de desastres: realidades y perspectivas. Conceptos de Geomática y Estudios de Caso en México. Coord. Aguirre G. R. México: UNAM, Instituto de Geografía.

Buckley, A. y D. Watkins (2007). Automated Map Production Workflows. Disponible en: <http://hostmaster.icaci.org/fi les/documents/ICC_proceedings/ICC2009/html/nonre/1_ 13.pdf.>. [Fecha de consulta: 11 de febrero 2014].

Chuvieco, E. (1990). Fundamentos de teledetección espacial. Madrid: Ediciones Rialp. 
Devine H. A. y R. C. Field (1986). "The gist of GIS". Journal of Forestry, august, 17-22.

Gregory, I. A. y P. S. Ell (2007). Historical GIS. Technologies, Methodologies and Scholarship, United Kingdom: Cambridge University Press.

Korte, G. B. (2001). The Gis Book: Updated and Expanded, 5a. ed. On Word Press Staff.

Longhorn, R. y M. Blakemore (2008). Geographic Information: Value, Pricing, Production, and Consumption, Boca Raton: Taylor \& Francis.

Longley, P. A., M. F. Goodchild, D. J. Maguire y D. W. Rhino (2011). Geographic Information Systems \& Science, 3a. ed. Estados Unidos: John Wiley \& Sons, Inc.

Maguire D. J., M. F. Goodchild y D. W. Rhind (1991). Geographical Information Systems: Principles, United Kingdom: Longman, v. 1.

Mc Master, R.A. y E. L. Usery. (2004). A Research Agend for Geographic Information Science. CRC Press.

Quintero P. J. A. (2009). "Definición y origen de los sistemas de información geográfica”. Conceptos de Geomática y estudios de caso en México, Coord. R. Gómez. México: UNAM, Instituto de Geografía, 115-147.

Tomlinson R. (2011). Thinking About Geographic Information System Planning for Managers. New York. 
Usuarios de la Información y Web 2.0. Instituto de Investigaciones Bibliotecológicas y de la Información/UNAM. La edición consta de 100 ejemplares. Coordinación editorial, Carlos Ceballos Sosa; Revisión especializada, Francisco Xavier González y Ortiz; Cotejo y corrección de pruebas, Zyanya Benavides Reyes; Formación editorial, Mario Ocampo Chávez. Fue impreso en papel cultural de 90 g. en Ediciones del Lirio S. A. de C.V., Azucenas 10, Colonia San Juan Xalpa, Delegación Iztapalapa, México, Ciudad de México. Se terminó de imprimir en el mes de mayo de 2017. 